\title{
CAE TOOLS FOR MODELING INERTIA AND AERODYNAMIC PROPERTIES OF AN R/C AIRPLANE
}

\author{
by \\ KARTIK KIRAN PARIKH \\ Presented to the Faculty of the Graduate School of \\ The University of Texas at Arlington in Partial Fulfillment \\ of the Requirements \\ for the Degree of
}

MASTER OF SCIENCE IN MECHANICAL ENGINEERING

THE UNIVERSITY OF TEXAS AT ARLINGTON

August 2009 
Copyright (c) by Kartik Kiran Parikh 2009

All Rights Reserved 
To My Guru Shri Gurumayiji. 


\section{ACKNOWLEDGEMENTS}

All throughout my Master's education, I was assisted and guided to the path of knowledge - knowledge which lied outside all the books and scholarly material available today. This type of knowledge gained is a special combination of years of experience and expertise in the field of Engineering, something that the faculty members at Autonomous Vehicle Lab (AVL) specialized in. Professor Atilla Dogan, Professor Kamesh Subbarao, Professor Brian Huff and Professor Arthur Reyes were instrumental in helping me with my research and I am indebted to them. The knowledge they taught and shared with me came a long way in completing my research successfully.

I am also thankful to Professor Brian Dennis for his suggestions on important aspects related to my experiments. I would like to appreciate the support of my lab mates, and even Mr. Richard Mitchell, who helped me get acquainted in using softwares part of my research work.

I express my wholehearted gratitude to my family members for their love, support and motivation to succeed in my academics. Last but not the least, I thank all my friends, especially Pooja, for standing by my side always.

July 28, 2009 


\begin{abstract}
CAE TOOLS FOR MODELING INERTIA AND AERODYNAMIC PROPERTIES

OF AN R/C AIRPLANE

Kartik Kiran Parikh, M.S.

The University of Texas at Arlington, 2009
\end{abstract}

Supervising Professors: Dr. Atilla Dogan and Dr. Kamesh Subbarao

Recently there has been significant research in the field of Unmanned Aerial Vehicles (UAV). For efficient deployment and operation of these vehicles, it is imperative that one understands the physical system. This in turn involves one to design efficient control algorithms for implementation in these platforms. Thus we need algorithms and methods that identify the physical system parameters, that in turn can be used to design robust model based control systems. This thesis employs CAE software such as SolidWorks, GAMBIT and FLUENT to calculate the aerodynamic coefficients and moment of inertia. The aerodynamic coefficients are analyzed to understand the sensitivity of the aerodynamic forces and moments due to change in angle of attack, side slip angle and control surface deflection. A detailed procedure on how to configure the various parameters required for solving the fluid flow around an $\mathrm{R} / \mathrm{C}$ airplane is demonstrated. Moment of inertia and center of mass are calculated using SolidWorks for empty and full fuel tank of the airplane model and compared against experimental results based on the pendulum method. 


\section{TABLE OF CONTENTS}

ACKNOWLEDGEMENTS ............................. iv

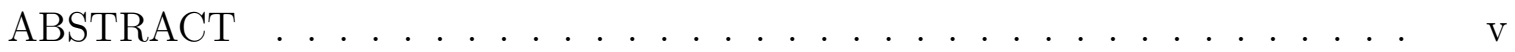

LIST OF FIGURES . . . . . . . . . . . . . . . . . . . viii

LIST OF TABLES ........................ xi

Chapter $\quad$ Page

1. INTRODUCTION ................................ 1

2. CAD MODEL AND INERTIA PROPERTIES CALCULATION . . . . . . 4

2.1 Introduction . . . . . . . . . . . . . . . . . . 4

2.2 CAD Model . . . . . . . . . . . . . . . . 5

2.3 Inertia Properties Calculation . . . . . . . . . . . . . . . 6

2.3.1 CAD Method . . . . . . . . . . . . 6

2.3.2 Pendulum Method ................ 8

3. AERODYNAMIC PROPERTIES CALCULATION . . . . . . . . . . . 12

3.1 Introduction . . . . . . . . . . . . . . . . . . . . 12

3.2 Setting Configuration Parameters . . . . . . . . . . . . . . . 19

3.2.1 Simplified Geometry . . . . . . . . . . . . . . . . . . 19

3.2.2 Reduction of Wall Interference Effect . . . . . . . . . . . . . 21

3.3 GAMBIT - FLUENT INTERFACE . . . . . . . . . . . . . . . 34

3.3.1 Meshing Procedure in GAMBIT . . . . . . . . . . . . . 34

3.3.2 Procedure for Solving in FLUENT . . . . . . . . . . . . . . 38

4. SECONDARY OBSERVATIONS . . . . . . . . . . . . . . 51

4.1 Infinite Wing and Finite Wing . . . . . . . . . . . . . . . . 51 
4.2 Effects Due Presence of Wingtip and Dihedral . . . . . . . . . . . . 52

4.3 Effect of Deviation in Airfoil Geometry . . . . . . . . . . . . . 53

4.4 Mirror Feature in SolidWorks . . . . . . . . . . . . . . . . . 54

4.5 Deviation in Symmetry . . . . . . . . . . . . . . . . 55

5. RESULTS AND DISCUSSIONS . . . . . . . . . . . . 58

5.1 Inertia Properties . . . . . . . . . . . . . . . . . 58

5.2 Aerodynamic Coefficients . . . . . . . . . . . . . . . 59

5.2.1 Aerodynamic Force Coefficients . . . . . . . . . . . . 59

5.2.2 Aerodynamic Moment Coefficients ............ 63

6. SUMMARY AND FUTURE WORK . . . . . . . . . . . . . . . 73 Appendix

A. SIG KADET AIRFOIL POSTPROCESSING . . . . . . . . . . . . 75

B. AERODYNAMIC COEFFICIENT RESULTS . . . . . . . . . . . . . 87

REFERENCES . . . . . . . . . . . . . . . . . . . 98

BIOGRAPHICAL STATEMENT . . . . . . . . . . . . . . . . . . 100 


\section{LIST OF FIGURES}

Figure $\quad$ Page

1.1 Sig Kadet Airplane . . . . . . . . . . . . . . . . . . . . . . . . 3

2.1 Sig Kadet Airplane - Stick Model . . . . . . . . . . . . . . . . . . . . 7

2.2 Sig Kadet Airplane - Solid Model . . . . . . . . . . . . . . . . . . . . 7

2.3 Experiment Setup for Moment of Inertia about X-axis . . . . . . . . . 10

2.4 Experiment Setup for Moment of Inertia about Y-axis . . . . . . . . . 10

2.5 Experiment Setup: Hanging Mechanism . . . . . . . . . . . . . . 11

3.1 Face Mesh of Sig Kadet Model . . . . . . . . . . . . . . . . . . . . . . 14

3.2 Trimesh and Size Function . . . . . . . . . . . . . . . . . 15

3.3 Difference in force plot due to displacement of

(a) Upperwall and (b) Lowerwall . . . . . . . . . . . . . . . . . . . . . 27

3.4 (a) Velocity Magnitude (b) Dynamic Pressure Contour Plot for Sig Kadet Airfoil at alpha 0 degrees with No Slip Condition at the Boundary Walls . . . . . . . . . . . . . 28

3.5 (a) Velocity Magnitude (b) Dynamic Pressure Contour Plot for Sig Kadet Airfoil at alpha 0 degrees with Zero Shear Stress Condition at the Boundary Walls . . . . . . . . . . . . .

3.6 (a) Velocity Magnitude (b) Dynamic Pressure Contour Plot for Sig Kadet Aircraft Model (simplified) at alpha 0 degrees with No Slip Condition at the Boundary Walls . . . . . . . . .

3.7 (a) Velocity Magnitude (b) Dynamic Pressure Contour Plot for Sig Kadet Aircraft Model (simplified) at alpha 0 degrees with Zero Shear Stress Condition at the Boundary Walls . . . . . . . 31

3.8 (a) Static Pressure (b) Dynamic Pressure (c) Velocity Magnitude Contour Plot for Sig Kadet Airfoil at alpha 8 degrees . . . . . . . . . 41

3.9 Variation in Drag Coefficient for change in flow volume size . . . . . . 42

3.10 Variation in Side Force Coefficient for change in flow volume size . . . 42 viii 
3.11 Variation in Lift Coefficient for change in flow volume size . . . . . . . 43

3.12 Viscous Model Comparison for NACA 0012 finite wing . . . . . . . . 43

3.13 Lift Coefficient vs Model Constant of $k-\epsilon$ Realizable Model

(a) TKE Prandtl Number, (b) C2-Epsilon and (c) TDR Prandtl

Number for NACA 0012 Finite Wing at 5 degrees Angle of Attack . .

3.14 Sensitivity of the Force in X-direction

due to mesh size and iterations . . . . . . . . . . . . . . . . . 45

3.15 Sensitivity of the Force in Y-direction

due to mesh size and iterations . . . . . . . . . . . . . . . . . 45

3.16 Sensitivity of the Force in Z-direction

due to mesh size and iterations . . . . . . . . . . . . . . . 46

3.17 Default Values for Size Function . . . . . . . . . . . . . . . 46

3.18 Source Faces for Fixed Size Function . . . . . . . . . . . . . . . . 47

3.19 Curvature Size Function . . . . . . . . . . . . . . . . . . . 48

3.20 Face Mesh . . . . . . . . . . . . . . . . . . . . . . . . . . . . . . . . 49

3.21 Volume Mesh . . . . . . . . . . . . . . . . . . . . . . . . 49

3.22 Boundary Type Specification . . . . . . . . . . . . . . . . . 50

4.1 Geometry Comparison (a) Clark Y Airfoil (b) Sig Kadet Airfoil . . . . 53

4.2 Drag Coefficient Comparison between Sig Kadet Airfoil and

Clark Y Airfoil . . . . . . . . . . . . . . . . 54

4.3 Lift Coefficient Comparison between Sig Kadet Airfoil and

Clark Y Airfoil . . . . . . . . . . . . . . . . . . . . . . 54

4.4 Side Force Coefficient vs Angle of Attack for

Sig Kadet Model . . . . . . . . . . . . . . . . . . . . . . . . . 55

4.5 Y component velocity on XZ Plane for Sig Kadet Model

w/o muffler . . . . . . . . . . . . . . . . . . 57

5.1 (a) Drag, (b) Lift and Side Force Coefficient vs

Angle of Attack for Sig Kadet Model . . . . . . . . . . . . . . . . . . 61

5.2 Lift vs Drag for Sig Kadet Model . . . . . . . . . . . . . . . . 62

5.3 (a) Drag, (b) Lift and (c) Side Force Coefficient vs 
Side Slip Angle for Sig Kadet Model . . . . . . . . . . . . . . . . . 65

5.4 (a) Drag, (b) Lift and Side Force Coefficient vs

Elevator Deflection Plot for Sig Kadet Model . . . . . . . . . . . 66

5.5 (a) Drag, (b) Lift and (c) Side Force Coefficient vs

Rudder Deflection Plot for Sig Kadet Model . . . . . . . . . . . . . . 67

5.6 (a) Drag, (b) Lift and (c) Side Force Coefficient

vs Aileron Deflection Plot for Sig Kadet Model . . . . . . . . . . . 68

5.7 Rolling, Pitching and Yawing Moment Coefficient

about the Nose vs Angle of Attack for Sig Kadet Model . . . . . . . . 69

5.8 Rolling, Pitching and Yawing Moment Coefficient

about the Nose vs Elevator Deflection Plot for Sig Kadet Model . . . 69

5.9 (a) Rolling, (b) Pitching and (c) Yawing Moment Coefficient about the Nose vs Side Slip angle for Sig Kadet Model . . . . . . . . . 70

5.10 (a) Rolling, (b) Pitching and (c) Yawing Moment Coefficient about the Nose vs Rudder Deflection Plot for Sig Kadet Model . . . . 71

5.11 (a) Rolling, (b) Pitching and (c) Yawing Moment Coefficient about the Nose vs Aileron Deflection Plot for Sig Kadet Model . . . . 


\section{LIST OF TABLES}

Table Page

2.1 Functions of Features in SolidWorks . . . . . . . . . . . . . . . 6

3.1 Force Comparison for Sig Kadet Geometry . . . . . . . . . . . . . . . 21

3.2 Force Comparison for change in Flow Volume Size . . . . . . . . . . . 24

3.3 Force comparison for change in flow volume size due to displacement of upper boundary wall along Z-direction . . . . . . . . 24

3.4 Force comparison for change in flow volume size due to displacement of lower boundary wall along the Z-direction . . . . . . . 25

3.5 Force Comparison for change in Flow Volume Size due to displacement of Side Boundary Wall along Y-direction . . . . . . . . . 26

3.6 Force Comparison for Sig Kadet Airfoil and Aircraft for different Boundary Wall Condition . . . . . . . . . . . . . 26

4.1 Lift Force Comparison for Finite Wing and Infinite Wing for Sig Kadet Geometry . . . . . . . . . . . . . . . . . . . . . . . . . 52

4.2 Effects on Forces due to Wingtip and Dihedral . . . . . . . . . . . . . 52

4.3 Half and Full Sig Kadet Model Comparison . . . . . . . . . . . . . . . 57

5.1 Moment of Inertia $\left(\mathrm{kg} \cdot \mathrm{m}^{2}\right)$ for Sig Kadet with empty fuel tank . . . . 59

5.2 Moment of Inertia $\left(\mathrm{kg} \cdot \mathrm{m}^{2}\right)$ for Sig Kadet with full fuel tank . . . . . . 59 


\section{CHAPTER 1 INTRODUCTION}

Unmanned Aerial Vehicles (UAV) have been used in reconnaissance and intelligence gathering role since 1950's. They are widely used for defense purposes, agricultural application, natural resource management, emergency response and homeland security. UAVs are equipped with different payloads depending on the application. They are finding applications as cargo planes for transferring goods or articles from one place to another, and for various civil/commercial purposes like traffic surveillance, storm tracking and public addressing system. Efforts are made to further develop the core technologies to reduce the cost of acquisition and operation and to increase flight safety in order to help develop commercial applications for these vehicles.

In recent years, the usefulness of UAVs as teaching and research tools is realized by the academic community [1]. Researchers have been using readily available or custom built small aircraft platforms for experimenting new theories or techniques. In order to verify the results it is usual to perform flight tests. This involves risk and is an expensive affair. It is beneficial to know how the aircraft would react in a given environment. Thus, implementing an autopilot system in a UAV requires to characterize the UAV's dynamics [2]. This involves system identification.

One technique of system identification is using flight test data and estimation theories. This technique is demonstrated in [2], [3] and [4]. Another technique is to directly calculate the aerodynamic forces and moments coefficients and moment of inertia, used in equation of motion in flight dynamics. Aerodynamic coefficients 
of a UAV are calculated from the wind tunnel experiments. Moment of inertia is calculated using Inertial Measurement Units (IMU), compound pendulum and bifilar pendulum methods as demonstrated in [5] and [6].

With recent advancement in technology and computing power there are various Computer Aided Engineering (CAE) software developed and available, that allows to do tasks such as design, analysis and simulation. This motivated to demonstrate the use of these CAE softwares in determining the aerodynamic coefficients and moment of inertia of an $\mathrm{R} / \mathrm{C}$ airplane. The advantage to use these software is that one can easily modify the design of an $\mathrm{R} / \mathrm{C}$ airplane and analyze its aerodynamics and structural strength. In this research the study is done to demonstrate the use of CAE software to calculate the aerodynamic forces, moments coefficients and moment of inertia of an $\mathrm{R} / \mathrm{C}$ airplane. Structural analysis is suggested as a future work. SolidWorks software, a Computer Aided Design software, is used to design an R/C airplane and FLUENT, a Computational Fluid Dynamics software, is used to calculate the aerodynamic forces and moments coefficients. GAMBIT is used to mesh the geometry as a prerequisite to FLUENT. In this research, a tool chain is demonstrated to calculate the inertia and aerodynamic properties of an $\mathrm{R} / \mathrm{C}$ airplane. An $\mathrm{R} / \mathrm{C}$ airplane is designed in SolidWorks, exported to GAMBIT for meshing and then meshed geometry is imported into FLUENT to calculate the aerodynamic coefficients. Moments of inertia are calculated in SolidWorks. The $\mathrm{R} / \mathrm{C}$ airplane used for this research is a Sig Kadet Senior airplane model, termed as Sig Kadet model through out the thesis.

The Sig Kadet airplane model is used as a UAV by the members of the Autonomous Vehicle Laboratory (AVL) at the University of Texas at Arlington (UTA) in the AUVSI- UAV competition. This R/C Airplane is modified into a UAV by adding a commercially available autopilot. The UAV model used is shown in the Fig. 1.1. The rules of the competition keep changing every year as well the level of diffi- 
culty of challenges. Currently the AVL team which includes undergraduate students, graduate students and professors of UTA, strives for autonomous image recognition, which requires implementation of innovative techniques and different payloads to complete the challenges of the competition. It is expected for the autonomous challenges to be more and more challenging. Thus the future use of the Sig Kadet model is intended for custom payloads that potentially require structural modifications and development of a computer system that includes autopilot, sensory functions, mission specific software etc.

The development of the tool chain will thus enable the team to rapidly analyze reconfiguration and structural changes and better tune the autopilot to accomplish the tasks specified by the competition requirements.

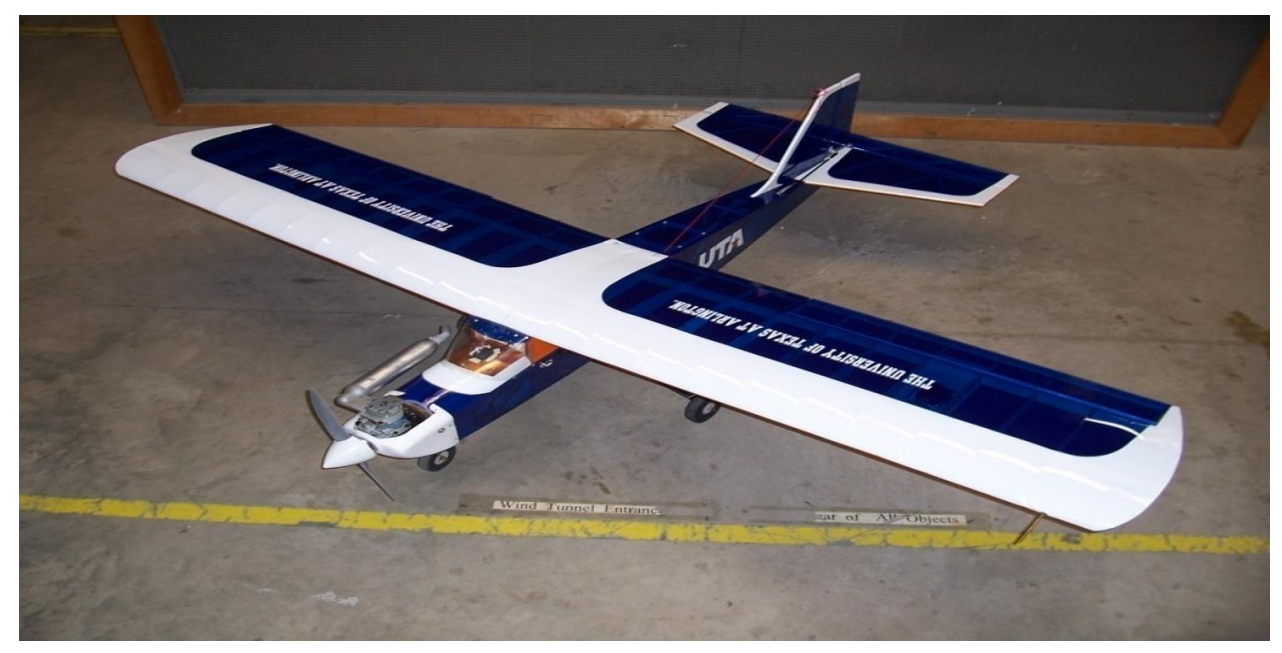

Figure 1.1. Sig Kadet Airplane. 


\section{CHAPTER 2}

\section{CAD MODEL AND INERTIA PROPERTIES CALCULATION}

This chapter discusses various design features used in creating a CAD model of an $\mathrm{R} / \mathrm{C}$ airplane and calculating the inertial properties within the CAD software.

\subsection{Introduction}

There are various Computer Aided Design (CAD) softwares developed in recent years, enabling the design engineer to design a product and then manufacture it. CAD softwares are used to design curves and figures in two-dimensional space, or curves, surfaces or solids in three-dimensional space. A CAD model of a part, either to be manufactured or already manufactured, gives a visual display and information about its shape and size. Parts designed separately are assembled together to form a component or product. CAD software validates the design by evaluating for any interference detection among the assembled parts and provides mass properties such as volume, mass, center of mass and inertia properties. 'Motion Study' is a newly developed feature that allows some of the CAD softwares to evaluate the working mechanism of a product system. Thus, CAD software empowers the design engineer to efficiently design and evaluate a product. Product designed in CAD software are either directly manufactured or documented or exported to other analysis software to analyze properties such as stress and fluid flow properties. The product file developed in a CAD software could be exchanged between softwares using Industrial Standard Neutral File Format such as IGES, ACIS and Parasolid format. 
The first step towards estimating the inertial and aerodynamic properties of an $\mathrm{R} / \mathrm{C}$ airplane is to design the CAD model. SolidWorks, a CAD software, is used in this research for generating the $\mathrm{CAD}$ model of an $\mathrm{R} / \mathrm{C}$ airplane, which is then used to calculate the inertial properties. Sig Kadet airplane model is used in this thesis to demonstrate the calculation of inertial properties of an $\mathrm{R} / \mathrm{C}$ airplane.

\subsection{CAD Model}

The objective for the design of the CAD model of the Sig Kadet airplane model is to calculate its inertia and aerodynamic properties. For calculating the aerodynamic properties, only the external profile of the Sig Kadet airplane is required, while for calculating the inertial properties a complete structure similar to the Sig Kadet airplane is required. The CAD model with only external profile of the airplane is termed as Solid Model, while CAD model representing the complete structure of the Sig Kadet airplane including the internal parts is termed as Stick Model, (also since the Sig Kadet airplane is made up of sticks of Balsa wood). To ease the modeling of Sig Kadet airplane model, the CAD model is built by first modeling several partial segments of Sig Kadet model and then assembling them together to complete the whole geometry. The features such as sketch, extrude, extrude-cut, loft, cavity, draft, fillet, combine, mirror, reference planes and mates are used for the 3D design. The function of the features used in this thesis are shown in Table 2.1. The stick model is saved for calculating the mass properties. The solid model is further processed to create a flow volume in order to mesh it in GAMBIT. Flow volume is defined as the volume around the solid model within which the air flow is captured. Flow volume could be even created in GAMBIT. Flow volume is created by creating a cavity of the solid model inside a cube. The location of the solid model within the cube is dependent on the placement of boundary condition with respect to the Sig Kadet solid 
model, which is discussed in Chapter 4. The stick model with body axis coordinate system is shown in Fig. 2.1 and solid model with custom coordinate system is shown in Fig. 2.2. Coordinate systems are discussed in section 3.2. The solid model designed in SolidWorks is exported to GAMBIT using the Parasolid neutral file format.

Table 2.1. Functions of Features in SolidWorks

\begin{tabular}{|l|l|}
\hline Features & Functions \\
\hline Sketch & To draw entities like line, arc, rectangle, circle etc., \\
\hline Extrude & Creates a solid 3D object by extruding existing 2D object \\
\hline Extrude Cut & Removes material from a part or an assembly \\
\hline Loft & Creates an object by making transitions between profiles \\
\hline Cavity & Creates molds with the shape of the design part \\
\hline Draft & Tapers faces using a specified angle \\
\hline Fillet & Rounds the edges of the object \\
\hline Combine & $\begin{array}{l}\text { Combine multiple solid bodies to create a single } \\
\text { or another multi-body parts }\end{array}$ \\
\hline Mirror & $\begin{array}{l}\text { Creates a mirror image of an object about a mirror } \\
\text { line / plane }\end{array}$ \\
\hline Reference Planes & Creates planes \\
\hline Mates & Creates geometric relationships between assembly components \\
\hline
\end{tabular}

\subsection{Inertia Properties Calculation}

Moment of inertia is defined as the tendency of an object/body to resist angular acceleration. It depends on the mass of the object and the distribution of mass with respect to the axis of rotation.

\subsubsection{CAD Method}

The stick model represents the Sig Kadet airplane model. Every part modeled to complete the stick model assembly is assigned with its density. The fuselage, wings, 


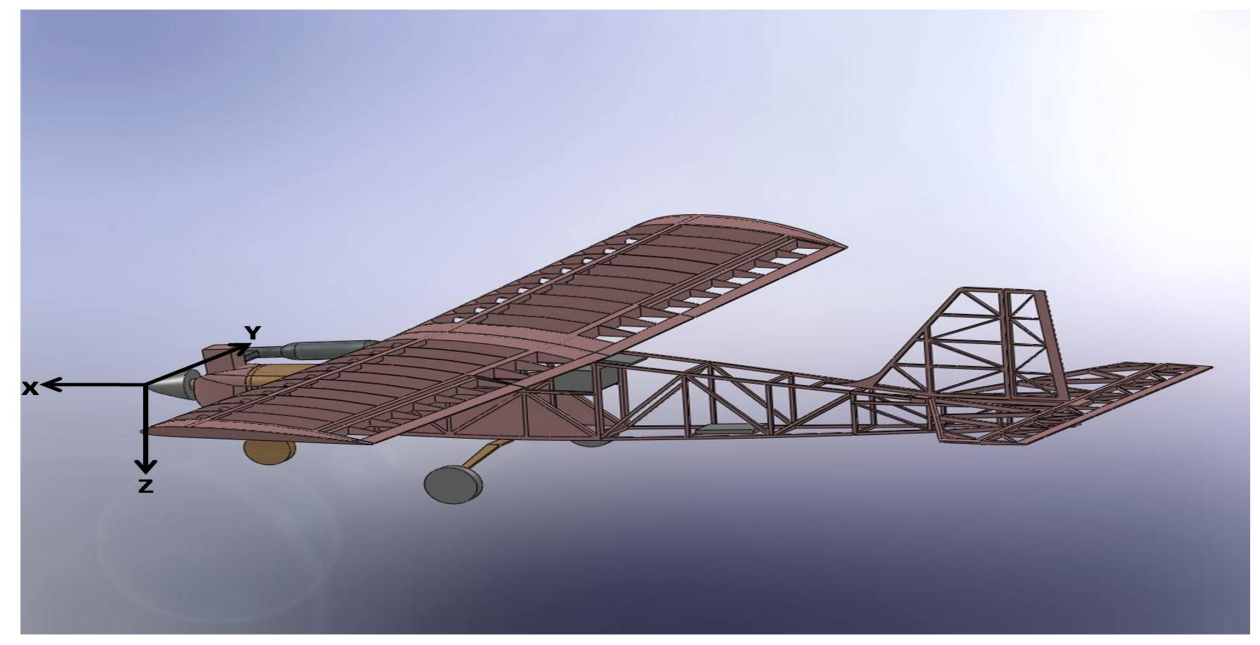

Figure 2.1. Sig Kadet Airplane - Stick Model.

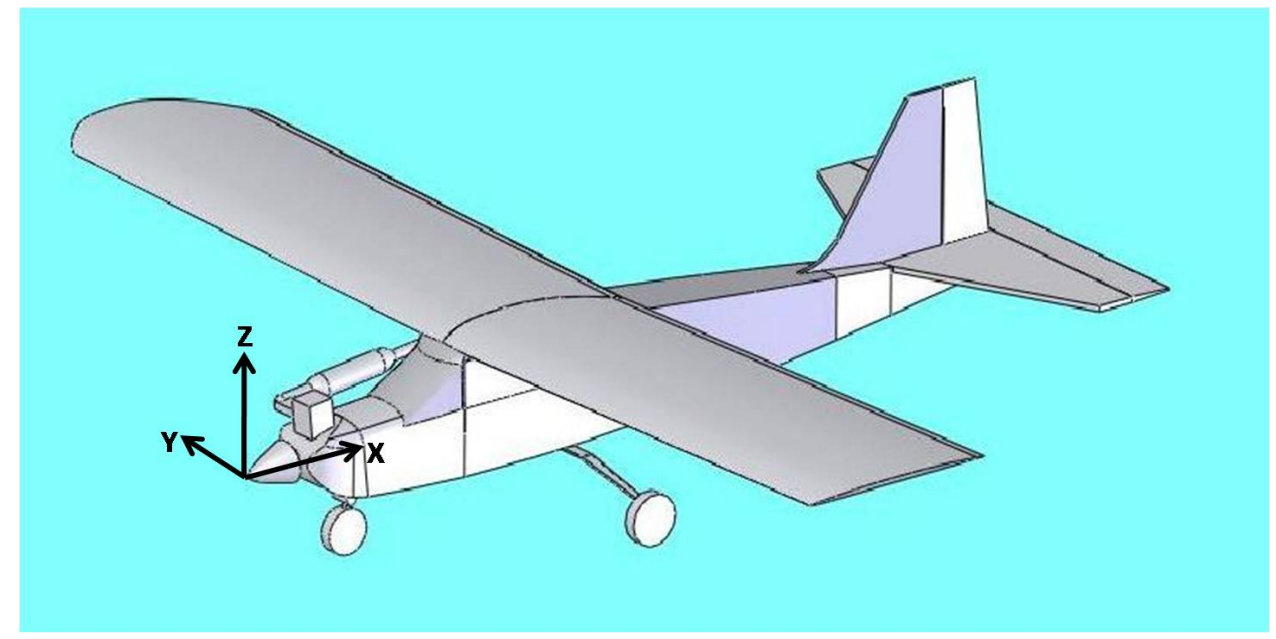

Figure 2.2. Sig Kadet Airplane - Solid Model.

elevator, rudder, ailerons, fin, stabilizer are assigned with the density of Balsa wood. The density of other parts such as engine, muffler and landing gears is calculated from their physical weights. An approximate CAD model of the engine is modeled keeping the overall size same. Wheels of the landing gears are modeled separately. The stick model includes internal parts such as modem, batteries, fuel tank. The moment of inertia and center of mass of the stick model is calculated using the feature 'Mass 
Properties' in SolidWorks. It even calculates the total volume and surface area. Moment of inertia is calculated for X,Y and Z-axis.

$$
\begin{aligned}
I_{x x} & =\int\left(y^{2}+z^{2}\right) d m \\
I_{y y} & =\int\left(z^{2}+x^{2}\right) d m \\
I_{z z} & =\int\left(x^{2}+y^{2}\right) d m \\
I_{x y} & =\int(x y) d m \\
I_{y z} & =\int(y z) d m \\
I_{z x} & =\int(z x) d m
\end{aligned}
$$

\subsubsection{Pendulum Method}

In this method moment of inertia of the Sig Kadet airplane is calculated from the frequency of oscillation about body $\mathrm{X}$ and Y-axis. Calculating moment of inertia using

the pendulum method is demonstrated in an AIAA paper [5]. A similar procedure is used to calculate the moment of inertia in this thesis except that the paper [5] calculates the period of oscillation from the frequency of oscillation obtained from the IMU data, while in this research, the period of oscillation is directly calculated using a stopwatch. A built Aluminum frame is used to hang the Sig Kadet airplane using a fishing line/hang cord and a wooden frame to rest the Sig Kadet airplane on it. The length of the chord from the support, fixed with the frame, is kept constant. The Sig Kadet airplane is balanced on the wooden support such that the landing gears are on the same level and there is no slack in the cord. The airplane is pulled forward and left free for it to oscillate. Care is taken to avoid jerks and have smooth oscillation. Moments of inertia about the axis of oscillation is analytically calculated 
using Eq.(2.7) and finally using the parallel axis theorem, refer Eq.(2.8), the moment of inertia of the airplane model about the body $\mathrm{X}$ and $\mathrm{Y}$-axes are calculated. The setup of the experiment for calculating the moment of Inertia about the X and Y-axes are shown in Figs. 2.3 and 2.4. The mechanism used to hang the Sig Kadet airplane is shown in Fig. 2.5. The experiment setup to calculate moment of inertia about the Z- axis is complicated and thus not included in this thesis.

$$
\begin{gathered}
I^{\prime}=W T^{2} L /\left(4 \pi^{2}\right) \\
I=I^{\prime}+M L^{2}
\end{gathered}
$$

where,

$I^{\prime}=$ Moment of Inertia about the pivot point

$I=$ Moment of Inertia about center of mass

$L=$ Distance between center of mass and axis of rotation

$M=$ Mass of the body

$W=$ Weight of the body

$T=$ Period of oscillation (sec)

The results of the above experiments are summarized and discussed in Chapter 5. 


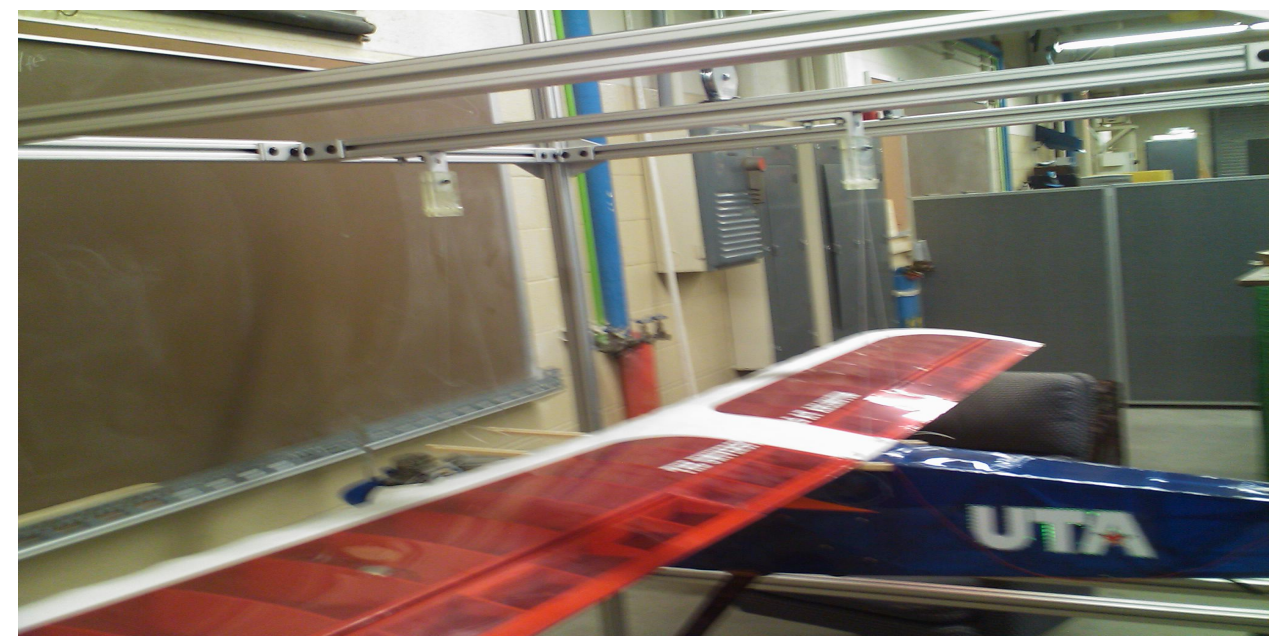

Figure 2.3. Experiment Setup for Moment of Inertia about X-axis.

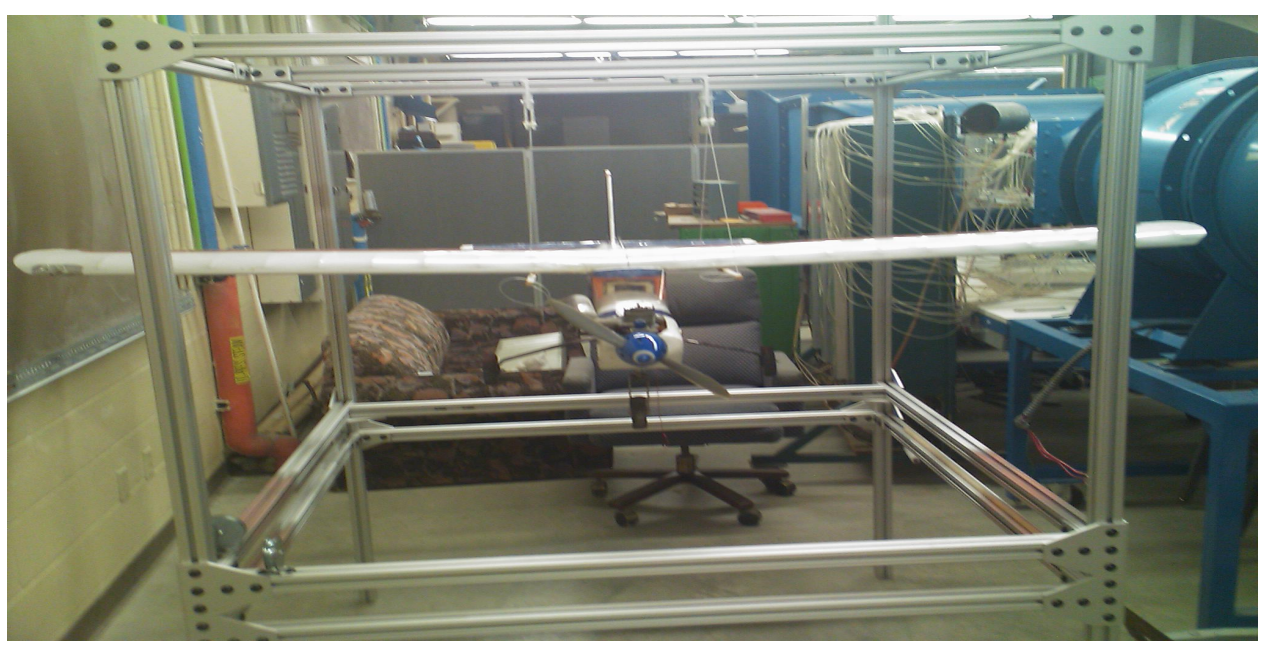

Figure 2.4. Experiment Setup for Moment of Inertia about Y-axis. 


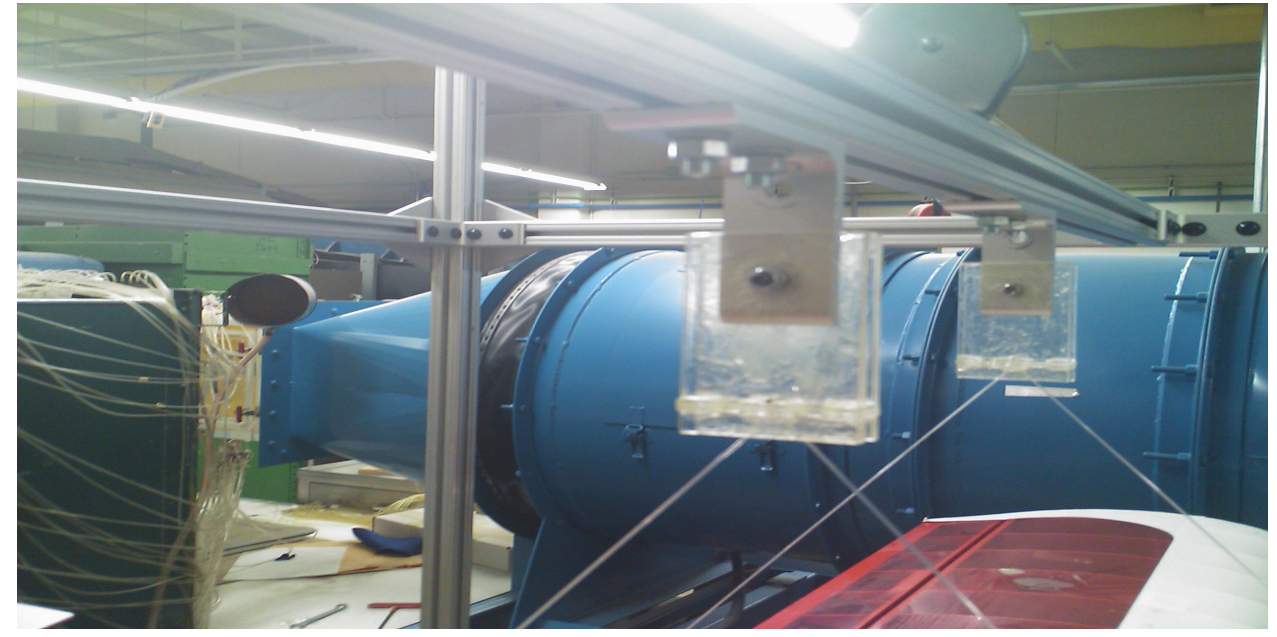

Figure 2.5. Experiment Setup: Hanging Mechanism. 


\section{CHAPTER 3}

\section{AERODYNAMIC PROPERTIES CALCULATION}

This chapter discusses the various parameters that are required to be configured to get appropriate aerodynamic force and moment coefficients of an $\mathrm{R} / \mathrm{C}$ airplane. It discusses the various commands and options that are useful and aids to calculate the aerodynamic properties of a given $\mathrm{R} / \mathrm{C}$ airplane. A step wise procedure for meshing the geometry of an R/C airplane in GAMBIT and solving for the aerodynamic properties in FLUENT is discussed.

\subsection{Introduction}

Computational Fluid Dynamics (CFD), branch of fluid mechanics, deals in solving the the governing laws of fluid dynamics numerically. Conservation of mass, moment and energy equation together forms the governing equations for a fluid. A given problem in practical environment exists in a continuous domain where each flow variable such as pressure and velocity is defined at every point in the domain. In CFD the basic strategy used to solve a given problem, for example solving the flow around an $\mathrm{R} / \mathrm{C}$ airplane, is to replace the continuous domain around the airplane with the discrete domain using a grid [7]. In discrete domain the flow variables are defined only at the grid points also called as nodes. Thus in order to generate a grid the domain is meshed by splitting the flow domain into smaller sub-domains. In CFD it is a common practice to use Finite Difference Method or Finite Volume method to solve the partial derivatives in the governing equations. 
Estimation of aerodynamic properties of an $\mathrm{R} / \mathrm{C}$ airplane involves meshing and simulation of the air flow around it. The first step towards the CFD is meshing which is done using GAMBIT. The later steps of simulating the flow around the model and the post processing is done using FLUENT software. FLUENT uses Finite Volume Method to solve the governing equations of fluid mechanics. The design of the model can be imported using Neutral files of various Industry Standard Formats such IGES, Parasolid, etc., formats. In this research, parasolid type of standard format is used to import the flow volume created in SolidWorks into GAMBIT. An adverse effect of this process to have some of the faces or edges of the model duplicated. 'Face' termed in GAMBIT and FLUENT is basically a surface constructed by joining edges or lines. The 'Make Tolerant' option assigns a default tolerance value of $10^{-6}$ to each imported vertex and edge to maintain the topological integrity for the geometry [8]. 'No Stand Alone Faces' option deletes the imported vertices, edges and/or faces which are not connected to higher topology. In GAMBIT, the geometric entities are designated as vertex, edge, face and volume, which define a complete geometry. Importing the geometry from the standard formats generates large number of faces. In order to simplify meshing it is required to check the model for holes, sharp angles, small edges and small faces. The 'Geometry Cleanup' command is used to clean the geometry for sharp angles, holes, small edges and small faces. The default setting for merging faces with sharp angles is to be changed from off to on (i.e. 0 to 1). Default settings are listed under the Edit menu on the Tool bar. Unless the default value is changed, the 'Geometry Cleanup' operation command remains incapable of merging faces with very sharp angles. 'Clean up small faces' command removes small faces by merging or collapsing the faces. 'Cleanup Small Faces' command helps in creating lesser number of mesh elements because the common edges are removed during the merging operation. 'Cleanup Short Edges' command removes the short edges by replacing 
them with vertices or by merging with the adjacent faces or edges. Presence of very short edges may lead in creating skew elements during meshing which is to be avoided. During the cleanup operations it is possible that some of the faces get converted from real to virtual entity. Real entities possess their own geometrical description, that is, they are defined by mathematical formulae that describe their locations and shapes. Virtual entities do not possess their own geometrical descriptions; instead; they derive their geometry by referencing to one or more real entities.

The model is ready for meshing once it is cleaned from the sharp angles. The Fixed, Curvature and Meshed type of Size functions are defined to control the size of element edges of the mesh in proximity of model entities to which they are attached. The default parameters for the size function is changed on similar basis as discussed in [9], for meshing of an airplane. The size functions in this case are attached to the faces. The faces are meshed using the Trimesh-Pave algorithm. Trimesh meshing has the advantage of meshing irregular shapes. Figure 3.1 shows the trimesh applied to all the faces of the Sig Kadet model with orientation of angle of attack (alpha) 8 degrees and elevator deflection 10 degrees. Figure 3.2 shows the use of the size function in meshing, part of the rudder is shown in the figure.

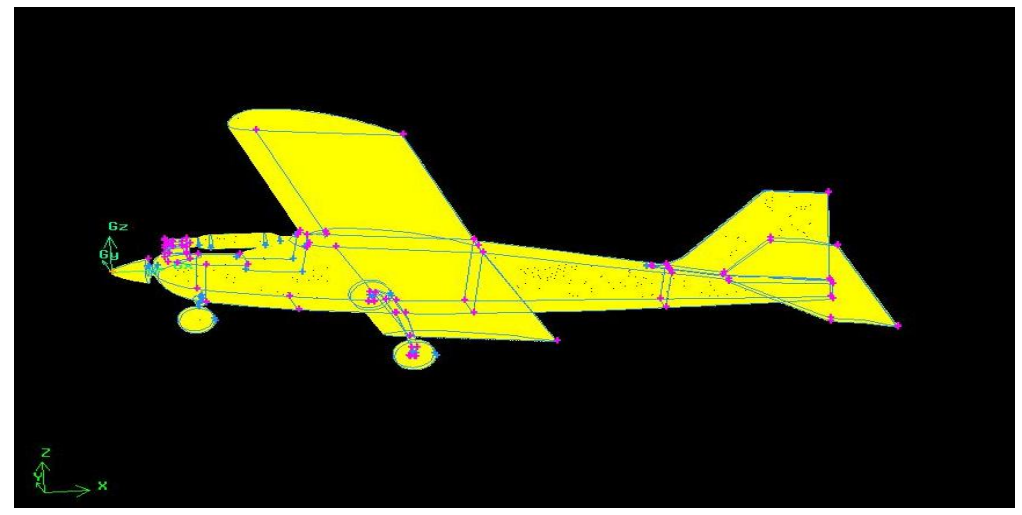

Figure 3.1. Face Mesh of Sig Kadet Model. 


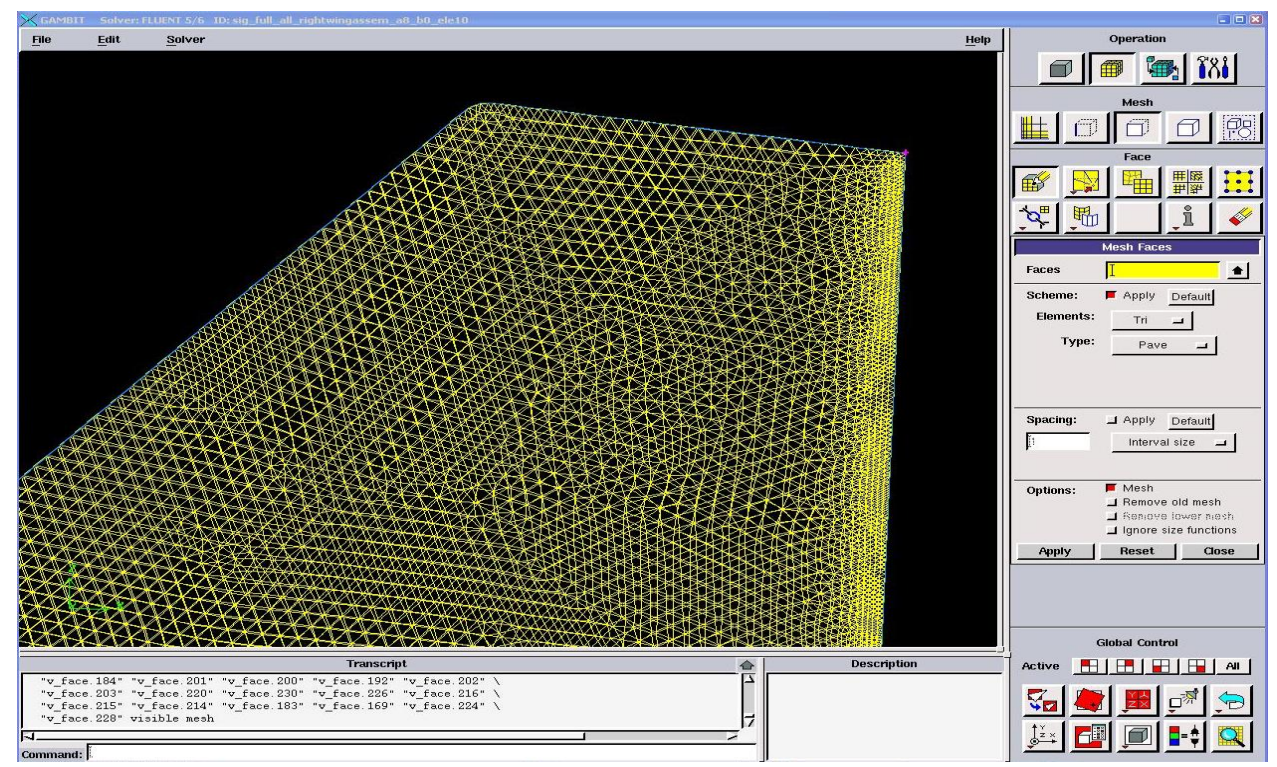

Figure 3.2. Trimesh and Size Function.

The flow volume is meshed by the default tetrahedral meshing scheme. The meshed volume is checked for the quality of the mesh. It is required to keep the geometry free from skewed elements otherwise it causes errors in FLUENT. The meshed geometry is exported from GAMBIT as a Mesh File which is then imported to FLUENT.

Simulation of the fluid flow in FLUENT requires an understanding of the problem itself. It is this understanding of the problem that leads to the answer for various question about which solver, viscous model, boundary conditions etc. to be selected. FLUENT software uses different type of solver which is related to how FLUENT solves the problem internally. FLUENT employs Pressure-based and Density-based Solvers. For Pressure-based Solver, the pressure equation is derived from the continuity and momentum equations such that the velocity field, corrected by the pressure satisfies the continuity. In the solution process entire set of governing equations are solved by an iterative method until the solution converges. This is done as the terms 
in governing equations are non-linear and coupled with each other. A choice between segregated or coupled type of algorithm for solving the flow field can be made in a pressure based solver. The segregated or decoupled type algorithm solves the governing equations sequentially while in the coupled type the governing equations are solved simultaneously. Segregated algorithm is memory efficient, however the convergence of the solution is comparatively slow. The density based solver uses coupled algorithm to solve the momentum and energy equations simultaneously. Solution control specification controls the convergence speed and the accuracy of the solution. Simple Pressure-Velocity coupling is chosen, with standard and first order discretization method selected for first few iterations and then changed to second order. This is specified by the user. The first few iterations are done with first order discretization technique so that the initial solution reches near the expected solution qickly and the discretization technique is changed to second order for accuracy. Refer to [10] for detailed information on the solvers and the discretization techniques. In this research, default pressure based, implicit, segregated solver is used. The flow over an $\mathrm{R} / \mathrm{C}$ airplane requires a viscous model to be defined. A fliud flow problem can be solved for Inviscid, Laminar or Turbulent type of flow. There are different models for simulating turbulent flow such as Spalart Allmaras, $k-\epsilon, k-\omega$, Reynolds Stress Model and Large Eddy Simulation Model. They differ in the number of equations that are used for solving turbulence. Spalart Allmaras, $k-\epsilon, k-\omega$ and Reynold Stress Models are based on the Reynolds Averaged Naiver Stokes (RANS) equation approach. In Reynolds averaging, the solution variables in the Navier-Stokes equations are decomposed into the mean and fluctuating components [11]. The terms representing the effects of the turbulence in the RANS equation are modeled in Spalart Allmaras, $k$ $-\epsilon$ and $k-\omega$ based on Boussinesq hypothesis [11]. The Spalart-Allmaras model solves one additional transport equation (representing turbulent viscosity) whereas $k-\epsilon$ and 
$k-\omega$ models solves two additional transport equations (for the turbulence kinetic energy, $k$, and either the turbulence dissipation rate, $\epsilon$, or the specific dissipation rate, $\omega)$.

Simulation of a fluid flow involves specifying boundary conditions. There are various boundary types available in FLUENT that specify the flow on the boundaries of the physical model. It is important to understand what boundary types should be specified depending on the problem statement. In this research, the flow is simulated over an $\mathrm{R} / \mathrm{C}$ airplane inside a wind tunnel with the walls of the test section far away from the model itself so that they have minimum effect on the aircraft model, resembling to the airplane model flying in the atmosphere. Velocity-Inlet, Pressure Outlet and 'Walls' boundary types are used in this thesis. Velocity-Inlet boundary type allows to specify the inflow velocity by different methods, either by specifying the magnitude and direction or velocity magnitude normal to the boundary or velocity components. The fluid flow is solved for incompressible type as the Mach number to be considered is very low. Static temperature at the velocity inlet boundary can be set in the temperature field for simulations involving energy equation. Pressure Outlet boundary condition requires to specify the static (gauge) pressure at the outlet. The static pressure specified is used for the subsonic flow. If the flow becomes locally supersonic the pressure is extrapolated from the interior. A moving or rotating or stationary wall condition can be specified using the the Boundary wall type. For viscous flow, no slip is enforced by default but slip conditions can be specified by specifying the shear conditions at the boundary wall. Symmetry boundary condition can be used if the physical boundary and the expected pattern of the flow solution is symmetric. This increases computational efficiency by reducing the simulation time as only half of the model is to be simulated. The interior of the flow volume is chosen as fluid representing air. 
Monitoring the progress of the solution is essential and gives an indication whether the solution is converging or diverging. Divergence of the simulation means that there is an error in setting up the problem such as the way the boundary conditions are defined or the model needs to be re-meshed with more finer mesh. Convergence can be monitored from plotting the residuals for every iteration by 'ResidualMonitor'. When aerodynamic coefficients are of interest, plotting force monitors aids in monitoring the changes in the aerodynamic coefficients for every iteration. If the changes in the results of the coefficients are not very significant while the simulation is still iterating, or if the curve for the coefficients converge to constants, then the solution is considered to have converged. Small fluctuations in the residual or force monitor plots can be ignored depending on the level of accuracy required. Large fluctuations mean that the solver is unable to solve the flow volume domain and thus finer re-meshing should be considered.

The solution can be post-processed graphically to visualize the flow in terms of various variables such as pressure, velocity, density. Understanding of the pressure distribution along the airfoil of the wing can aid in design analysis. Thus postprocessing is very useful in understanding the fluid flow behavior. An objective of this thesis is to calculate the aerodynamic coefficients for an $\mathrm{R} / \mathrm{C}$ airplane and to understand the sensitivity to change in angle of attack, side slip angle and control surface deflection. 'Force' option in 'Report Forces' gives the net pressure force, viscous force and total force as well its coefficients along the specified direction acting on the selected wall surface. 'Moments' option reports the moments acting on the selected wall surface about the specified point. It is important to remember that the FLUENT calculates the coefficients in terms of the area and length specified in the 'Reference Values'. In this thesis, planform area of the full wing is considered as the reference area. The results calculated by the simulation depends on the number 
of iterations, mesh size and convergence criteria. It is necessary to properly set various parameters within FLUENT for better results which is discussed in the section of Setting Configuration Parameters. The procedure to configure the parameters , mesh the flow volume in GAMBIT and solve for aerodynamic forces and moments in FLUENT is demonstrated using the Sig Kadet airplane model.

\subsection{Setting Configuration Parameters}

This section explains how the configuration parameters in Fluent are selected such as which viscous model is used, how the size of the flow volume is determined and how many iterations needed for convergence. Flow volume is the volume around the model within which the air flow is captured. The Sig Kadet UAV model is generally flown within 30 to 50 knots airspeed. Thus, in the simulation the velocity of the air with respect to the model is specified to be $20 \mathrm{~m} / \mathrm{s}$ (approximately 40 knots). For convenience, the flow volume is designed such that the origin of the coordinate axes is located at the nose of the Sig Kadet Model with zero angle of attack and side slip angle, with $\mathrm{X}$-axis pointing towards the tail of the fuselage; $\mathrm{Y}$-axis pointing along the right wing and Z-axis pointing upwards. This coordinate system is different from the body fixed coordinate frame in which the X-axis points towards the front of the fuselage; Y-axis along the right wing, Z-axis pointing downwards and the origin located at the nose. The custom coordinate system was chosen so as to keep the Xaxis along the direction of the airflow at the inlet boundary and the Z- axis direction such that it gives a positive lift force.

\subsubsection{Simplified Geometry}

Sig Kadet Airplane model contains various parts of detailed geometry such as landing gear, muffler and fillets (defined as the rounding of the sharp corners in 
design). A simplified geometry free from muffler and lading gears is first designed. Small fillets are ignored in the model design. This is done to simplify the meshing. Since the simplified Sig Kadet model and resulting flow field around it is symmetric with respect to the $\mathrm{X}-\mathrm{Z}$ plane, only half of the flow volume is designed in SolidWorks and imported to GAMBIT using parasolid format. The size of the flow volume for this case is arbitrarily chosen such that it is larger than the simplified Sig Kadet model itself. After the cleaning operation of the geometry from holes, small faces and sharp angles, meshing is done in accordance with the GAMBIT tutorial on meshing of an airplane geometry [9]. The mesh file thus created in GAMBIT is exported to FLUENT and solved using segregated pressure based, implicit solver for steady flow with $20 \mathrm{~m} / \mathrm{s}$ velocity of air at inlet boundary. The viscous model selected is $k-\epsilon$ - Realizable model. The turbulence effect is specified in the form of intensity and length. The intensity specified is $0.04 \%$ and length scale $1 \mathrm{e}-6 \mathrm{~mm}$ to model low turbulence effect. The solution is iterated for 700 iterations for it to converge. The results are tabulated in the Table 3.1. Another full model of simplified Sig Kadet (without landing gears and muffler) and a half model of Sig Kadet with muffler and without landing gears are designed; meshed and solved in the same manner as the previous one. This is done to compare the forces for half model and full model of Sig Kadet. From the comparison of the forces it is seen that the drag $\left(F_{x}\right)$ and lift $\left(F_{z}\right)$ forces are doubled for the full model without landing gears and muffler when compared with the half model without the landing gears and muffler. The side force $\left(F_{y}\right)$ for the full model without muffler and landing gears is required to be zero as the model is symmetric but it rather reports a small value of force. Drag force is increased due to the presence of the muffler when the two cases of half model are compared while there is no significant change in Lift force. 
Table 3.1. Force Comparison for Sig Kadet Geometry

\begin{tabular}{|c|c|c|c|}
\hline Forces & $\begin{array}{c}\text { Half Model } \\
\text { w/o Landing Gears } \\
\& \text { Muffler }\end{array}$ & $\begin{array}{c}\text { Full Model } \\
\text { w/o Landing Gears } \\
\& \text { Muffler }\end{array}$ & $\begin{array}{c}\text { Half Model } \\
\text { w/o Landing Gears } \\
\text { only }\end{array}$ \\
\hline$F_{x}$ & $4.535 \mathrm{~N}$ & $9.083 \mathrm{~N}$ & $4.746 \mathrm{~N}$ \\
\hline$F_{y}$ & $1.7 \mathrm{~N}$ & $0.02 \mathrm{~N}$ & $1.62 \mathrm{~N}$ \\
\hline$F_{z}$ & $40.36 \mathrm{~N}$ & $80.79 \mathrm{~N}$ & $40.37 \mathrm{~N}$ \\
\hline
\end{tabular}

\subsubsection{Reduction of Wall Interference Effect}

It is required to model the flow volume such a way that it represents as if the aircraft is flying in the atmosphere. The flow volume for calculating the aerodynamic coefficients is designed in such a way that it represents as if the Sig Kadet airplane model is placed inside an infinitely big test section of the wind tunnel, so that it does not have any wall interference effect. Wall Interface depends on the size of the flow volume and properties of the wall such as roughness and slip condition. Minimizing the wall interference effect on the Sig Kadet model would give a better solution of the flow around the aircraft under environmental condition.

\subsubsection{Size of Flow Volume Domain}

Boundary walls kept closer to the test model would give a flow field that does not represent the airplane flight condition because of the effects of the boundary walls on the flow field. It is thus required that the boundary walls are kept at an infinite distance from the test model, which is an ideal condition but unattainable. The distance of the boundary from the test model is to be determined such that the wall effect is minimum and computing resource and time required are adequate. Larger the size of the flow volume for same meshing pattern, the longer the simulation time. It is significant to determine an appropriate size of the flow volume that will capture 
the flow field around the Sig Kadet model without having much interference from the boundary walls.

The forces for the simplified Sig Kadet model (without muffler and landing gears) to determine the effect of the boundary wall are compared. The first flow volume termed as flow volume size1 has the size of $3000 \mathrm{~mm}$ x $1500 \mathrm{~mm} \times 1500 \mathrm{~mm}$ that is the volume of $6.75 \times 10^{9} \mathrm{~mm}^{3}$ and the second flow volume termed as flow volume size2 has the size of $4000 \mathrm{~mm}$ x $2000 \mathrm{~mm}$ x $2500 \mathrm{~mm}$ that is the volume of $20 \times 10^{9} \mathrm{~mm}^{3}$. The flow volume sizes mentioned are for the half model as the flow field around the simplified Sig Kadet model is symmetric. The second size was obtained by basically moving the inlet, outlet planes and boundary walls away by $500 \mathrm{~mm}$. The results are tabulated in the Table 3.2. The difference in the forces are significant, which indicates the presence of interference from the boundary walls. It is required to understand the sensitivity of the forces due to the change in distance of the boundary walls from the Sig Kadet model. Sensitivity of the forces for upperwall and lowerwall when moved along the Z- axis at an interval of $100 \mathrm{~mm}$ was recorded and are tabulated in the Table 3.3 and Table 3.4. Graphs between the difference in the forces due to change in the upperwall and lowerwall position are plotted in Fig. 3.3. The force difference is calculated by subtracting the force value of the smaller flow volume from the larger one. It is seen from the graph that the sensitivity decreased as the wall was moved further away. The next step is to understand the sensitivity against the changes of the volume size in each axis, separately. The flow volume expanded in Z- and Y-directions separately and the results are tabulated in the Table 3.5, which shows that displacements of the wall in Y-direction caused a significant change in the force along the Z-direction as well as in Y-direction. Thus, determination of an appropriate volume size requires a large number of simulations for 
different positions of the walls and it is difficult to predict how many such simulations would be necessary.

For an aircraft, the lift force is produced mainly by the wings. The pressure distribution around the wing surface can be predicted by the flow around its airfoil. To decide with the flow volume size such that the wall interference effect is minimum on the Sig Kadet airplane model, the flow field around its airfoil is first developed and visually inspected for any wall interference effect on the 2D airfoil. Simulation for the flow around the Sig Kadet Airfoil is conducted for zero angle of attack, the velocity and dynamic pressure contour plot is shown in Fig. 3.4. Here, the angle of attack is considered as the angle between the horizontal line of the airfoil and the wind direction. The wing of the Sig Kadet is such that the bottom surface of the wing is flat. The airfoil of the Sig Kadet wing is similar to the Clark Y airfoil, this is discussed later in Chapter 4. The Sig Kadet airfoil is sketched in SolidWorks by drawing a spline connecting through several points based on the coordinates measured from a rib of the wing that came along with the Sig Kadet model building kit. It is verified by comparing it with the wing of the Sig Kadet Almost Ready to Fly model. In general as a common practice the boundary walls of the flow area are kept 10-15 times the chord length of the airfoil away from the airfoil itself. The same concept as that of 2D airfoil flow area is used for the 3D Sig Kadet model. The chord length of the Sig Kadet wing is $385 \mathrm{~mm}$. The length of the flow volume is 13,000 mm such that the inlet section is approximately 12.5 times while the outlet section is approximately 20 times the chord length of the Sig Kadet airfoil away from the wing. The flow volume height is $10,000 \mathrm{~mm}$ such that the upper and lower boundary wall are approximately 12.5 times the chord length away from the horizontal plane passing through the nose of the Sig Kadet airplane model. The width is specified as $10,000 \mathrm{~mm}$ which is arbitrarily chosen such that the effect of the side boundary wall 
on the Sig Kadet model is minimum. The forces considering the flow volume built in accordance with the $2 \mathrm{D}$ airfoil case are compared with the previous cases of flow volumes and tabulated in Table 3.2. This flow volume is termed as flow volume size3.

Table 3.2. Force Comparison for change in Flow Volume Size

\begin{tabular}{|c|c|c|c|}
\hline \multirow{2}{*}{ Forces } & \multicolumn{3}{|c|}{ Sig Kadet Half Model w/o Muffler and Landing Gears } \\
\cline { 2 - 4 } & $\begin{array}{c}\text { Flow Volume Size1 } \\
6.75 \times 10^{9} \mathrm{~mm}^{3}\end{array}$ & $\begin{array}{c}\text { Flow Volume Size2 } \\
20 \times 10^{9} \mathrm{~mm}^{3}\end{array}$ & $\begin{array}{c}\text { Flow Volume Size3 } \\
1300 \times 10^{9} \mathrm{~mm}^{3}\end{array}$ \\
\hline Drag & $4.535 \mathrm{~N}$ & $4.523 \mathrm{~N}$ & $4.543 \mathrm{~N}$ \\
\hline Side & $1.7 \mathrm{~N}$ & $1.128 \mathrm{~N}$ & $0.190 \mathrm{~N}$ \\
\hline Lift & $40.36 \mathrm{~N}$ & $37.25 \mathrm{~N}$ & $34.857 \mathrm{~N}$ \\
\hline
\end{tabular}

Table 3.3. Force comparison for change in flow volume size due to displacement of upper boundary wall along Z-direction (Note: - value in wall displacement indicates moving towards and + value indicates moving away from the Sig Kadet Simplified Model)

\begin{tabular}{|c|c|c|c|c|}
\hline \multicolumn{5}{|c|}{ Sig Kadet Half Model w/o Muffler and Landing Gears } \\
\hline Flow volume & $4 \mathrm{~m} \mathrm{x}$ & $4 \mathrm{~m} \mathrm{x}$ & $4 \mathrm{~m} \mathrm{x}$ & $4 \mathrm{~m} \mathrm{x}$ \\
Size & $2 \mathrm{~m} \mathrm{x}$ & $2 \mathrm{~m} \mathrm{x}$ & $2 \mathrm{~m} \mathrm{x}$ & $2 \mathrm{~m} \mathrm{x}$ \\
& $2.40 \mathrm{~m} \mathrm{x}$ & $2.50 \mathrm{~m} \mathrm{x}$ & $2.60 \mathrm{~m} \mathrm{x}$ & $2.70 \mathrm{~m} \mathrm{x}$ \\
\hline $\begin{array}{c}\text { Upperwall displacement } \\
\text { along Z-Direction }\end{array}$ & $-100 \mathrm{~mm}$ & $0 \mathrm{~mm}$ & $100 \mathrm{~mm}$ & $200 \mathrm{~mm}$ \\
\hline Drag Force & $4.524 \mathrm{~N}$ & $4.523 \mathrm{~N}$ & $4.522 \mathrm{~N}$ & $4.520 \mathrm{~N}$ \\
\hline Side Force & $1.108 \mathrm{~N}$ & $1.128 \mathrm{~N}$ & $1.140 \mathrm{~N}$ & $1.151 \mathrm{~N}$ \\
\hline Lift Force & $37.289 \mathrm{~N}$ & $37.250 \mathrm{~N}$ & $37.221 \mathrm{~N}$ & $37.199 \mathrm{~N}$ \\
\hline
\end{tabular}

\subsubsection{Boundary Wall Condition}

Another parameter that can influence the interference effect due to wall is the no-slip condition and the roughness of the wall. The roughness and slip or no slip 
Table 3.4. Force comparison for change in flow volume size due to displacement of lower boundary wall along the Z-direction (Note: - value in wall displacement indicates moving towards and + value indicates moving away from the Sig Kadet Simplified Model)

\begin{tabular}{|c|c|c|c|c|}
\hline \multicolumn{5}{|c|}{ Sig Kadet Half Model w/o Muffler and Landing Gears } \\
\hline Flow volume & $4 \mathrm{~m} \mathrm{x}$ & $4 \mathrm{~m} \mathrm{x}$ & $4 \mathrm{~m} \mathrm{x}$ & $4 \mathrm{~m} \mathrm{x}$ \\
Size & $2 \mathrm{~m} \mathrm{x}$ & $2 \mathrm{~m} \mathrm{x}$ & $2 \mathrm{~m} \mathrm{x}$ & $2 \mathrm{~m} \mathrm{x}$ \\
& $2.40 \mathrm{~m} \mathrm{x}$ & $2.50 \mathrm{~m} \mathrm{x}$ & $2.60 \mathrm{~m} \mathrm{x}$ & $2.70 \mathrm{~m} \mathrm{x}$ \\
\hline $\begin{array}{c}\text { Lowerwall displacement } \\
\text { along Z-Direction }\end{array}$ & $-100 \mathrm{~mm}$ & $0 \mathrm{~mm}$ & $100 \mathrm{~mm}$ & $200 \mathrm{~mm}$ \\
\hline Drag Force & $4.519 \mathrm{~N}$ & $4.523 \mathrm{~N}$ & $4.527 \mathrm{~N}$ & $4.529 \mathrm{~N}$ \\
\hline Side Force & $1.226 \mathrm{~N}$ & $1.128 \mathrm{~N}$ & $1.048 \mathrm{~N}$ & $0.980 \mathrm{~N}$ \\
\hline Lift Force & $37.491 \mathrm{~N}$ & $37.250 \mathrm{~N}$ & $37.068 \mathrm{~N}$ & $36.922 \mathrm{~N}$ \\
\hline
\end{tabular}

condition is to be specified in the wall type boundary condition for each wall. To model the wall roughness effect, it is required to specify the wall roughness height $\left(K_{s}\right)$ and roughness constant $\left(C_{s}\right)$. By default, the value for wall roughness height is set to zero corresponding to smooth walls while the roughness constant set to value of 0.5 , which represents tightly packed, uniform sand grain roughness [12]. Defaults values of wall roughness height and roughness constant are chosen so that the all the boundary condition with wall type boundary correspond to a smooth surface. Shear conditions can be specified as no slip condition or as slip condition. The default no slip condition implies that the flow has zero velocity with respect to the wall. The no slip wall condition is used for the boundary wall defining the aircraft geometry. The no slip condition causes a velocity gradient near the wall such that the velocity of the fluid at the stationary wall is zero and gradually increases until it reaches the free stream velocity. If no slip condition is selected for the boundary walls of the flow volume then there will be a velocity gradient near the walls which might cause some interference in the airflow. This is well understood from the results of the forces 
Table 3.5. Force Comparison for change in Flow Volume Size due to displacement of Side Boundary Wall along Y-direction (Note: - value in wall displacement indicates moving towards and + value indicates moving away from the Sig Kadet Simplified Model)

\begin{tabular}{|c|c|c|}
\hline \multicolumn{3}{|c|}{ Sig Kadet Half Model w/o Muffler and Landing Gears } \\
\hline Flow volume Size & $4 \mathrm{~m} \times 2 \mathrm{~m} \times 2.5 \mathrm{~m}$ & $4 \mathrm{~m} \times 2.10 \mathrm{~m} \times 2.5 \mathrm{~m}$ \\
\hline $\begin{array}{c}\text { Sidewall displacement } \\
\text { along Y-Direction }\end{array}$ & $0 \mathrm{~mm}$ & $100 \mathrm{~mm}$ \\
\hline Drag Force & $4.523 \mathrm{~N}$ & $4.561 \mathrm{~N}$ \\
\hline Side Force & $1.128 \mathrm{~N}$ & $0.998 \mathrm{~N}$ \\
\hline Lift Force & $37.250 \mathrm{~N}$ & $36.784 \mathrm{~N}$ \\
\hline
\end{tabular}

tabulated in the Table 3.6 and from the velocity and dynamic pressure contour plots for Sig Kadet airfoil oriented at zero degrees angle of attack for both no slip and slip condition as shown in Fig. 3.4 and Fig. 3.5. Slip condition is set by specifying the $\mathrm{x}$ and $\mathrm{y}$ component of shear stress as zero pascal. The forces over the Sig Kadet Model for slip and no slip condition with the size of the flow volume as selected in the previous subsection are tabulated in the Table 3.6. To minimize the wall interference effect on the Sig Kadet model, it is selected that the boundary walls of the flow volume are to be modeled with zero shear stress slip condition.

Table 3.6. Force Comparison for Sig Kadet Airfoil and Aircraft for different Boundary Wall Condition

\begin{tabular}{|c|c|c|c|c|}
\hline \multirow{2}{*}{ Forces } & \multicolumn{2}{|c|}{ Sig Kadet Airfoil } & \multicolumn{2}{c|}{ Sig Kadet Aircraft Model } \\
\cline { 2 - 5 } & $\begin{array}{c}\text { No Slip } \\
\text { Condition }\end{array}$ & $\begin{array}{c}\text { Zero Shear Stress } \\
\text { Condition }\end{array}$ & $\begin{array}{c}\text { No Slip } \\
\text { Condition }\end{array}$ & $\begin{array}{c}\text { Zero Shear Stress } \\
\text { Condition }\end{array}$ \\
\hline Drag & $1.89 \mathrm{~N}$ & $1.418 \mathrm{~N}$ & $4.52 \mathrm{~N}$ & $4.48 \mathrm{~N}$ \\
\hline Side & - & - & $1.13 \mathrm{~N}$ & $0.52 \mathrm{~N}$ \\
\hline Lift & $51.91 \mathrm{~N}$ & $38.91 \mathrm{~N}$ & $37.25 \mathrm{~N}$ & $36.97 \mathrm{~N}$ \\
\hline
\end{tabular}




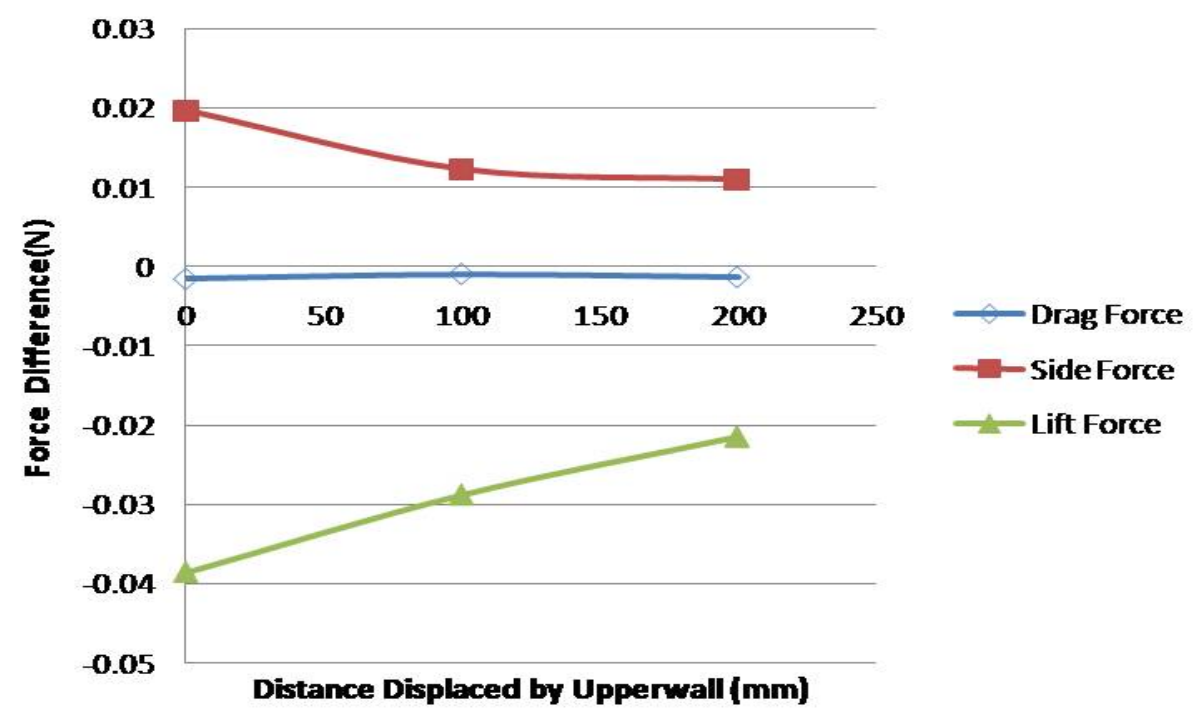

(a)

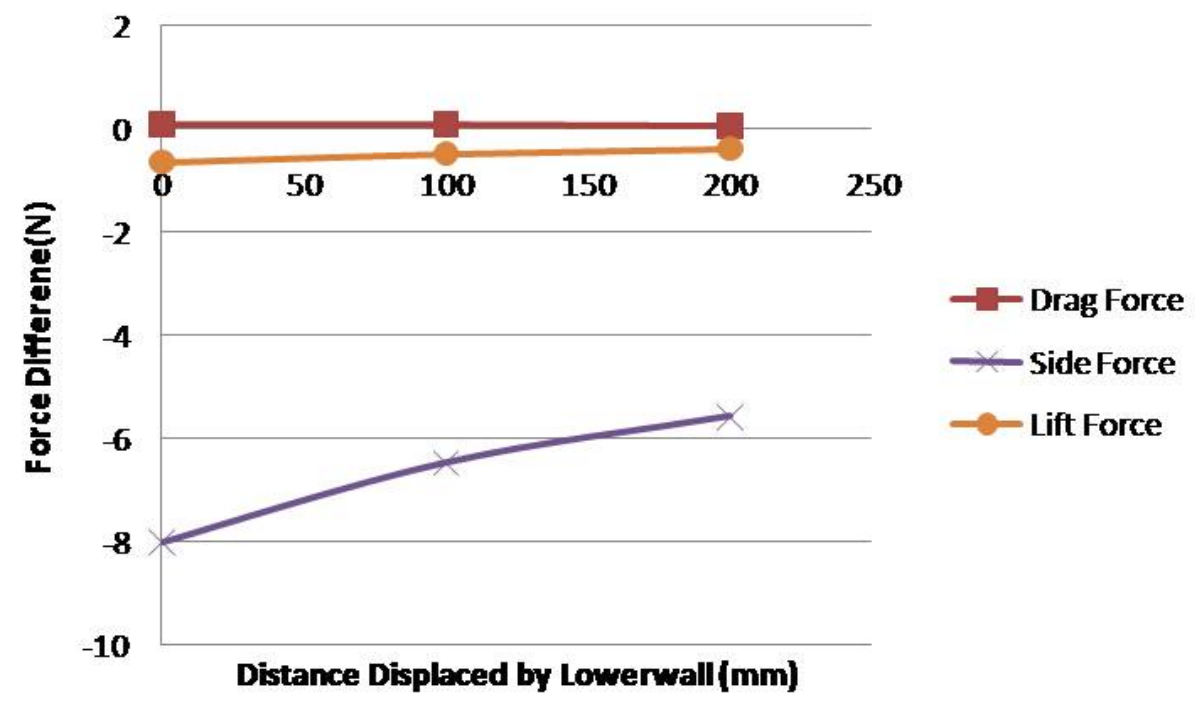

(b)

Figure 3.3. Difference in force plot due to displacement of (a) Upperwall and (b) Lowerwall.

\subsubsection{Wall Interference Check for Angles of Attacks}

The size of the flow volume was selected considering zero degrees angle of attack. It is obvious that the pressure contour will change with the change in the angle of 

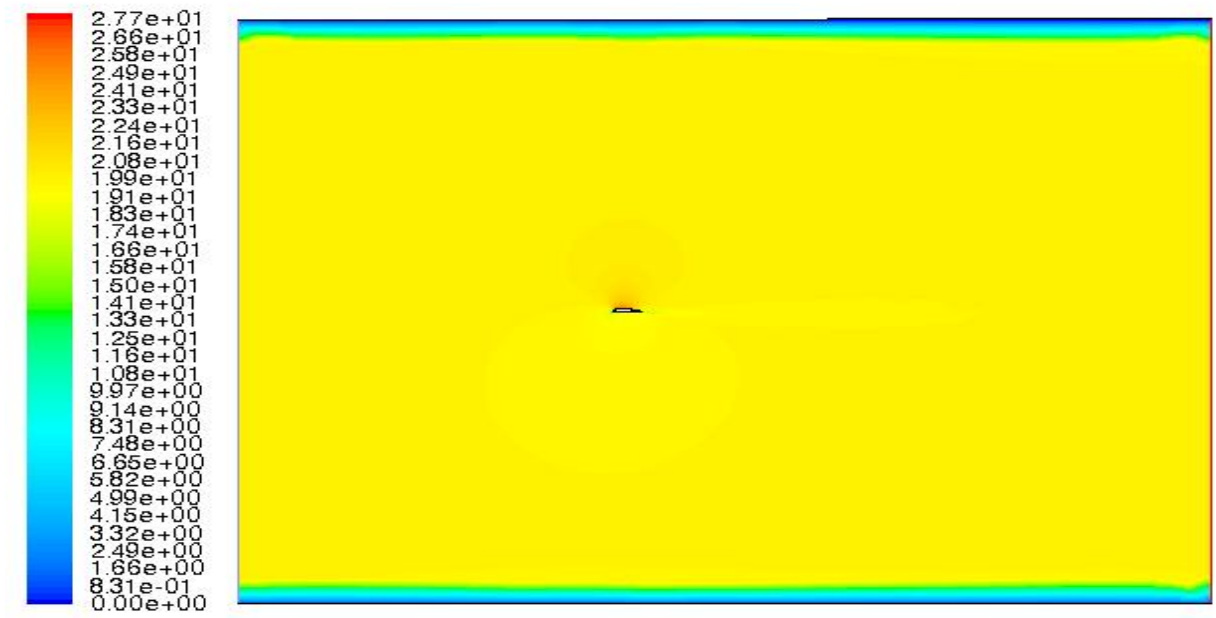

(a)
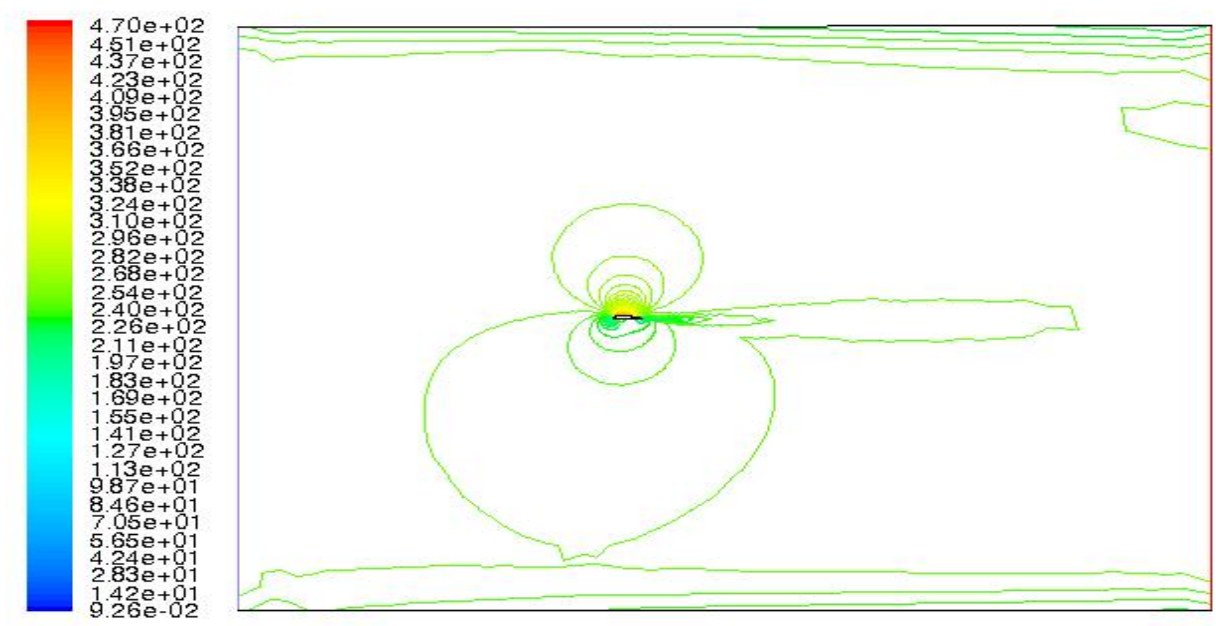

Contours of Dynamic Pressure (pascal)

Jun 25,2009 FLUENT 6.3 (2d, dp, pbns, rke)

(b)

Figure 3.4. (a) Velocity Magnitude (b) Dynamic Pressure Contour Plot for Sig Kadet Airfoil at alpha 0 degrees with No Slip Condition at the Boundary Walls.

attack. It becomes necessary to know if there is any wall interference effect due to variation in angle of attack. To investigate this, pressure and velocity contours around Sig Kadet Airfoil for various angles of attack are plotted for visual inspection. 


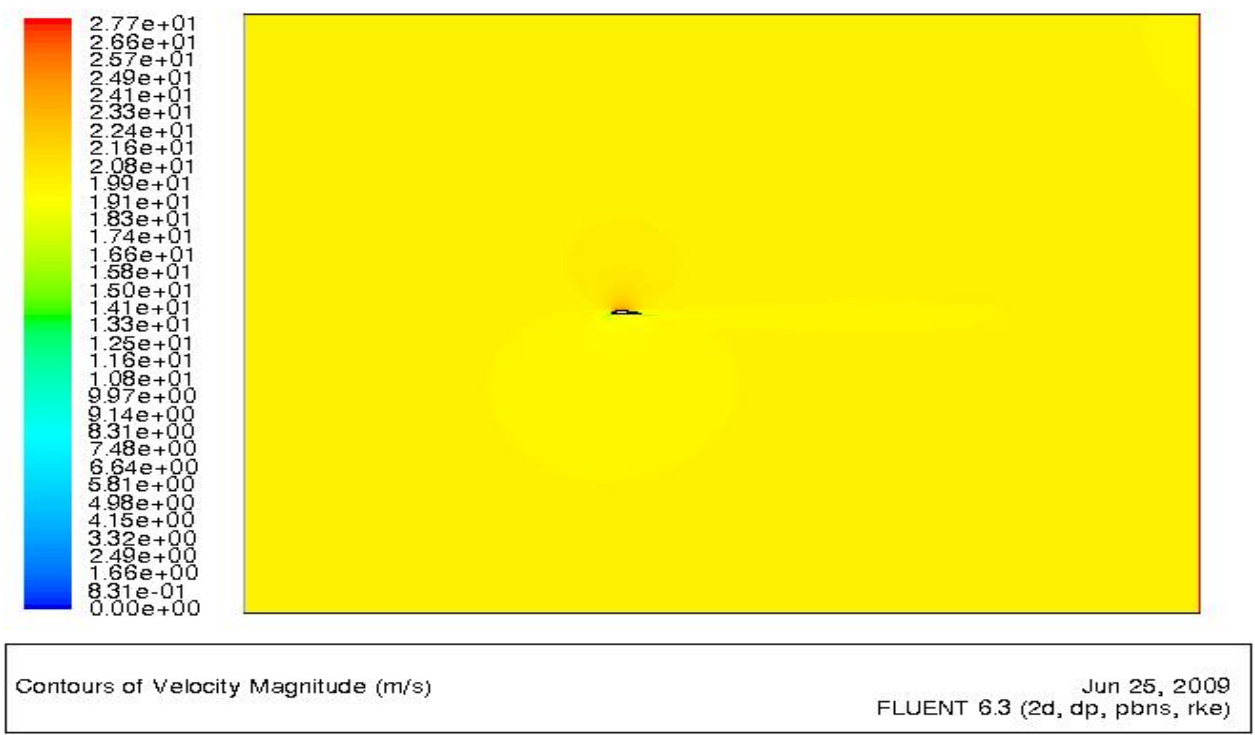

(a)

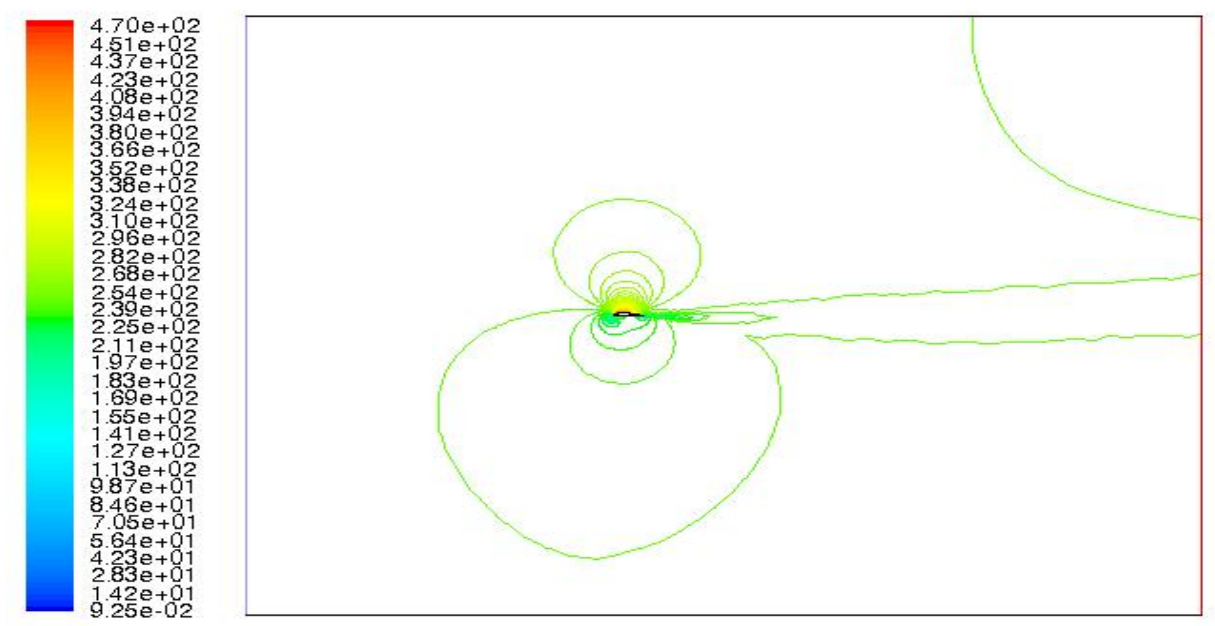

Contours of Dynamic Pressure (pascal)

Jun 25, 2009 FLUENT 6.3 (2d, dp, pbns, rke)

(b)

Figure 3.5. (a) Velocity Magnitude (b) Dynamic Pressure Contour Plot for Sig Kadet Airfoil at alpha 0 degrees with Zero Shear Stress Condition at the Boundary Walls.

The static pressure, dynamic pressure and velocity magnitude plot for the Sig Kadet airfoil at 8 degrees angle of attack is shown Fig. 3.8, for the contour plot for other angles of attack refer to Appendix A. Slip condition of zero shear stress is modeled 


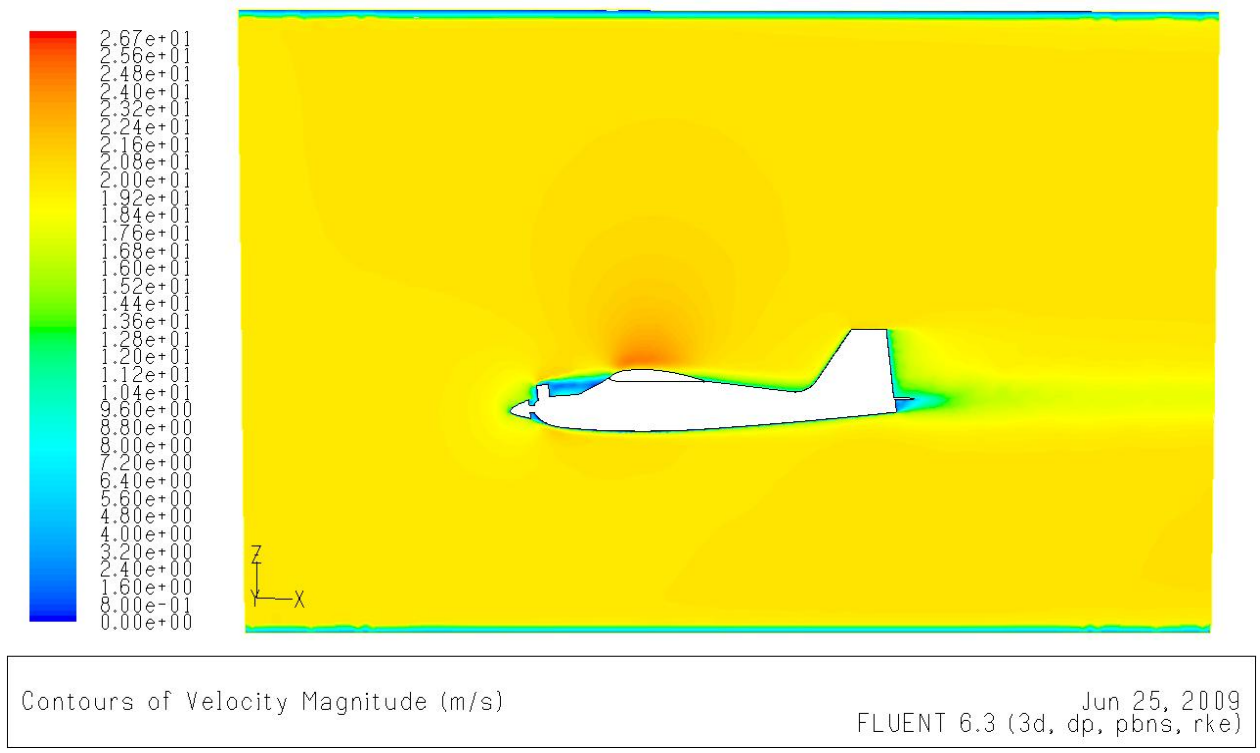

(a)

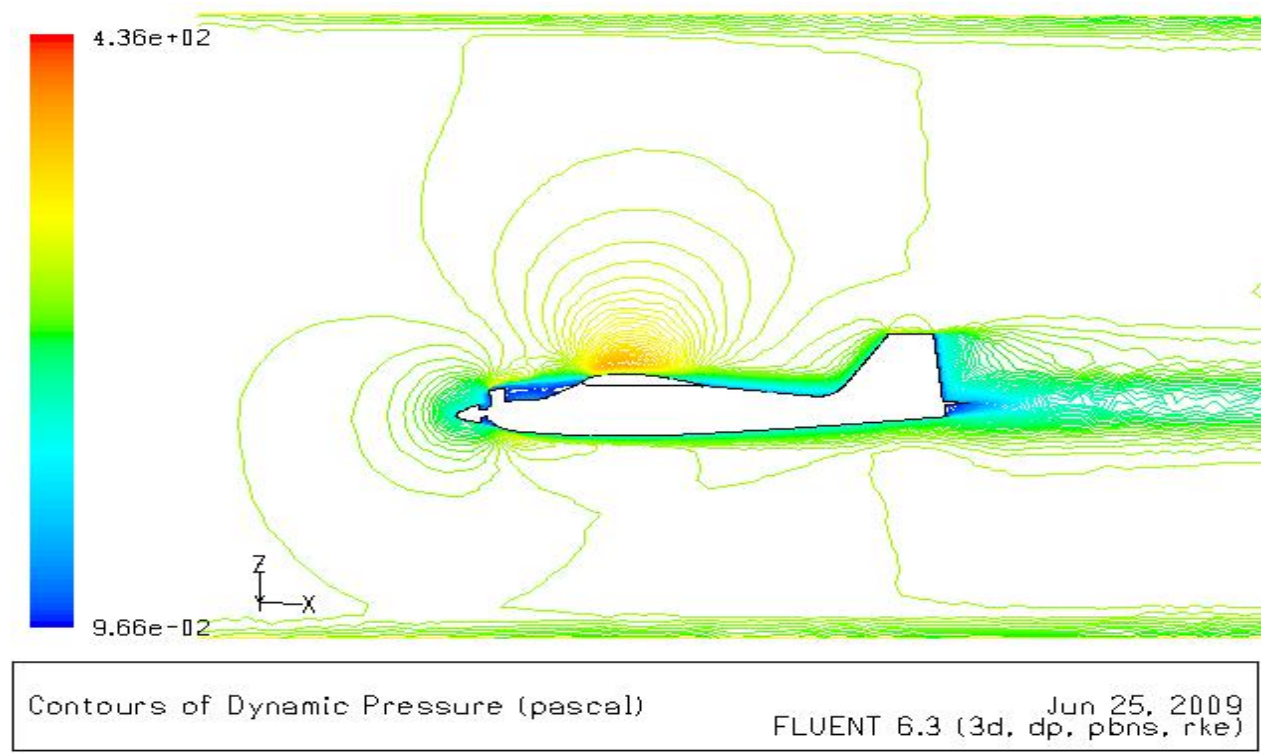

(b)

Figure 3.6. (a) Velocity Magnitude (b) Dynamic Pressure Contour Plot for Sig Kadet Aircraft Model (simplified) at alpha 0 degrees with No Slip Condition at the Boundary Walls.

for the boundary walls. There are no significant interference seen and thus no change in the selected flow volume is required. 


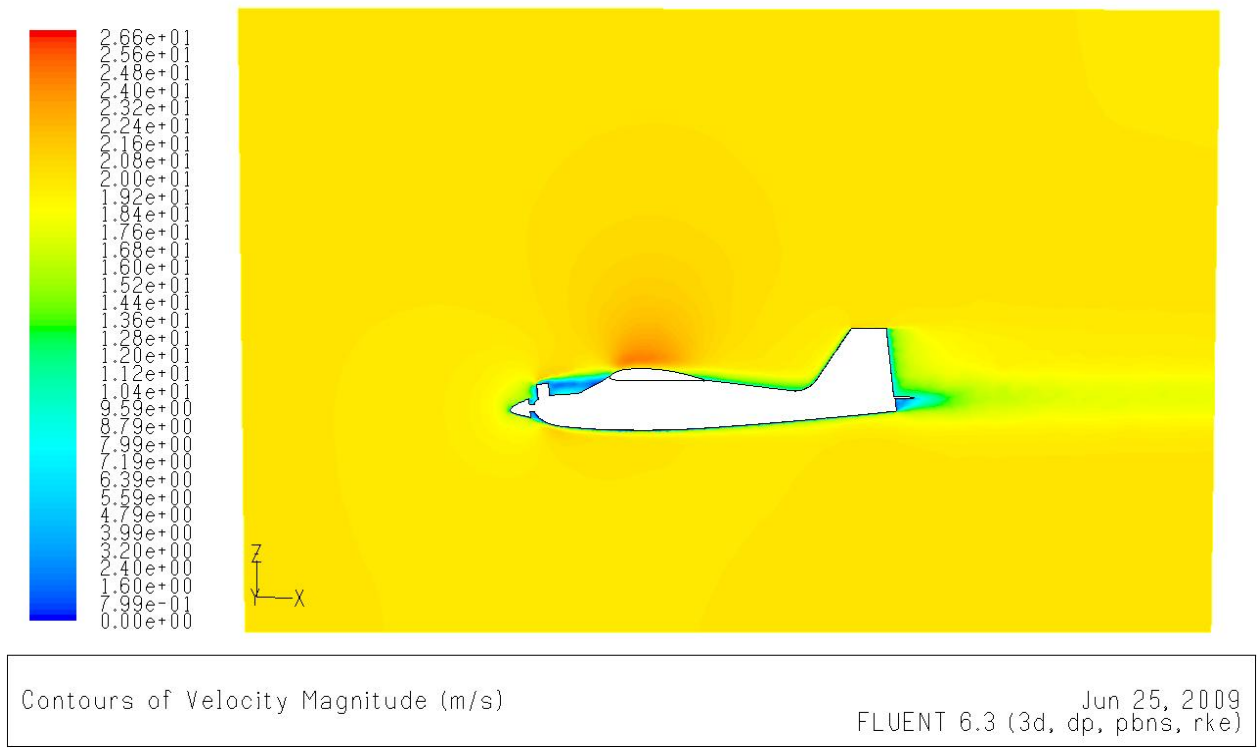

(a)

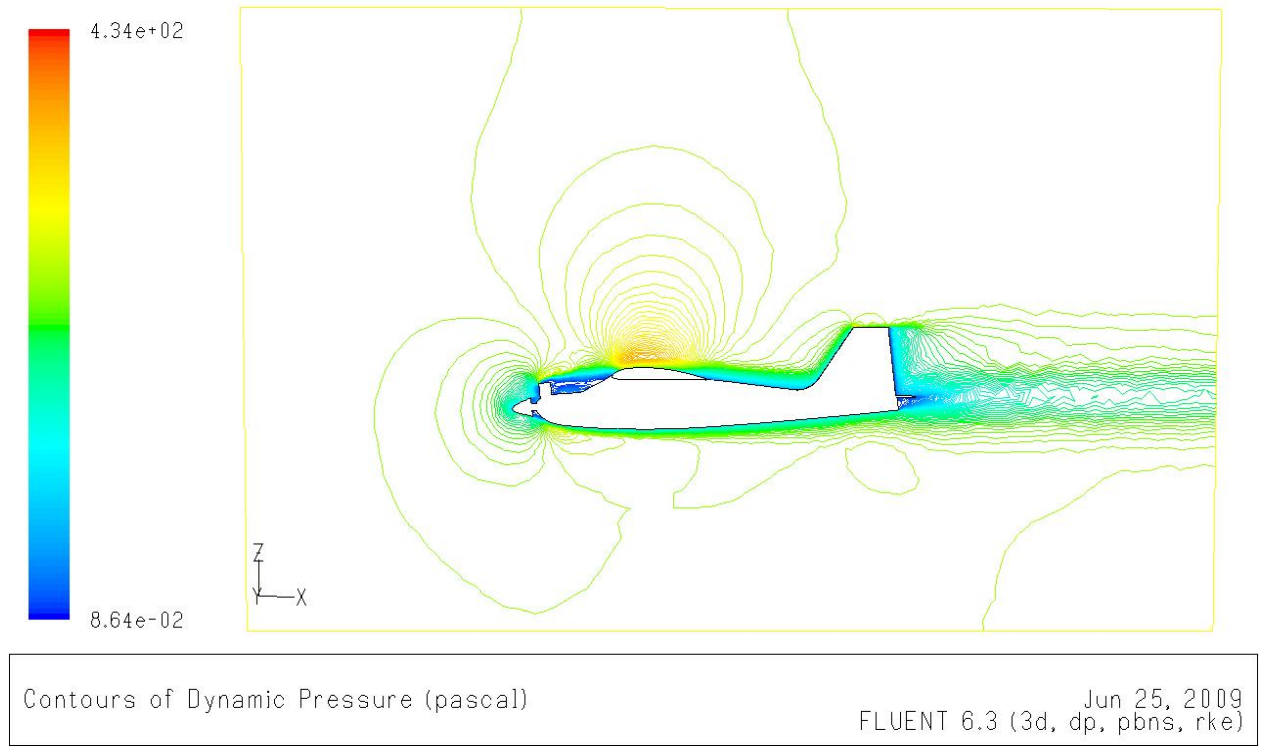

(b)

Figure 3.7. (a) Velocity Magnitude (b) Dynamic Pressure Contour Plot for Sig Kadet Aircraft Model (simplified) at alpha 0 degrees with Zero Shear Stress Condition at the Boundary Walls.

\subsubsection{Flow volume Size Sensitivity}

To quantify the sensitivity of the force and moment calculation against the final selection of the flow volume size, the simulation is repeated with varying flow volume 
by $\pm 1000 \mathrm{~mm}$ along the three axes. In these simulations the slip condition with zero shear stress is used. The variations in the force coefficients are shown in Fig. 3.9 to 3.11 .

\subsubsection{Choice of Viscous Model}

It is important to choose a viscous model which is appropriate to a given physical problem. There has not been any well defined theory set in regards to which viscous model is suitable for a given physical problem [11]. Viscous models available in FLUENT are Inviscid, Laminar, Spalart Allmaras, $k-\epsilon, k-\omega$, Reynolds stress model, Detached Eddy Simulation and Large Eddy Simulations. Since Reynolds Stress Model, Detached Eddy Simulation and Large Eddy Simulation require high computational resources and would involve longer simulation time, they are excluded from comparison with other models in this section. Inviscid flow does not consider the viscous layer between the fluid and the wall. Finite NACA 0012 wing for low Reynolds number is selected as a test case to determine the viscous model to be used. The measurements needed for modeling NACA 0012 in SolidWorks are obtained from [13]. The chord length and the span of the wing are $20.32 \mathrm{~cm}$ taken from [13]. The results for lift coefficient of NACA 0012 wing from the simulation are compared with the experimental data from the thesis paper [13] for Reynolds number 84122. The comparison are done in Fig. 3.12 for 0 to 8 degrees angle of attack to avoid the experimental uncertainty at higher angles of attack. The simulation results show that the lift coefficient is linear for angles of attack less than 8 degrees. Results from all the models as shown in Fig. 3.12 are within a range 5-10 percent of the experimental results. $k-\epsilon$ with realizable variant viscous model is chosen as it is commonly used in the industry. 
Choosing a viscous model sometimes involves tuning the model constants. The model constants for the $k-\epsilon$ with realizable model are C2-Epsilon, Turbulent Kinetic Energy $(T K E)$ Prandtl Number and Turbulent Dissipation Rate (TDR) Prandtl Number. TKE Prandtl Number is the effective Prandtl number for the transport of turbulent kinetic energy while TDR Prandtl number is the effective Prandtl number for the transport of the turbulent dissipation rate. These model constants are used in the transport equations for the given model. The default values of the model constants are $\mathrm{C} 2-\mathrm{Epsilon}=1.9 ; \mathrm{TKE}=1.0$ and $\mathrm{TDR}=1.2$. It is required to know whether the model constants chosen are suitable for the specific problem to be solved in FLUENT. The model constant are varied to check the effect of the model constants on the lift coefficient for the specific problem of flow around an object. The test object considered is the finite NACA 0012 wing oriented at 5 degrees angle of attack. One constant at a time is altered by \pm 0.1 keeping the other constant at the default values. The results, as plotted in Fig. 3.13, do not show any significant change in the lift coefficient for small changes in the values of model constants. Thus, the default model constants for $k-\epsilon$ are chosen for the simulations.

\subsubsection{Mesh Size and Iteration Considerartion}

FLUENT uses the Finite Volume Method to solve a physical problem where the domain is divided into a finite number of control volumes and the values of flow variables are calculated at discrete points on a meshed geometry. A proper solution is obtained only if the solution converges. Convergence criteria depends upon the mesh size considered and the number of iterations the solution is solved for. Forces computed for finer and coarser mesh sizes for the same number of iterations are compared using the graph as shown in Fig. 3.14 to Fig. 3.16. The mesh size and number of iterations with the minimum slope of the curve is selected. In summary, 
meshing scheme used to generate the finer mesh is selected and the meshed geometry is solved for 1000 iterations.

\subsection{GAMBIT - FLUENT INTERFACE}

A complete procedure used to mesh the model in GAMBIT and solving for the aerodynamic forces in FLUENT is discussed in this section. The model used is Sig Kadet Aircraft Model with zero angle of attack and side slip angle and no deflection in the control surfaces.

\subsubsection{Meshing Procedure in GAMBIT}

Step I: Import:

The Sig Kadet model is designed in SolidWorks and imported to GAMBIT using parasolid format. The 'Parasolid Import' command is listed under the 'File' menu. The parasolid file with the file extension *.x_t is imported into GAMBIT by selecting the option 'Make Tolerant' and 'No Stand Alone Faces'. 'Make Tolerant' option assigns a tolerance value enabling it to avoid duplicating any entities; 'No Stand Alone Faces' option aids in removing faces that are not associated with the volume. In general, 'No Stand Alone' option deletes any geometrical entity which is not connected with higher topological entity.

Step II: Edit Default Values:

The 'Edit Defaults' command is listed under the 'Edit' menu, The value of 'Maximum Number of Elements' under the Mesh Tab for Trimesh is modified from 500000 to -1 . This removes the limit on number of mesh elements created on a face. The value for sharp angle merge is changed from 0 to 1 under the Geometry Tab for Faces. This allows faces with sharp angles to merge with the adjacent faces. BGRID_MAX_TREE_DEPTH was changed to 20, BGRID_NONLINEAR_ERR_PERCENT was changed 
to 15 and CURVATURE_CHECK_FACE_EDGES was changed to 1. Default values for 'Size Function' are shown in Fig. 3.17. Description of the default variables can be found from GAMBIT Default Guide [14]. In GAMBIT, for applying size function specification in order to mesh a model, background grid is constructed by subdividing the model into a set of subsections. BGRID_MAX_TREE_DEPTH (q) specifies the maximum background grid tree depth and controls the total number of subsections $(N)$ by the relation $N=n^{q}, n=(k-1)^{3}$, where $k$ represents BGRID_MAX_LINE_NUM [15]. Depending on the number of background-grid subsections, the speed and accuracy of size function application is affected. Larger number of subsections results in higher accuracy and computational time. For more detail refer to the note of Using the Modeling Tools in GAMBIT Modeling Guide [15]. BGRID_NONLINEAR_ERR_PERCENT specifies the level of accuracy required as percent deviation of the linearly interpolated mesh size at the center of a background grid from the defined mesh size. If the specified level of accuracy is not acquired, the background grid needs to be refined. CURVATURE_CHECK_FACE_EDGES specifies whether to check the edge curvature of the source faces. The values specified for BGRID_MAX_TREE_DEPTH and BGRID_NONLINEAR_ERR_PERCENT represent moderate and intermediate values [9].

Step III: Cleaning Geometry:

Merge Faces: The 'Merge Faces' command button is located in 'Face' command button of 'Geometry' operation button. The Merge faces button is selected by right clicking on the 'Split Faces' button. Some of the faces having sharp angles or short edges are merged with adjacent faces so that small edges or sharp angles are removed. Clean Geometry:

'Cleanup Sharp Angles' button is listed under the 'Geometry-Cleanup' command 
button of 'Tools' operation button. List of faces that have sharp angles are seen for default size. The model was cleaned for the sharp angles.

Step IV: Size Function:

The 'Create Size Function' command is listed in 'Sizing-Function' command button of 'Tools' operation. 'Size Function' is the command that controls the mesh size. The applied size function is created starting from the entities listed as sources and applied to all the entities attached to the 'Size Function'. Fixed type of 'Size Function' is applied to the narrow faces of wing, rudder, elevator and landing gears as sources as shown in Fig. 3.18 and attached to all the faces of the Sig Kadet model. The parameters for fixed size function are specified as follows: Start Size $=0.3$; Growth Rate $=1.3$ and Maximum Size $=6$. These specifications aid in meshing the faces such that the mesh size increases at the growth rate of 1.3 starting from the source faces with the size 0.3 until it reaches the maximum of 6 . Since GAMBIT is non dimensional, units are not specified and the sizes depend on the units in which the geometry is created. 'Fixed' type of 'Size Function' limits the length of the mesh element edges and thus controls the size of the mesh elements. 'Curvature' type of 'Size Function', shown in Fig. 3.19, is applied by selecting the faces of the Sig Kadet under 'Source' and 'Attach To'. The parameters for the the curvature size function specified are angle $=20$, growth rate $=1.3$, size limit $=6$ and minimum element size $=0.01$. The angle specified in the curvature size function is the maximum allowable angle between the outward pointing normals for any two adjacent mesh elements.

Step V: Meshing:

'Mesh Faces' command is listed in the 'Face' command button of 'Mesh' operation. The faces of the Sig Kadet model are selected under faces and meshed with Trimesh - Pave Type Elements. Spacing is not applied as size functions are already attached to the faces. Even if the spacing were applied, it would be ignored during meshing 
due to attached size functions. Figure 3.20 shows the graphical user interface for the meshing the faces of the Sig Kadet model. The selected faces are highlighted in orange color.

'Mesh Volumes' command is listed in the 'Volume' command button of 'Mesh' operation. The whole flow volume is selected and meshed using Tetrhedral-TGrid type of elements meshing scheme with interval size 300. The mesh size grows from the Sig Kadet model faces up to the boundary walls where the elements size becomes 300. This creates large number of elements near the Sig Kadet model so that the flow is captured properly when solving in FLUENT. The whole meshed flow volume is shown in Fig. 3.21

Step VI: Boundary and Continuum Types Specification: 'Specify Boundary Types' command is listed in the 'Zones' operation. 'Velocity Inlet' type of Boundary condition is applied to the face ahead of the Sig Kadet model and termed as inlet. 'Pressure Outlet' type of Boundary condition is applied to the face behind the Sig Kadet model and termed as outlet. Other faces are specified as 'Wall' type boundary condition and termed as upperwall, lowerwall, sidewall_right, sidewall_left and sig. Figure 3.22 shows the assigned boundary types. Inlet type of boundary condition is highlighted and shown in orange color in the graphical window of GAMBIT.

'Specify Continuum Types' command is listed in the 'Zones' operation. The Continuum type for the flow volume is specified as fluid to model air in FLUENT.

Step VII: Save and Export:

'Save As' command is listed under the 'File' menu. The model thus meshed using the above procedure is saved. The flow volume model for Sig Kadet oriented at zero degrees angle of attack and side slip angle with no control surface deflection is exported as mesh file by selecting the 'Export Mesh' command under the 'File' menu. 
Same procedure was used for meshing for the model with various angle of attack and side slip angles as well as different control surface deflections.

\subsubsection{Procedure for Solving in FLUENT}

A detailed step wise procedure is discussed in this section using the graphical user interface commands. The commands can also be typed in the text user interface. The procedure is automated by creating a journal file that contains all the commands to be executed in a step wise manner.

\section{Step I: Starting FLUENT:}

Solving the flow around the Sig Kadet Model involves large number of mesh elements, thus FLUENT is started with parallel processing. To start FLUENT in parallel mode, command ' $F L U E N T 3 d-t 4$ is typed in the command prompt window on windows-based operating systems. This command is specified in the directory where the FLUENT.exe file is located. The command mentioned starts 3D FLUENT with four computer node processes. The argument $-t x$ signifies the number of processor to be used, in this case the FLUENT is started on a quadcore system. This is done to overcome the limitation of reading a mesh file with number of element greater than 2 million into a single solver process in FLUENT. The mesh files generated for this work contain around 3 million elements, thus parallel processing in FLUENT is opted to utilize the full capability of the computer system.

Step II: Reading and Manipulating Grid:

The mesh file *.msh created in GAMBIT is read into FLUENT. The 'Read Case' command is listed under the 'File' menu. The grid read into FLUENT is checked for any errors by selecting the 'Check' command under the 'Grid' menu. It provides volume statistics, grid topology and verification of grid. The domain is reordered for improving the solver's computational performance by rearranging the faces, nodes 
and cells in memory, thereby increasing the memory access efficiency. The reordering of the domain is done by selecting the command 'Reorder Domain' under the 'Grid' menu. 'Scale' command under the 'Grid' menu is selected. Since the Sig Kadet geometry is modeled in mm units, the length units is changed to mm units by selecting mm in 'Grid was created in' column. The Domain extents are scaled using the scaling factor 0.001 such that they represent the correct dimensions in mm units from meter units.

Step III: Problem Definition:

The default Pressure Based Implicit Steady Solver is chosen in the 'Solver' command box under 'Define' menu. The $k-\epsilon$ with Realizable variant is chosen in the 'Viscous Model' command box under the 'Define' menu. The Realizable variant is chosen as it is recommended in the 'Case Check' under Solve Menu. The model constants are not altered. The default material type fluid with density of air $1.225 \mathrm{~kg} / \mathrm{m}^{3}$ and viscosity 1.7894e-05 kg/(m.s) is chosen in 'Material' under 'Define' menu. The 'Operating Pressure', under the 'Define' menu, is specified as 101325 Pascal which represents standard atmospheric pressure. Pressure specified or computed by FLUENT are gauge pressures. Absolute Pressure is the sum of Gauge and Operating Pressure.

Boundary conditions are defined in 'Boundary Condition' command under the 'Define' menu. Velocity inlet type of boundary condition is chosen for the inlet zone with velocity magnitude $20 \mathrm{~m} / \mathrm{s}$ and direction normal to the boundary whereas Pressure outlet type of boundary conditions is selected for the outlet zone with gauge pressure of 0 Pascal and direction normal to the boundary. Turbulence is specified as Turbulent Intensity $0.04 \%$ and Turbulent Lenth Scale 1e-06 mm for both inlet and outlet zones. Sidewall_right, sidewall_left, upperwall and lowerwall zones are specified as stationary wall type boundary condition with 0 Pascal shear stress, $0 \mathrm{~mm}$ Roughness Height and 0.5 Roughness Constant while sig zone defined in GAMBIT 
is specified as stationary wall with no slip condition so that the velocity of the air particels at the surface of the Sig Kadet Model is zero.

Step IV: Solution Control Parameters:

Discretization techniques are specified in the 'Solution Control' under the 'Solve' menu. Simple Pressure-Velocity Coupling with standard discretization for pressure and first order upwind for momentum, turbulent kinetic energy and turbulent dissipation rate for both flow and turbulence equations is selected for the first 100 iterations. After the 100 iterations second order discretization technique is used. This is done to increase the accuracy of the solution.

The solution is initialized by selecting the 'Initialize' command listed under the 'Solve' menu. During the initialization, the initial values such as gauge pressure, velocity, turbulent kinetic energy and turbulent dissipation rate are computed from the inlet zone. Print option for 'Residual Monitor' command under the 'Solve' menu is selected to monitor the continuity, velocity, $k$ and $\epsilon$ residuals. Absolute criteria for the residuals is specified as 1e-06. The problem is solved for 1000 iterations for the solution to converge. The solution is said to be converged as the residual plot converges to a constant or if the absolute criteria for the residuals have been reached.

Step V: Post Processing:

Forces along the $\mathrm{X}, \mathrm{Y}$ and $\mathrm{Z}$ direction are recorded for the sig wall zone. Moments are calculated about the origin which is the nose of the Sig Kadet model.

Step VI: Save and Exit

The solved problem is saved as *.cas and *.dat files. 'Exit' command is used to exit from the parallel FLUENT.

The same procedure is used for simulating the flow around the Sig Kadet model with various angles and control surface deflections. 


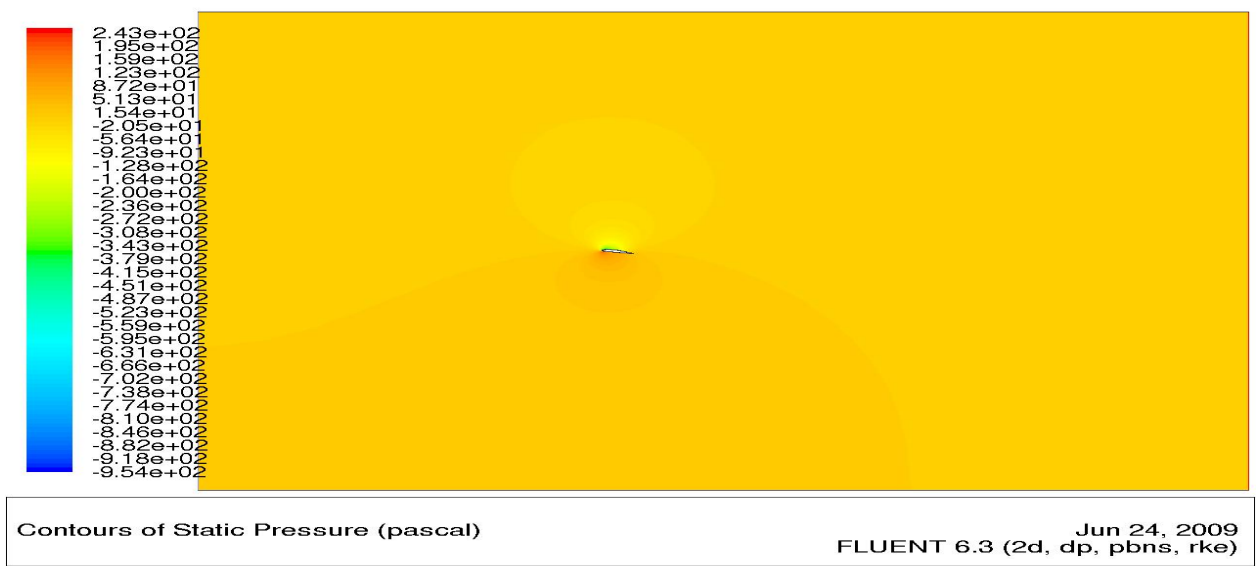

(a)

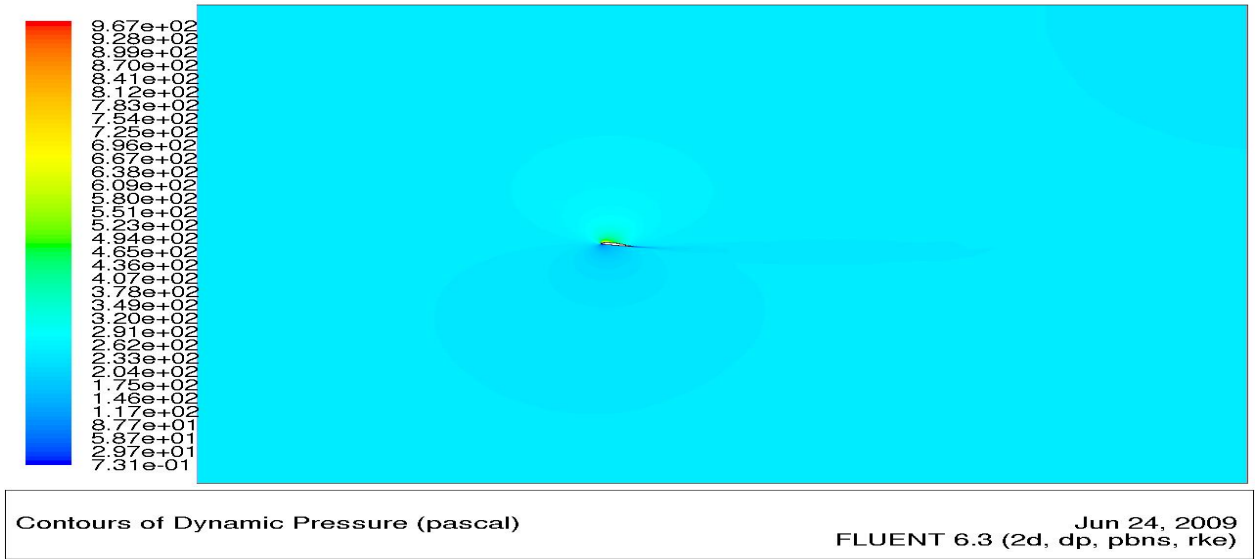

(b)

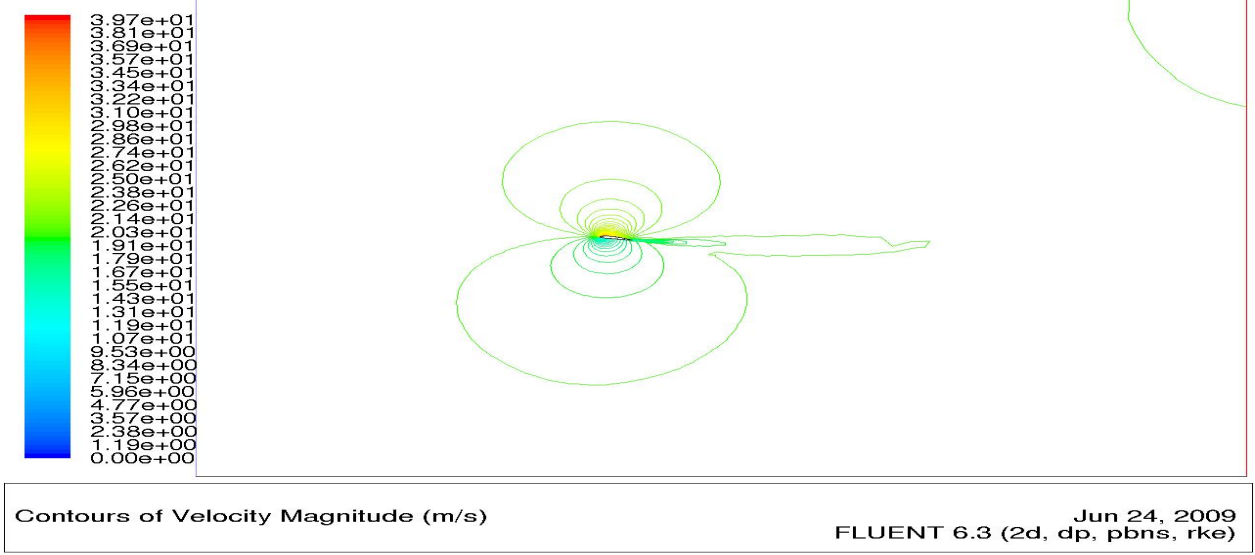

(c)

Figure 3.8. (a) Static Pressure (b) Dynamic Pressure (c) Velocity Magnitude Contour Plot for Sig Kadet Airfoil at alpha 8 degrees. 


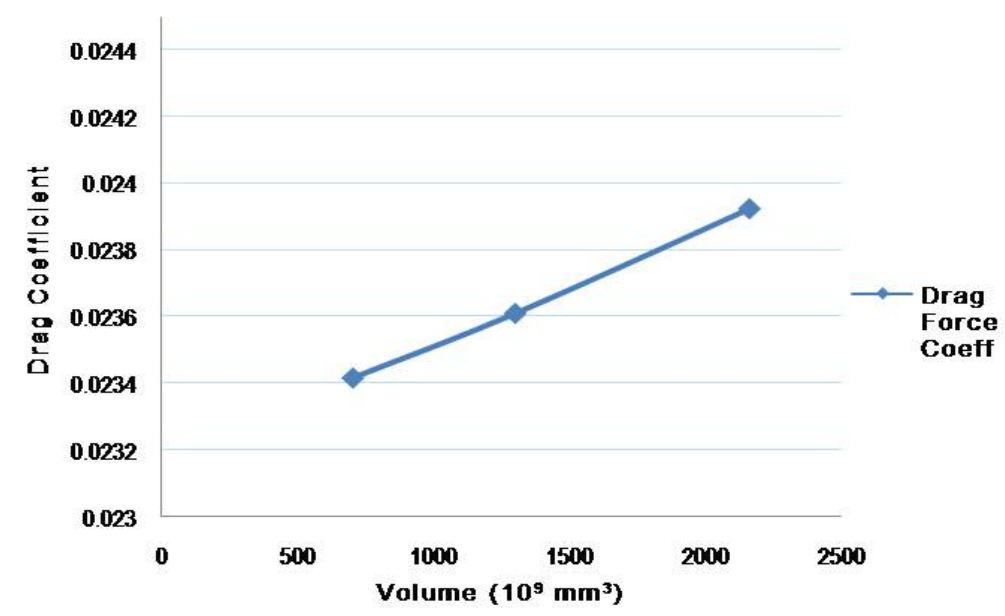

Figure 3.9. Variation in Drag Coefficient for change in flow volume size.

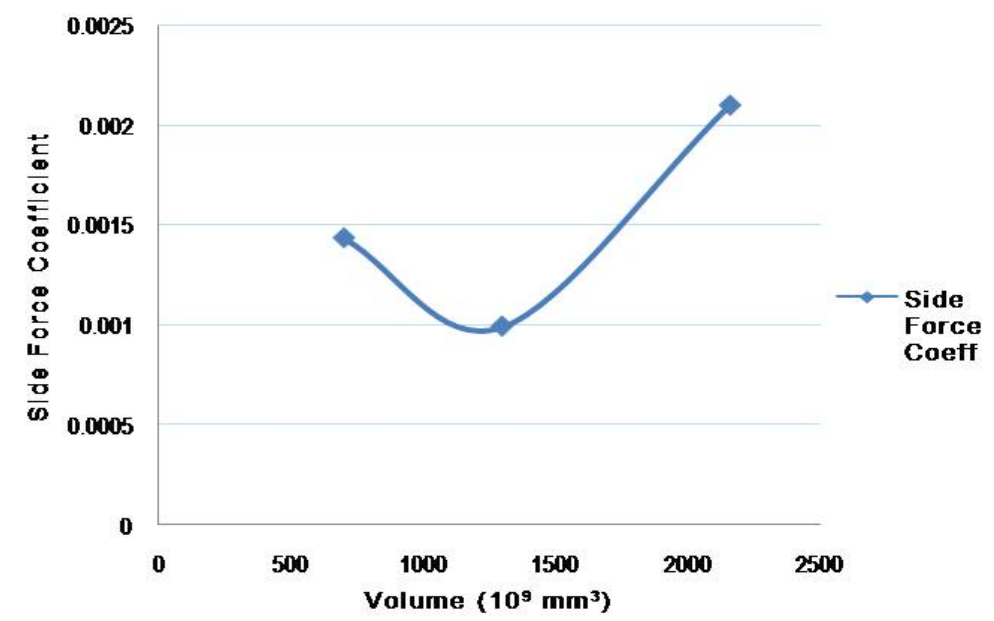

Figure 3.10. Variation in Side Force Coefficient for change in flow volume size. 


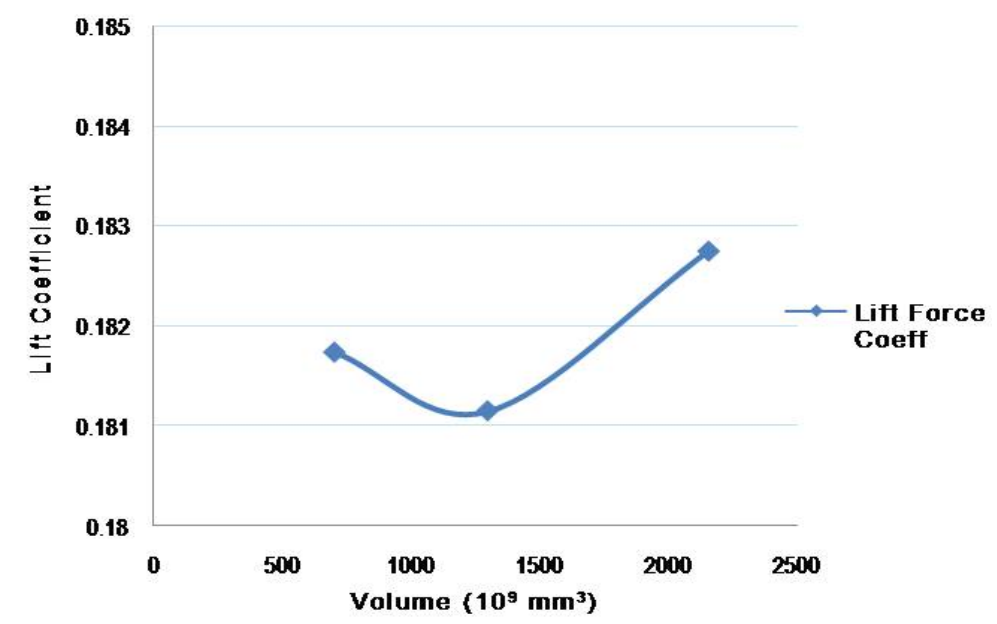

Figure 3.11. Variation in Lift Coefficient for change in flow volume size.

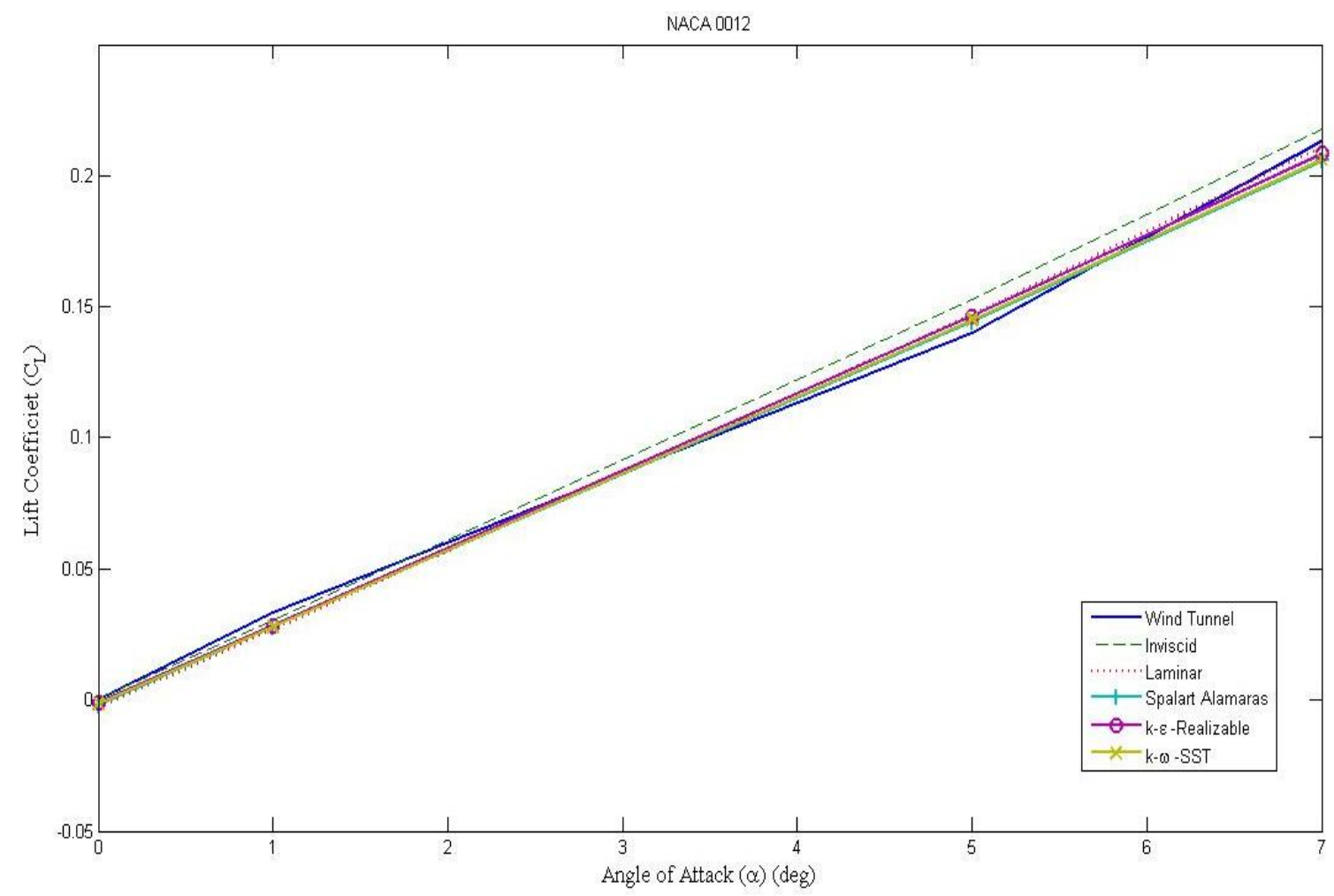

Figure 3.12. Viscous Model Comparison for NACA 0012 finite wing. 


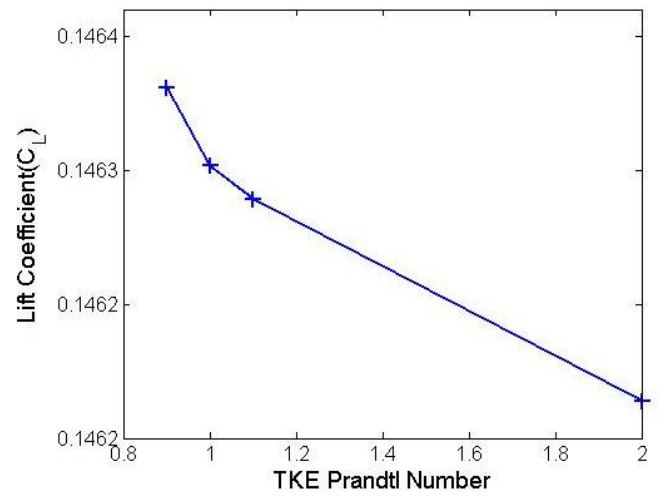

(a)

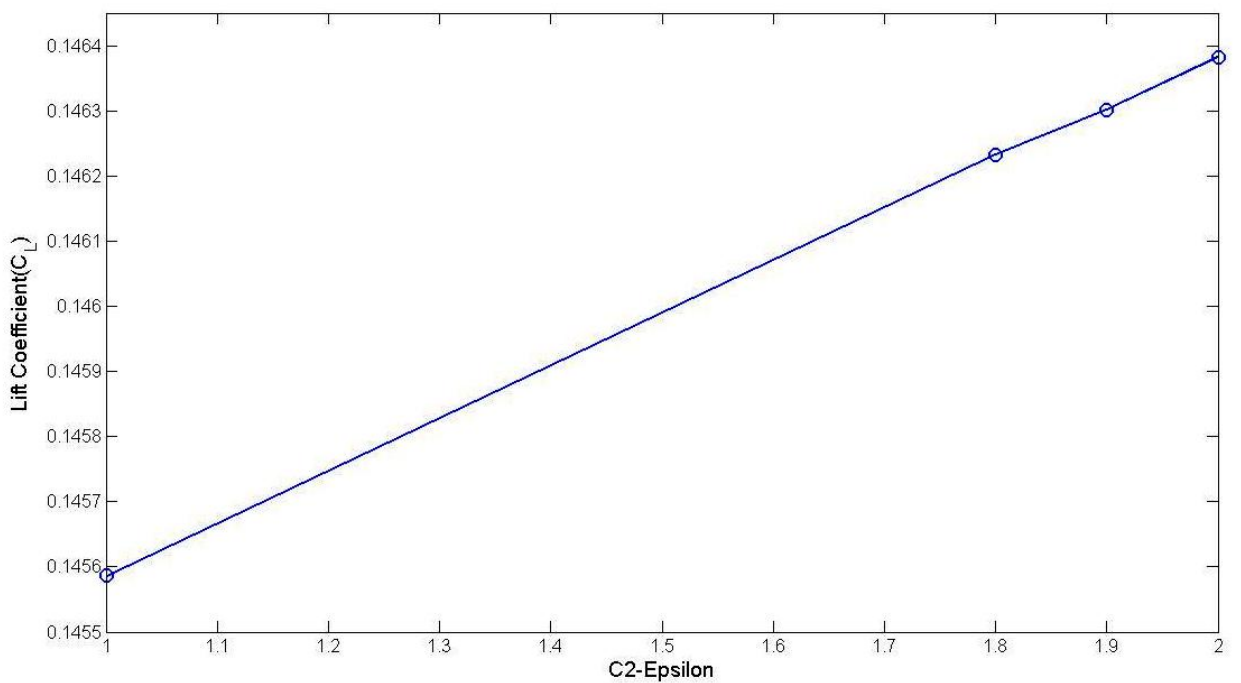

(b)

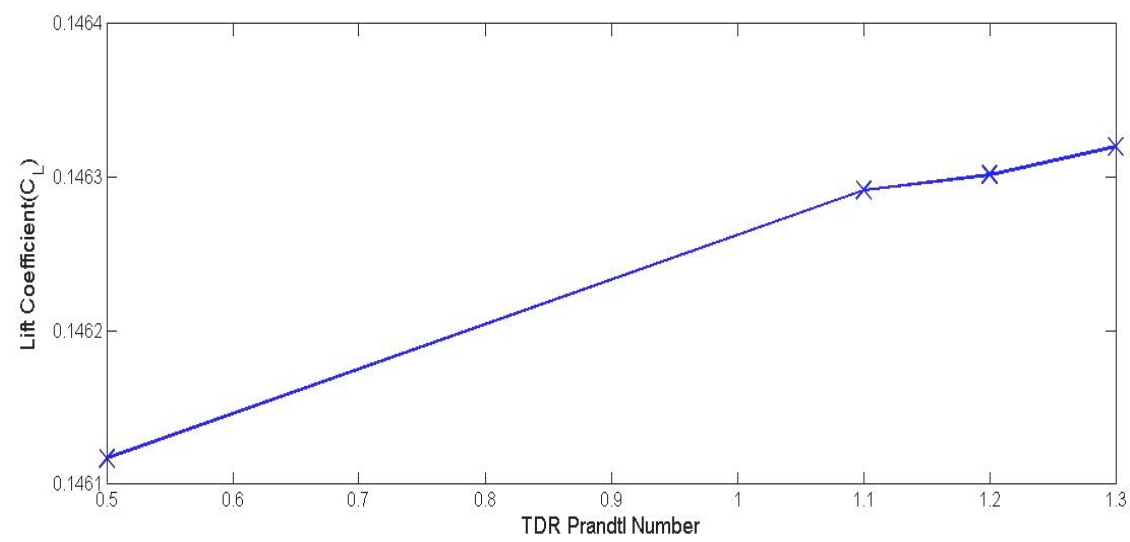

(c)

Figure 3.13. Lift Coefficient vs Model Constant of $k-\epsilon$ Realizable Model (a) C2Epsilon, (b) TDR Prandtl Number and (c)TKE Prandtl Number for NACA 0012 Finite Wing at 5 degrees Angle of Attack. 


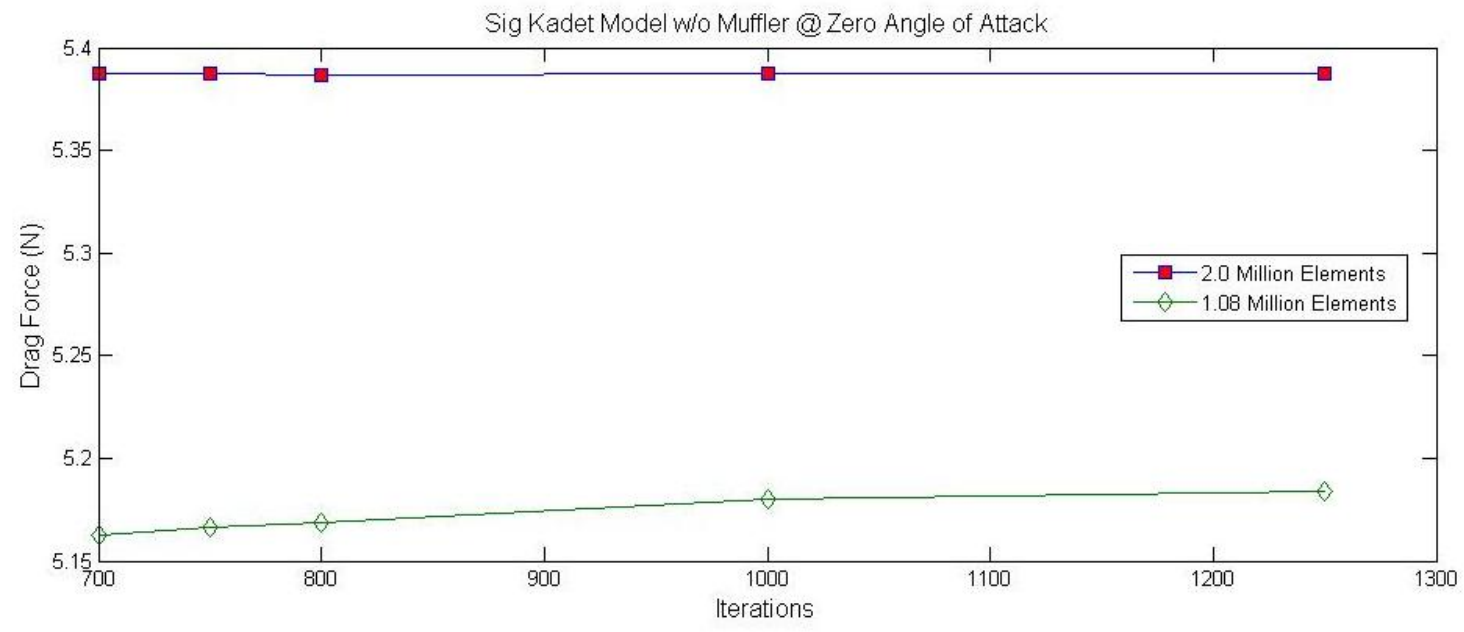

Figure 3.14. Sensitivity of the Force in X-direction due to mesh size and iterations.

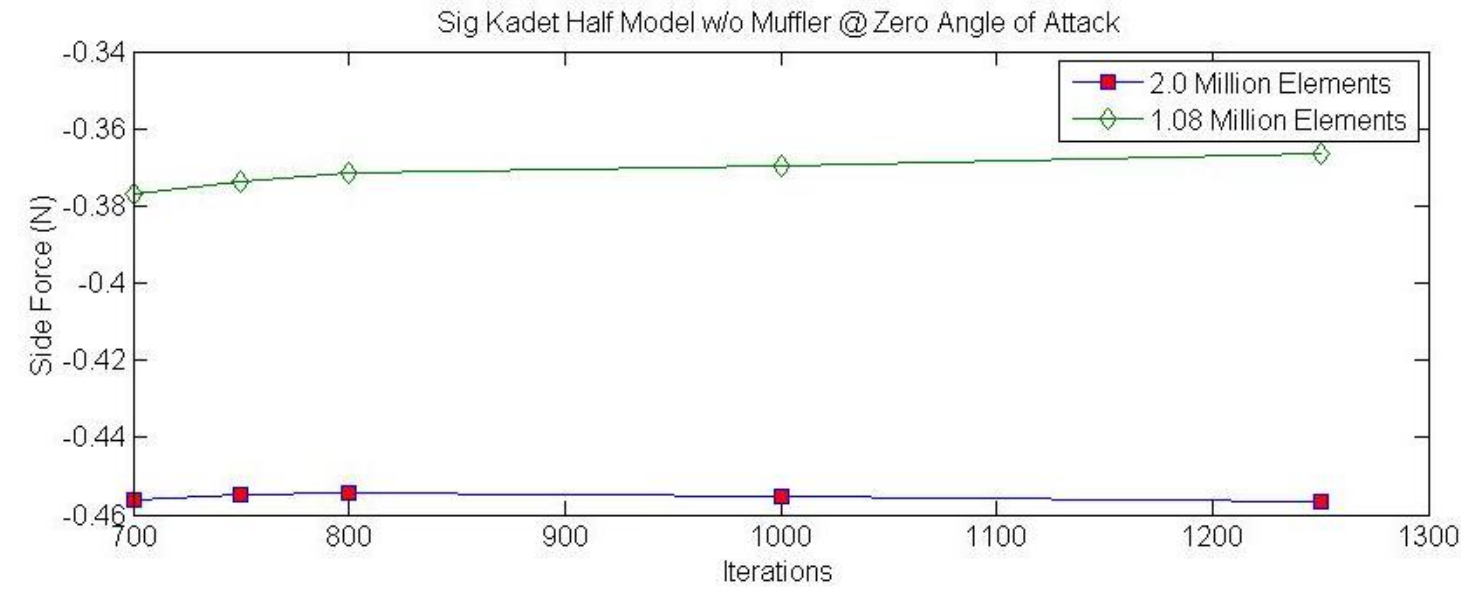

Figure 3.15. Sensitivity of the Force in Y-direction due to mesh size and iterations. 


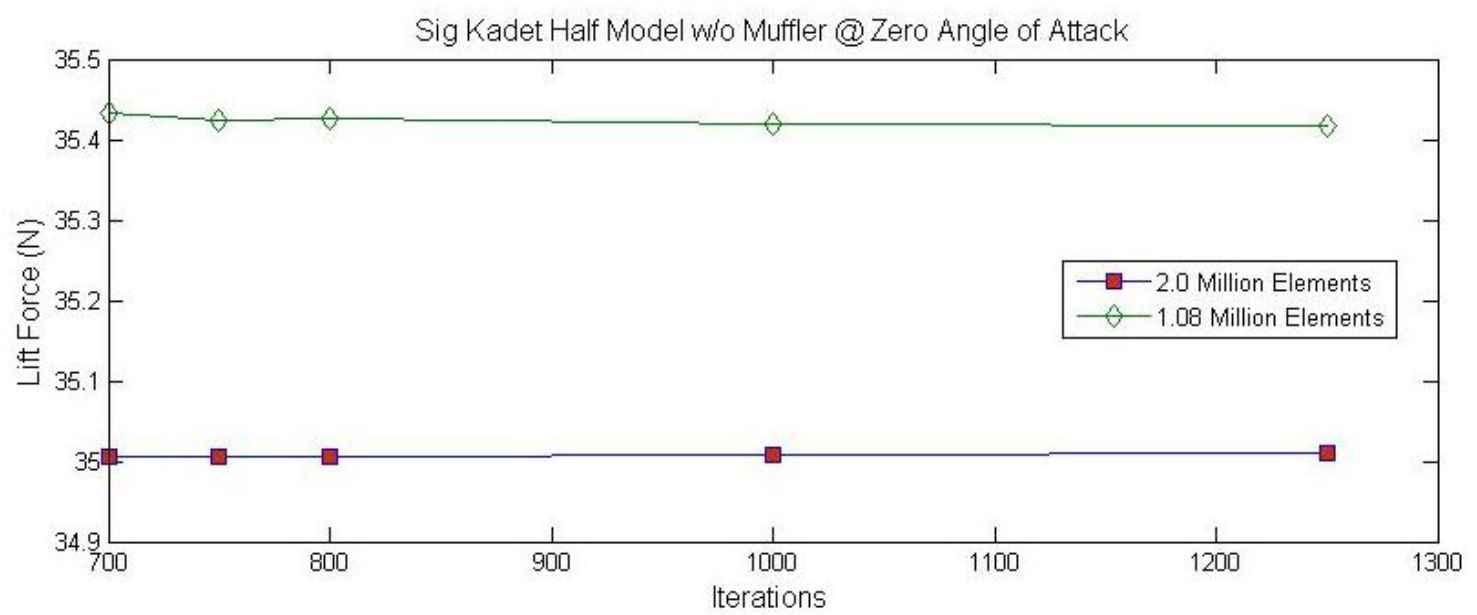

Figure 3.16. Sensitivity of the Force in Z-direction due to mesh size and iterations.

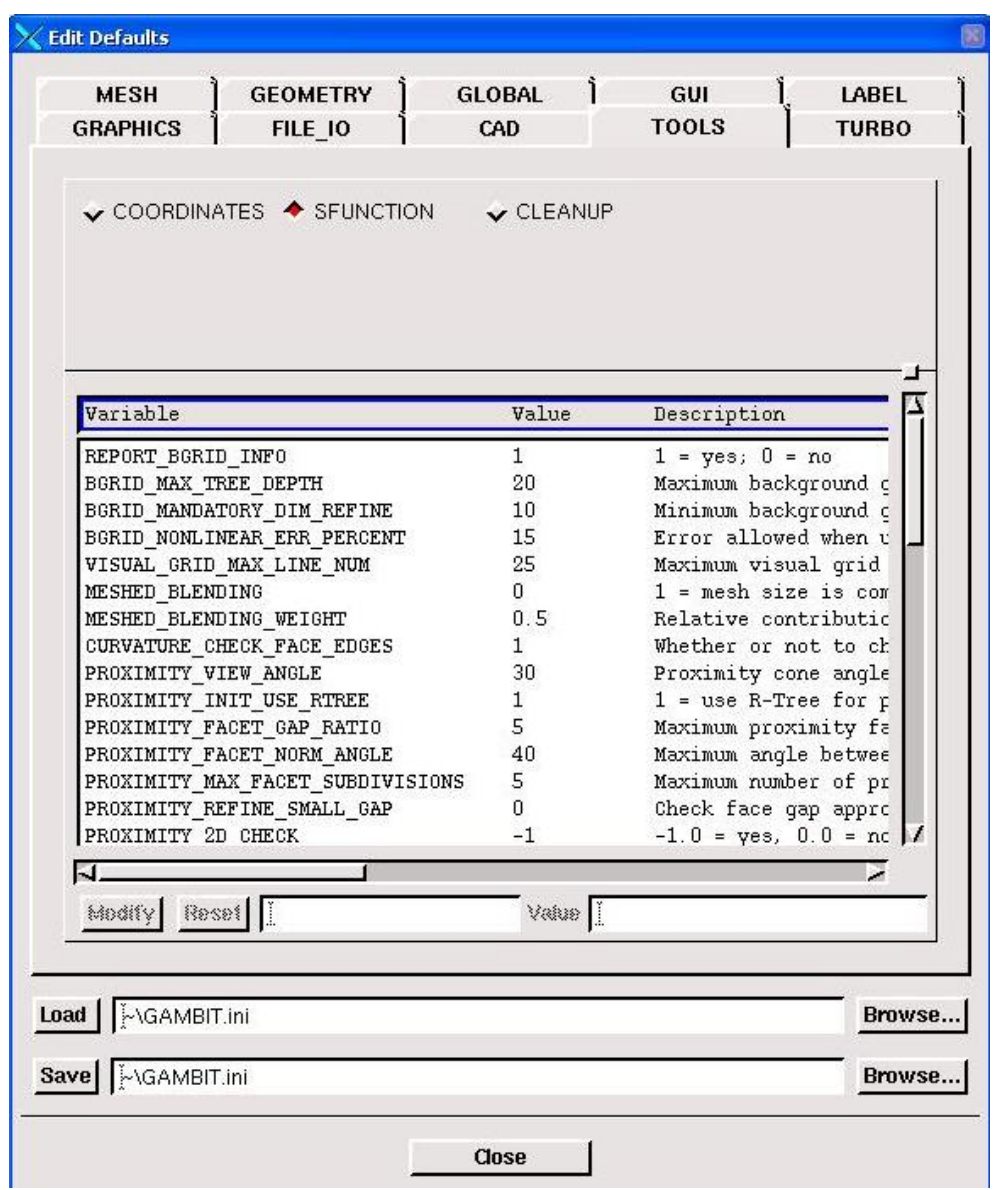

Figure 3.17. Default Values for Size Function. 


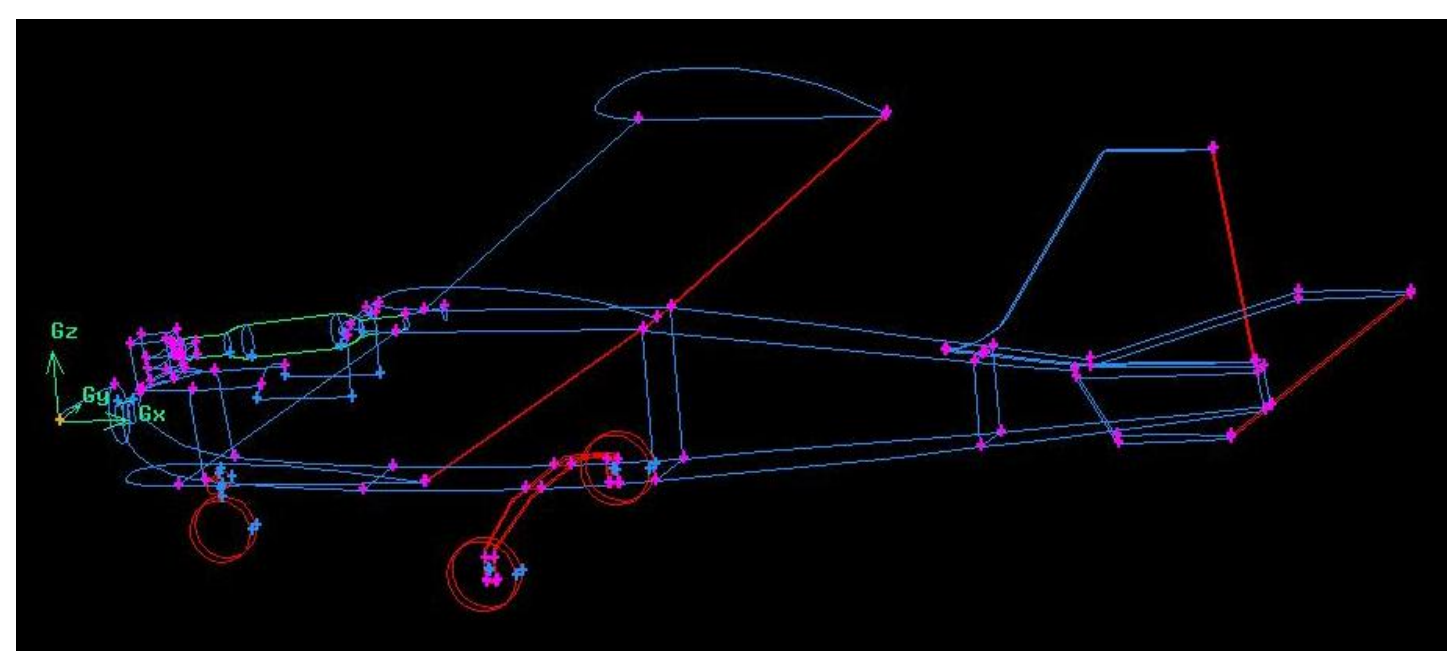

Figure 3.18. Source Faces for Fixed Size Function. 


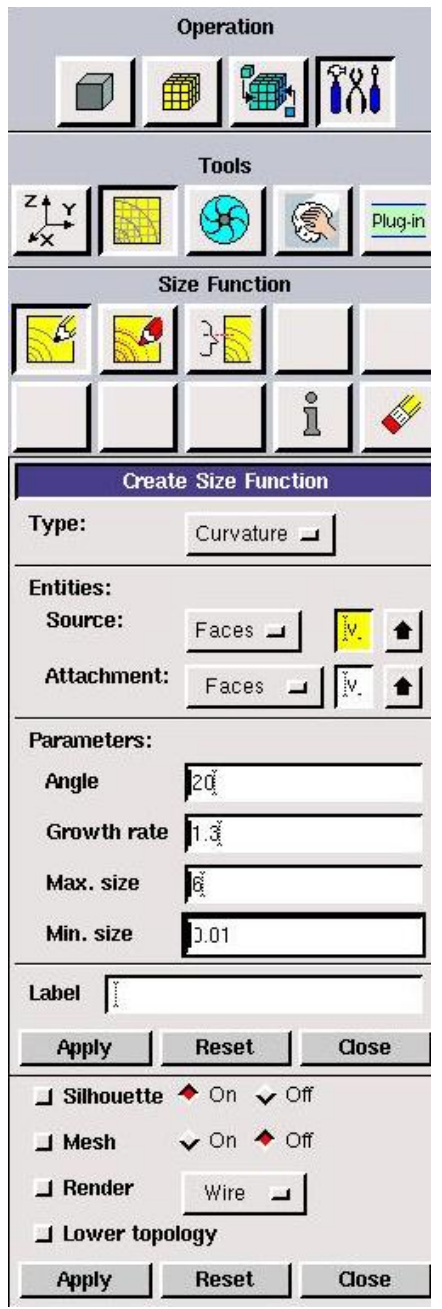

Figure 3.19. Curvature Size Function. 


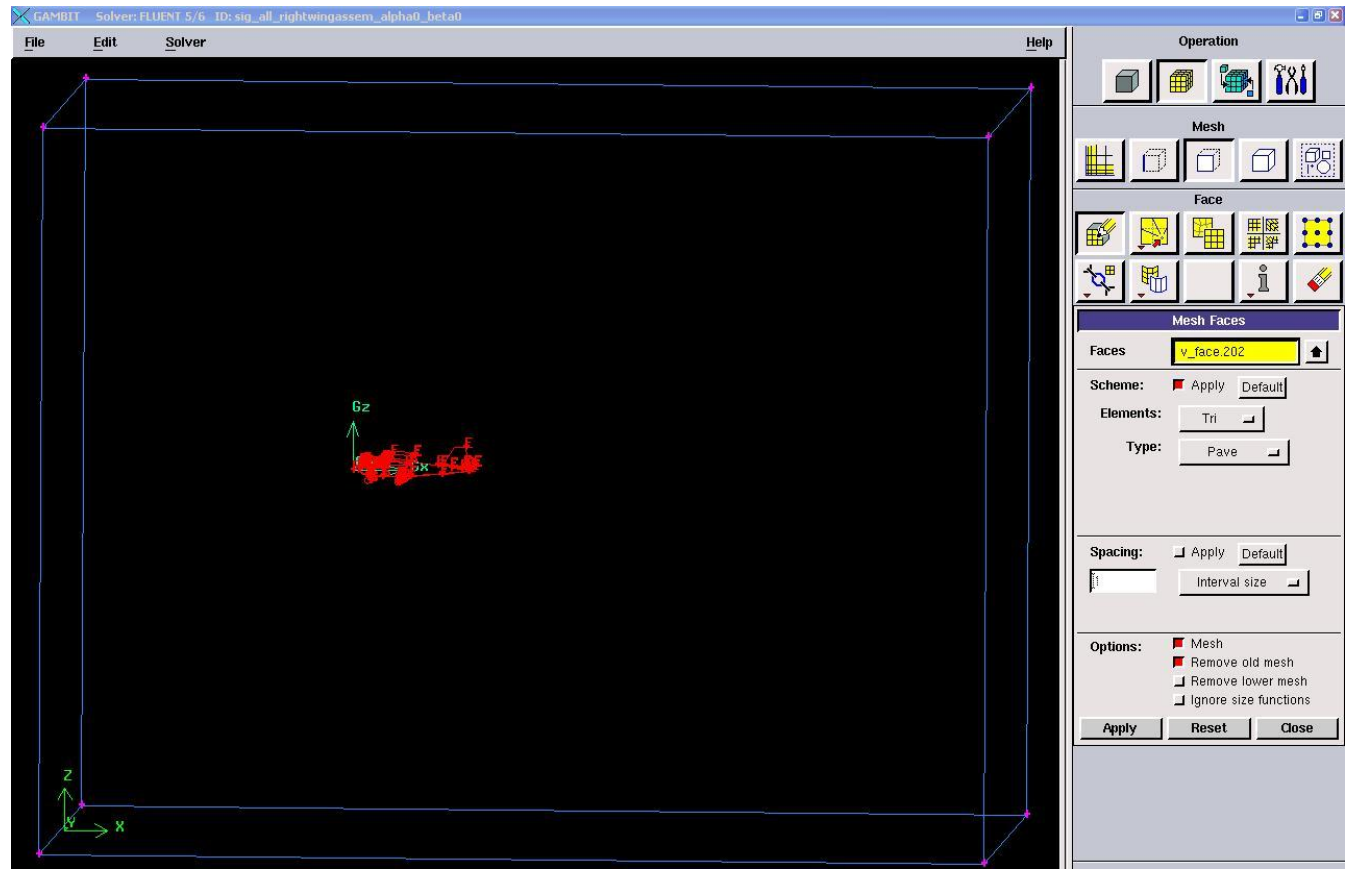

Figure 3.20. Face Mesh.

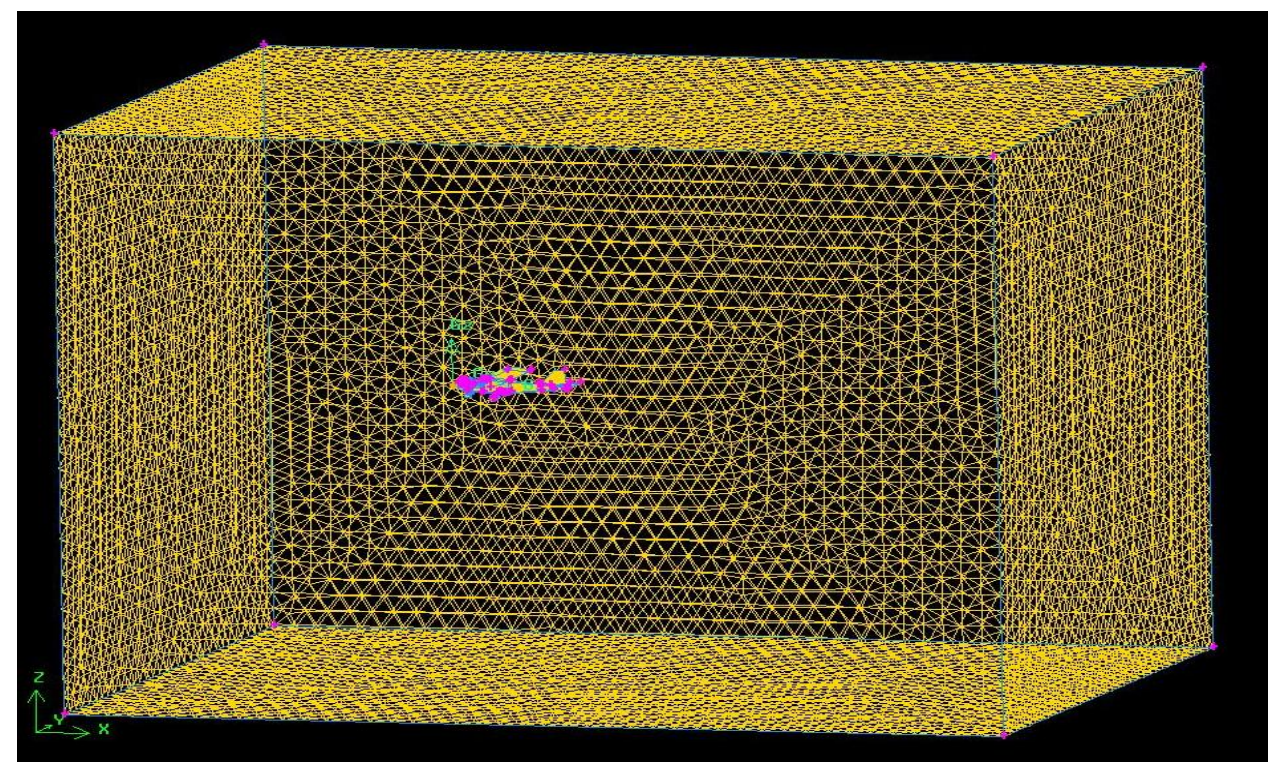

Figure 3.21. Volume Mesh. 


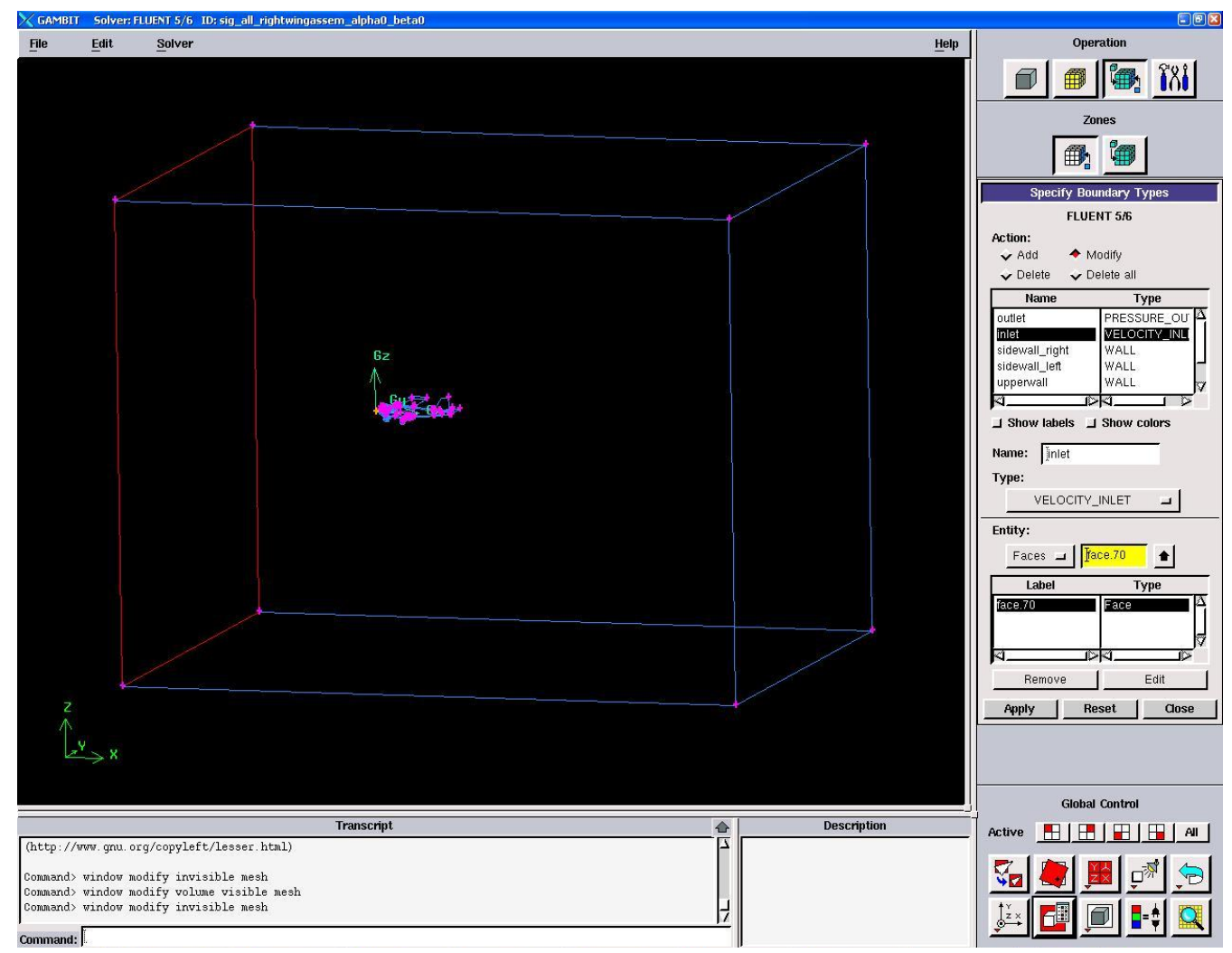

Figure 3.22. Boundary Type Specification. 


\section{CHAPTER 4}

\section{SECONDARY OBSERVATIONS}

This chapter reports various secondary observations made while setting the configuration parameters.

\subsection{Infinite Wing and Finite Wing}

Airfoil section of the Sig Kadet Airfoil with zero angle of attack (alpha) is built in SolidWorks and exported to GAMBIT. Angle of attack here is defined as the angle between the horizontal surface of the airfoil or wing with the direction of the airflow. The forces calculated by solving the flow around the airfoil in FLUENT following the same procedure discussed in the section 3.3.2 except that the problem is a 2-D. Force in the $\mathrm{X}$ direction denotes the drag force and force in $\mathrm{Y}$ direction denotes the lift force for the 2-D case. Airfoil case can be considered as a cross-section of an infinitely long wing. Thus it is termed as the Infinite Wing. Finite wing of the Sig Kadet model is designed in SolidWorks with the size same as the actual half wing of the Sig Kadet Model. The Model is meshed using the same procedure explained in section 3.3.1 except that model is divided into half at the plane of symmetry. The same procedure discussed in Chapter 3 is used to calculate the aerodynamic forces. The lift force for the infinite wing and the finite wing of the Sig Kadet are compared in the Table 4.1. It is clearly seen that the finite wing produces smaller lift than the infinite wing does. 
Table 4.1. Lift Force Comparison for Finite Wing and Infinite Wing for Sig Kadet Geometry

\begin{tabular}{|c|c|c|}
\hline Forces & Infinite Wing & Finite Wing \\
\hline Lift & $40.916611 \mathrm{~N}$ & $36.955412 \mathrm{~N}$ \\
\hline
\end{tabular}

\subsection{Effects Due Presence of Wingtip and Dihedral}

It is of interest to check the effect on the aerodynamic forces due to the change in wingtip angle and dihedral angle. Two different variants of wing model of the Sig Kadet are modeled in SolidWorks: (i) The dihedral from 1.5 to 0 degrees, keeping wing tip flat i.e wing tip at 90 degrees to the horizontal surface, (ii) The wingtip angle is changed from 90 to 30 degrees while keeping dihedral angle constant at 0 . The results are compared in Table 4.2. It is seen that the lift is slightly increased for the wing having wing tip angle 30 degrees compared to wing with perpendicular wing tip surface. This might be attributed to the effect of the vortex created at the tip of the wing has been reduced due to the wing tip angle.

Table 4.2. Effects on Forces due to Wingtip and Dihedral

\begin{tabular}{|c|c|c|c|c|}
\hline \multirow{2}{*}{ Forces } & \multicolumn{4}{|c|}{ Sig Kadet Wing } \\
\cline { 2 - 5 } & \multicolumn{2}{|c|}{ with Dihedral 0 deg } & \multicolumn{2}{c|}{ with Dihedral 1.5 deg } \\
\cline { 2 - 5 } & Wingtip 30 deg & Wingtip 90 deg & Wingtip 90 deg & Wingtip 30 deg \\
\hline Drag & $2.811 \mathrm{~N}$ & $2.771 \mathrm{~N}$ & $2.762 \mathrm{~N}$ & $2.819 \mathrm{~N}$ \\
\hline Side & $-0.211 \mathrm{~N}$ & $-0.512 \mathrm{~N}$ & $0.459 \mathrm{~N}$ & 0.820 \\
\hline Lift & $39.167 \mathrm{~N}$ & $36.955 \mathrm{~N}$ & $36.996 \mathrm{~N}$ & $39.261 \mathrm{~N}$ \\
\hline
\end{tabular}




\subsection{Effect of Deviation in Airfoil Geometry}

Large number of airfoils are designed. The geometric parameters of the Sig Kadet Airfoil are similar to the Clark Y Airfoil. A comparison between the Clark Y and Sig Kadet airfoil is shown in Fig. 4.1. This is verified by the comparing both the profiles. There exists some deviation in the geometry of the Sig Kadet Airfoil when compared to Clark Y Airfoil and this could be attributed due to manufacturing defect or to inaccuracy in measuring the Sig Kadet Airfoil. The aerodynamic force coefficients are compared for -2 to 12 degrees angle of attack in Fig. 4.2 and in Fig. 4.3 .

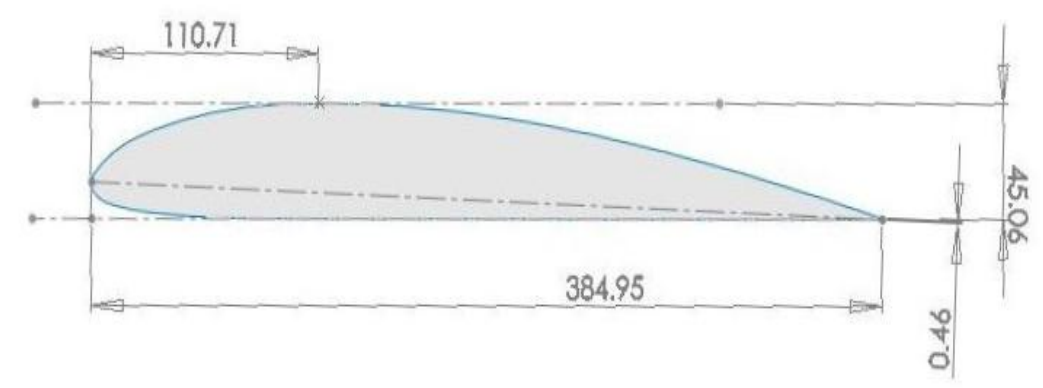

(a)

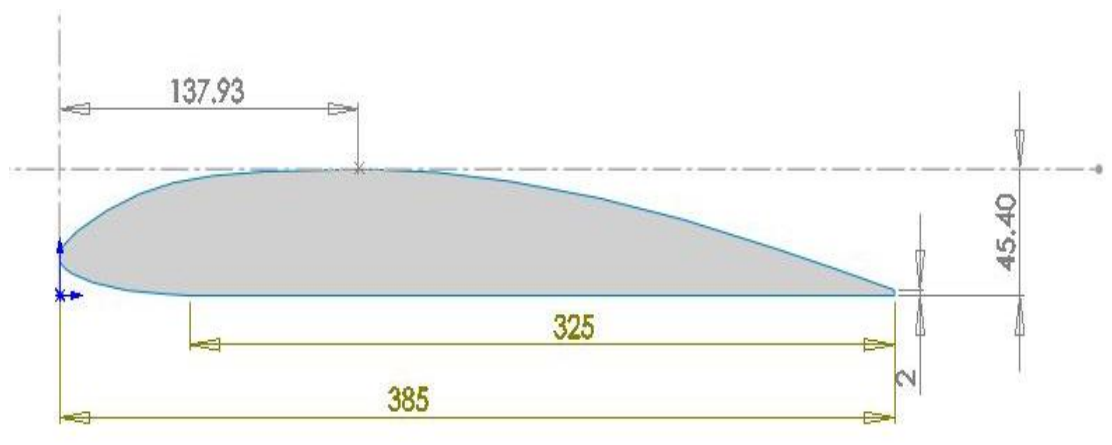

(b)

Figure 4.1. Geometry Comparison (a) Clark Y Airfoil (b) Sig Kadet Airfoil. 


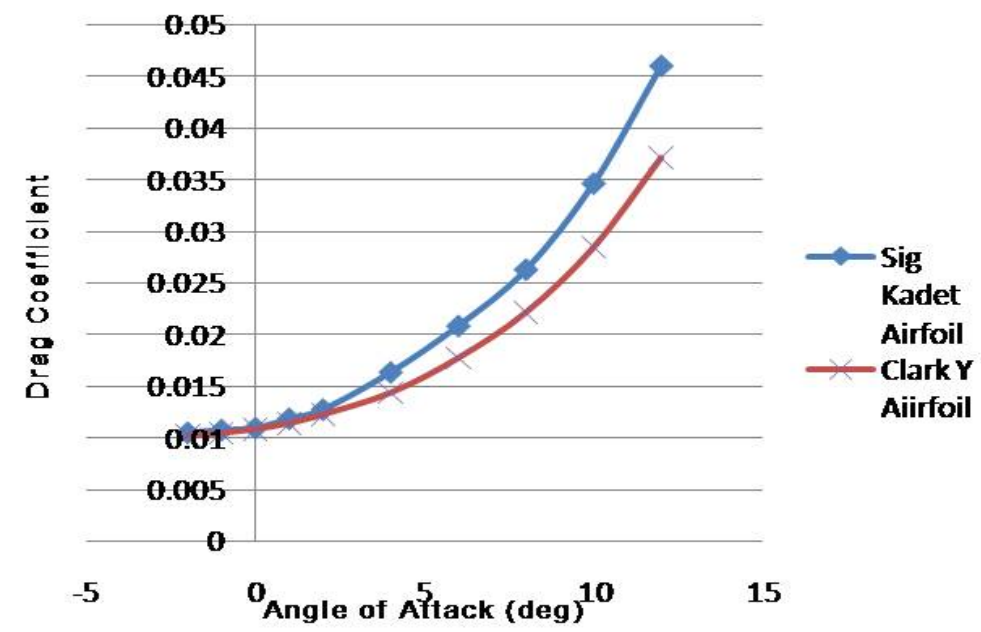

Figure 4.2. Drag Coefficient Comparison between Sig Kadet Airfoil and Clark Y Airfoil.

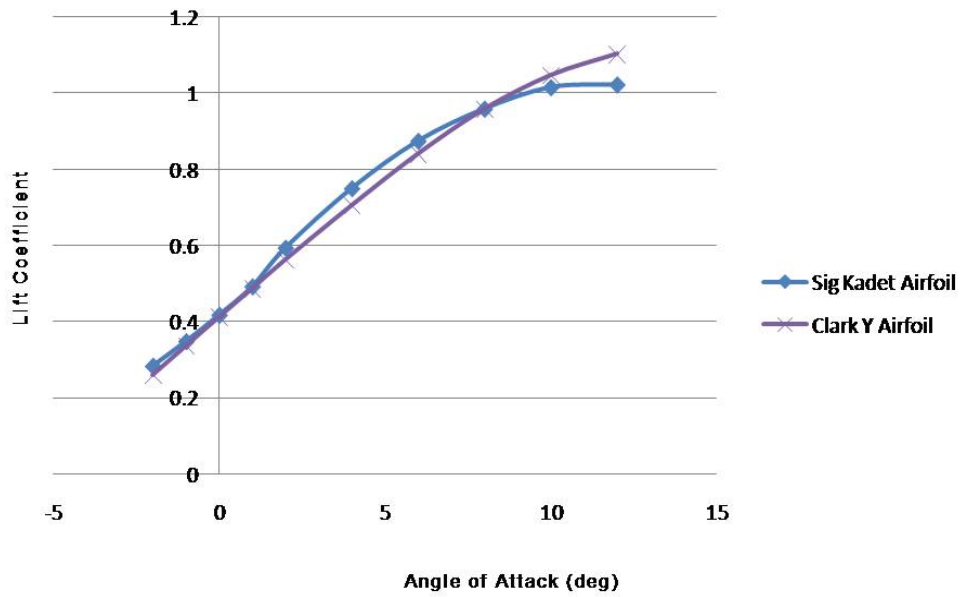

Figure 4.3. Lift Coefficient Comparison between Sig Kadet Airfoil and Clark Y Airfoil.

\subsection{Mirror Feature in SolidWorks}

The Sig Kadet model is designed in SolidWorks. There are various features that the software offers. Mirror feature is one of the features that the software provides. Mirror feature mirrors the part in the assembly mode. It is the most convenient feature which avoids redrawing the mirror image of a given part. Wings of the Sig Kadet model is one such part that can be mirrored to complete the whole model. In 
order to assemble the whole Sig Kadet model right half of the wing termed as right wing are designed and mirrored to create the left part of the wing. For zero degree aileron deflection, the ailerons are combined with the wing itself. After the right half of the wing and its mirror image are assembled, it is noticed that the center of mass is slightly offset from the plane of symmetry. Procedure is repeated with stabilizer to confirm this effect: the stabilizer and its mirrored part when assembled have an offset in location of the center of mass. This has been reported to SolidWorks. An email has been received stating that the observation is reported to the SolidWorks development team.

\subsection{Deviation in Symmetry}

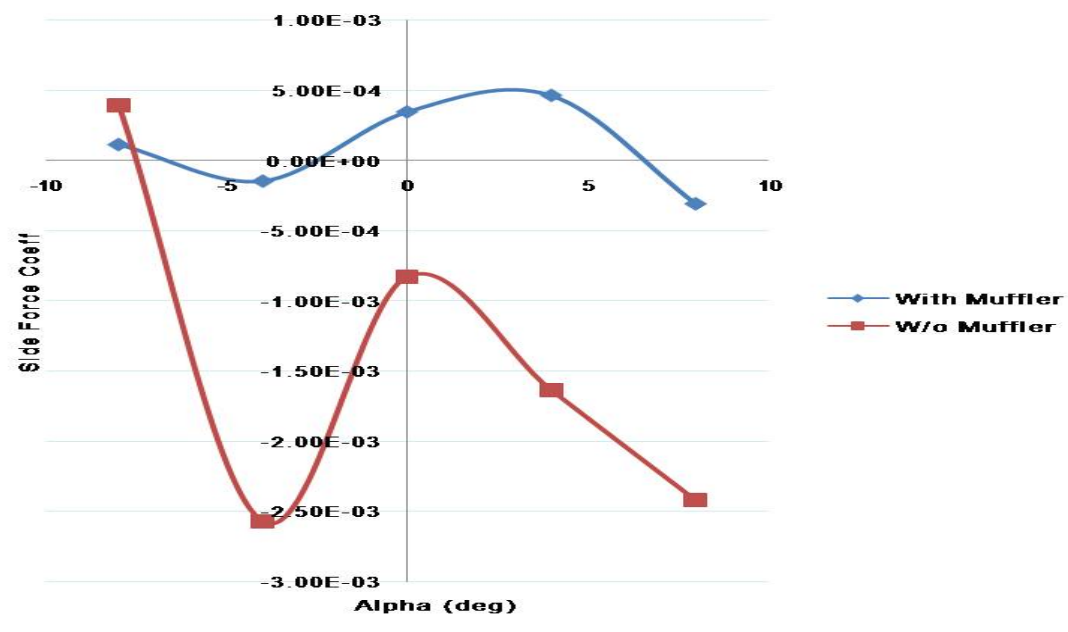

Figure 4.4. (a) Rolling, (b) Pitching and (c) Yawing Moment Coefficient about the Nose vs Rudder Deflection Plot for Sig Kadet Model.

The asymmetry in the actual Sig Kadet model is due to the presence of the muffler. It is expected that the Sig Kadet model without the muffler to be symmetric about the XZ plane. For a symmetric model the side force should be zero and should 
remain zero for any change in angle of attack. Fig. 4.4 shows that the Side force coefficient, while with very small magnitude, fluctuates for the Sig Kadet model with and without muffler. Fig. 4.5 shows that the Y-component of velocity is not zero on the XZ plane which is considered to be the plane of symmetry for the Sig Kadet model without the muffler. It is clear from the figure that there exists small amount of side force, as the Y-component of velocity is not zero on $\mathrm{XZ}$ plane. This can be due to the asymmetry in the geometrical or meshed model even though the Sig Kadet model without muffler is symmetric. Results from the experiment considering right and left half of the model separately for the same meshing scheme and simulation parameters, shows difference in the magnitude of the side force and magnitude, which indicates that GAMBIT meshing results in a slightly asymmetric mesh model even though the Sig Kadet airplane without the muffler is symmetric. These results are tabulated in Table 4.3. The number of mesh elements created for the right and left half of the Sig Kadet model without muffler for the same meshing scheme is found to be different. The number of mesh elements generated for the the right half of the model is 2112628 , while that for the left half is 2112166 . 
Table 4.3. Half and Full Sig Kadet Model Comparison

\begin{tabular}{|c|c|c|c|c|c|c|}
\hline & \multicolumn{5}{|c|}{ Coefficients } \\
\cline { 2 - 7 } & \multicolumn{3}{|c|}{ Forces $N$} & \multicolumn{3}{c|}{ Moments } \\
\cline { 2 - 7 } & Drag & Side & Lift & Rolling & Pitching & Yawing \\
\hline Left Half & $2.82 \mathrm{E}-02$ & $-1.97 \mathrm{E}-03$ & $1.81 \mathrm{E}-01$ & $8.83 \mathrm{E}-02$ & $-2.31 \mathrm{E}-01$ & $-9.65 \mathrm{E}-03$ \\
\hline Right Half & $2.81 \mathrm{E}-02$ & $1.99 \mathrm{E}-03$ & $1.81 \mathrm{E}-01$ & $-8.84 \mathrm{E}-02$ & $-2.32 \mathrm{E}-01$ & $9.57 \mathrm{E}-03$ \\
\hline $\begin{array}{c}\text { Left Half+ } \\
\text { Right Half }\end{array}$ & $5.63 \mathrm{E}-02$ & $2.18 \mathrm{E}-05$ & $3.62 \mathrm{E}-01$ & $-8.76 \mathrm{E}-05$ & $-4.63 \mathrm{E}-01$ & $-8.38 \mathrm{E}-05$ \\
\hline $\begin{array}{c}\text { Sig Kadet } \\
\text { w/o muffler }\end{array}$ & $5.74 \mathrm{E}-02$ & $-8.29 \mathrm{E}-04$ & $3.64 \mathrm{E}-01$ & $-5.43 \mathrm{E}-04$ & $-4.68 \mathrm{E}-01$ & $5.06 \mathrm{E}-04$ \\
\hline $\begin{array}{c}\text { Mirror Image } \\
\text { of Right Half }\end{array}$ & $2.81 \mathrm{E}-02$ & $-2.00 \mathrm{E}-03$ & $1.81 \mathrm{E}-01$ & $8.84 \mathrm{E}-02$ & $-2.32 \mathrm{E}-01$ & $-9.57 \mathrm{E}-03$ \\
\hline $\begin{array}{c}\text { Right Half+ } \\
\text { Mirror Image }\end{array}$ & $5.63 \mathrm{E}-02$ & $-5.30 \mathrm{E}-06$ & $3.62 \mathrm{E}-01$ & $-3.62 \mathrm{E}-06$ & $-4.63 \mathrm{E}-01$ & $6.28 \mathrm{E}-07$ \\
\hline
\end{tabular}

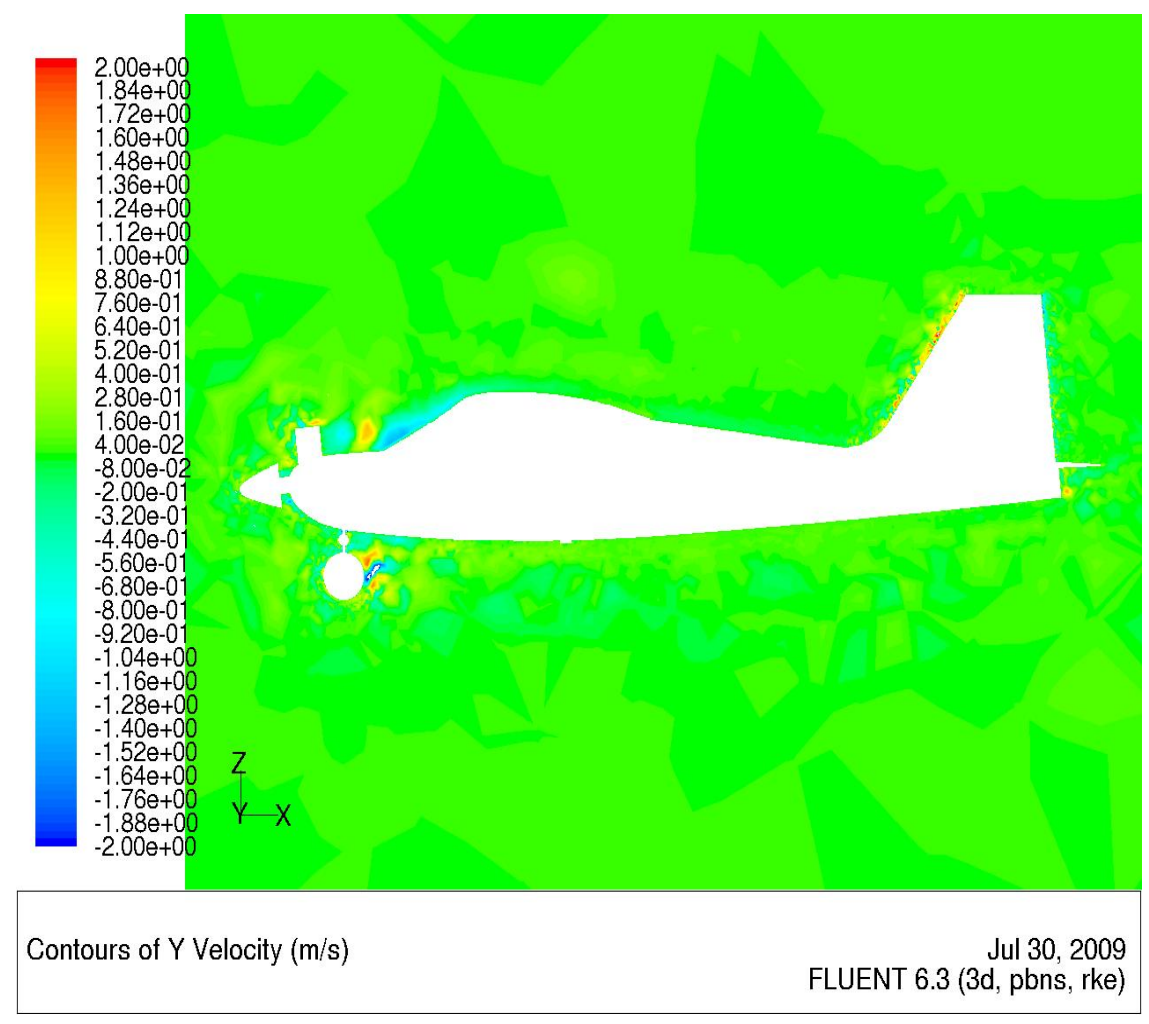

Figure 4.5. Y component velocity on XZ Plane for Sig Kadet Model w/o muffler. 


\section{CHAPTER 5}

\section{RESULTS AND DISCUSSIONS}

\subsection{Inertia Properties}

The stick model is designed considering empty fuel tank initially. The stick model is discussed in section 2.2. The moment of inertia obtained from the stick model with empty fuel tank in SolidWorks is tabulated in Table 5.1. The body fixed coordinate system, as defined in section 3.2 is used for calculating the moment of inertia for Sig Kadet airplane model.

The moment of inertia calculated about the body $\mathrm{X}$ and $\mathrm{Y}$-axis using the com-

pound pendulum method are $I_{x x}=0.5644 \mathrm{~kg} \cdot \mathrm{m}^{2}$ and $I_{y y}=0.6776 \mathrm{~kg} \cdot \mathrm{m}^{2}$. The actual mass of the aircraft with empty fuel tank is $4.893 \mathrm{~kg}$ and the mass from the stick model is $4.61 \mathrm{~kg}$. One of the reason for the difference in mass could be due to the missing connectors, servos and servo links.

The center of mass calculated using mass properties in SolidWorks is found to be 0.26 times the chord length behind the leading edge of the wing. The coordinates for the center of mass with reference to the origin located at the nose of the airplane aligned with body axes is found to be $(-506.72 \mathrm{~mm}, 3.13 \mathrm{~mm},-46.61 \mathrm{~mm})$.

To show the capability of the tool in calculating the moment of inertia and center of mass, the stick model with full fuel tank is considered. The moment of inertia calculated from SolidWorks for the full fuel tank is tabulated in the Table 5.2. The center of mass is shifted by $14 \mathrm{~mm}$ in the positive $\mathrm{X}$ direction, due to the extra mass of the fuel of 300 grams, to a new location in $(-492.64 \mathrm{~mm}, 2.94 \mathrm{~mm},-44.80$ 
$\mathrm{mm}$ ) in body fixed frame. The density of the Omega $15 \%$ fuel is calculated to be $9.58 e^{-4}$ grams $/ \mathrm{mm}^{3}$ and the volume of the fuel tank is $3.2 e^{5} \mathrm{~mm}^{3}$.

Table 5.1. Moment of Inertia $\left(\mathrm{kg} \cdot \mathrm{m}^{2}\right)$ for Sig Kadet with empty fuel tank

\begin{tabular}{|c|c|c|c|c|c|}
\hline$I_{x x}$ & 0.5235 & $I_{x y}$ & 0.0035 & $I_{x z}$ & 0.0215 \\
\hline$I_{y x}$ & 0.0035 & $I_{y y}$ & 0.5686 & $I_{y z}$ & -0.0005 \\
\hline$I_{z x}$ & 0.0215 & $I_{z y}$ & -0.0005 & $I_{z z}$ & 1.0167 \\
\hline
\end{tabular}

Table 5.2. Moment of Inertia $\left(\mathrm{kg} \cdot \mathrm{m}^{2}\right)$ for Sig Kadet with full fuel tank

\begin{tabular}{|c|c|c|c|c|c|}
\hline$I_{x x}$ & 0.5238 & $I_{x y}$ & 0.0033 & $I_{x z}$ & 0.0235 \\
\hline$I_{y x}$ & 0.0033 & $I_{y y}$ & 0.5841 & $I_{y z}$ & -0.0005 \\
\hline$I_{z x}$ & 0.0235 & $I_{z y}$ & -0.0005 & $I_{z z}$ & 1.0319 \\
\hline
\end{tabular}

\subsection{Aerodynamic Coefficients}

The aerodynamic force and moment coefficients for various angles of attack, side slip angles and control surface deflections are presented in this section. The reference lengths used in the calculation of the aerodynamic coefficients are the chord length of $385 \mathrm{~mm}$ and wing span is $2.04 \mathrm{~m}$ and the wing planform area of $0.7854 \mathrm{~m}^{2}$

\subsubsection{Aerodynamic Force Coefficients}

The drag coefficient versus angle of attack is plotted in Fig. 5.1(a) for Sig Kadet model with and without muffler. The presence of muffler causes asymmetry in the Sig Kadet airplane model. The drag coefficient versus angle of attack shows a parabolic curve, as shown in the Fig. 5.1(a), which indicates that the drag increases with the 
square of the angle of attack. The drag is affected by small magnitude due to the presence of muffler. Lift coefficient and side force coefficient as a function of angle of attack is plotted in the Fig. 5.1(b) for the Sig Kadet airplane model with and without the muffler. The lift coefficient versus angle of attack gives a linear function of angle of attack with a positive slope, i.e with the increase in the angle of attack the lift coefficient increases. The slope for side force versus angle of attack is insignificant when compared to the slope for lift versus angle of attack. Figure. 5.2 shows the lift versus drag coefficient for change in angle of attack for the case with and without muffler. It is clear from this figure that drag coefficient is proportional to square of lift coefficient which is in agreement with the theory. Angle of attack is varied from -8 to 8 degrees. Angle of attack is considered positive for positive pitch.

The drag coefficients versus side slip angle curve for various angles of attack is plotted in Fig. 5.3(a). It is noticed from this figure that as there is an increase in drag due to side slip angle. This indicates that the drag coefficient increases as the square of side slip angle $(\beta)$. Fig. 5.3(b) indicates that lift coefficient is not changed with side slip angle within the range of angles simulated. Fig. 5.3(c) shows the variation of side force coefficient as a function of side slip angle for various angles of attack. Note that side force has linear dependency on side slip angle and the slope changes with angle of attack. Side slip angle is considered to be positive for negative yaw.

Figure 5.4(a) shows that the drag dependency on elevator deflection is parabolic. The parabolic dependency varies with angle of attack. This can be explained by the fact that the location of the elevator in the wake of the fuselage changes as the angle of attack varies. For example, when the Sig Kadet model is oriented at an angle of the attack of 4 degrees with the positive elevator deflection of 20 degrees, the drag coefficient is higher than with the negative elevator deflection of 20 degrees at same angle of attack of 4 degrees. Fig. 5.4(b) shows that the lift coefficient 


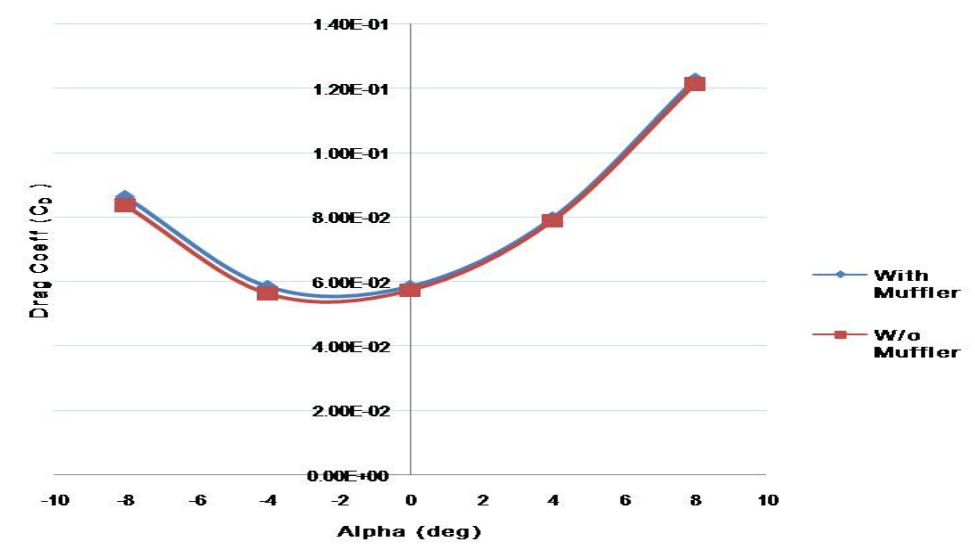

(a)

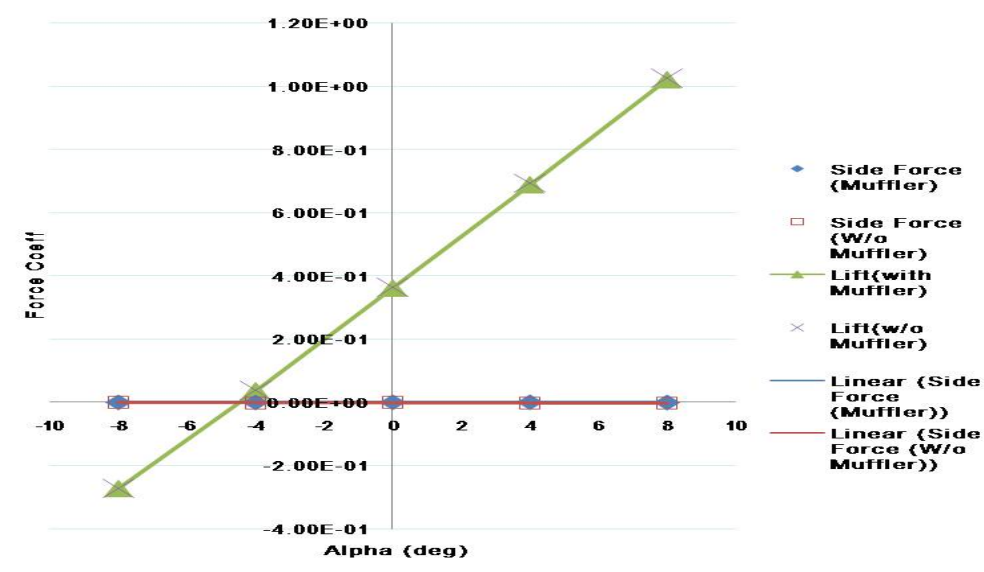

(b)

Figure 5.1. (a) Drag, (b) Lift and Side Force Coefficient vs Angle of Attack for Sig Kadet Model.

varies almost linearly with a positive slope within the range of -20 to +20 degrees of elevator deflection. The elevator when deflected downwards is considered as a positive deflection. The range of the elevator deflection considered is -40 degrees to +30 degrees based on the maximum allowable deflection. Fig. 5.4(b) also shows that the elevator deflection does not generate side force at any elevator deflection.

Fig. 5.5(a) shows that the rudder deflection generates drag in a parabolic manner at all angles of attack simulated. As seen in Fig. 5.5(b), the lift coefficient is not affected by rudder deflections. The side force depends linearly on the rudder 


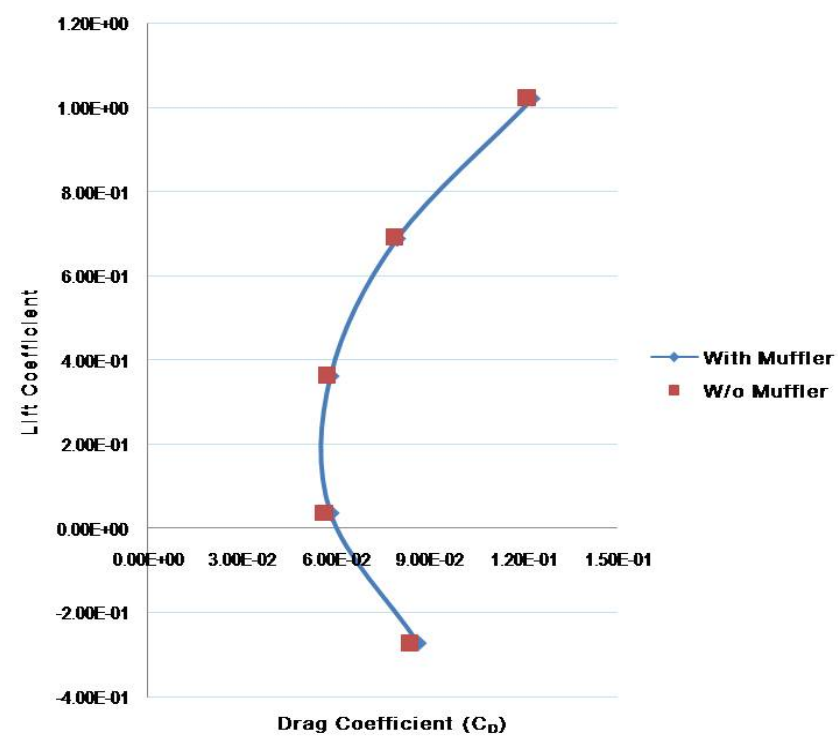

Figure 5.2. Lift vs Drag for Sig Kadet Model.

deflection, as seen in Fig. 5.5(c). The slope of the linear dependency has little variation with the angle of attack. The range of rudder deflection considered is between -25 to +25 degrees which is maximum allowable deflection of the rudder. The rudder when deflected towards right i.e towards the positive Y axis of the wind axes coordinate system, is considered positive.

In Fig. 5.6(a), the drag coefficient is shown to depend on the aileron deflection in a parabolic manner. Fig. 5.6(b) shows that the lift is not affected by the aileron deflection. The lift coefficient seems to be slightly higher at zero aileron deflection than at any other aileron deflection. This is because the design of the aileron in SolidWorks is slightly altered to avoid sharp angles and skew elements. Fig. 5.6(c) shows that very small side force is generated in a linear manner by the aileron deflection. The range of aileron deflection considered is from -25 to +25 degrees. The aileron deflection is considered positive for the downward deflection of the right wing. 


\subsubsection{Aerodynamic Moment Coefficients}

The aerodynamic moment coefficients are calculated about the nose in body axis coordinate system as defined in 3.2. It is seen from Fig. 5.7 that rolling and yawing moment coefficients are insensitive while, pitching moment coefficient is much sensitive to variation in angle of attack. It is clear from Fig. 5.7 that pitching moment is a linear function of angle of attack with negative slope which indicates that the pitching moment about nose decreases with the increase in angle of attack.

Figure 5.8 shows the near linear dependency of pitching moment coefficient on elevator deflection for the range of -20 to +20 degrees. It is observed from Fig. 5.8 that rolling and yawing moment coefficient are unaffected by any elevator deflection. These observations are valid for different angles of attack.

Figures 5.9(a) and 5.9(b) shows that side slip angle generates rolling and yawing moment coefficients in a linear manner at all angles of attack. The slope of linear dependency varies with angle of attack. As seen in Fig. 5.9(b), the pitching moment coefficient remains unaffected by variation in side slip angle.

Figure 5.10(a) shows that the rolling moment dependency on rudder deflection is linear except for 8 degrees angle of attack. This might be because the flow is no longer steady. Figure 5.10(c) shows yawing moment coefficient as a linear function of rudder deflection. From Fig. 5.10(a) and (c) it is seen that yawing moment changes significantly for any change in rudder deflection when compared to the very small changes in rolling moment coefficient. It is observed from the Fig. 5.10(b) that pitching moment is unaffected by rudder deflections.

Figures 5.11(a) and (c) show that rolling and yawing moment coefficients are linear function of aileron deflection. It is noticeable from Figs. 5.11(a) and (c) that the rolling moment coefficient has a significant change for aileron deflection than 
compared to yawing moment coefficient. Fig. 5.11 shows that pitching moment is not affected by aileron deflection.

The results for the aerodynamic coefficients for Sig Kadet model are tabulated in Appendix B. 


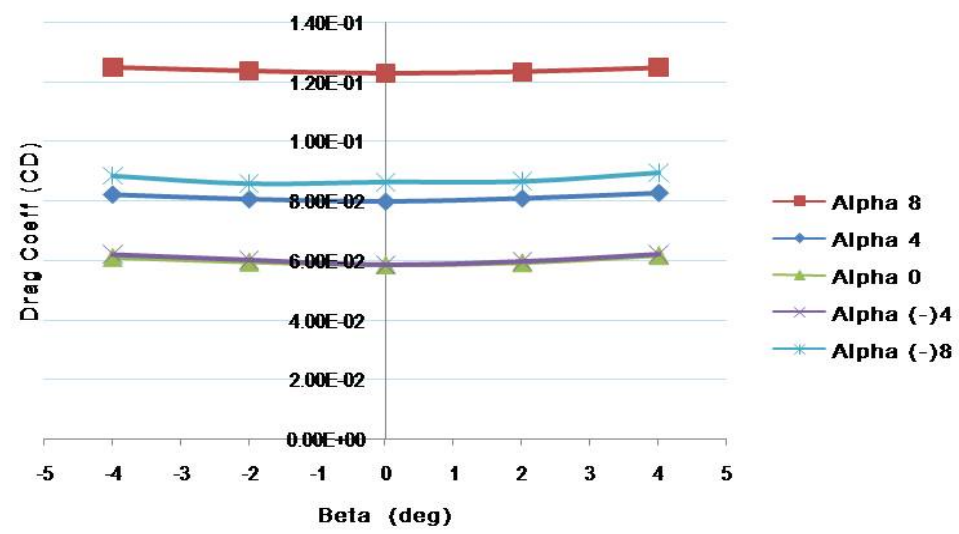

(a)

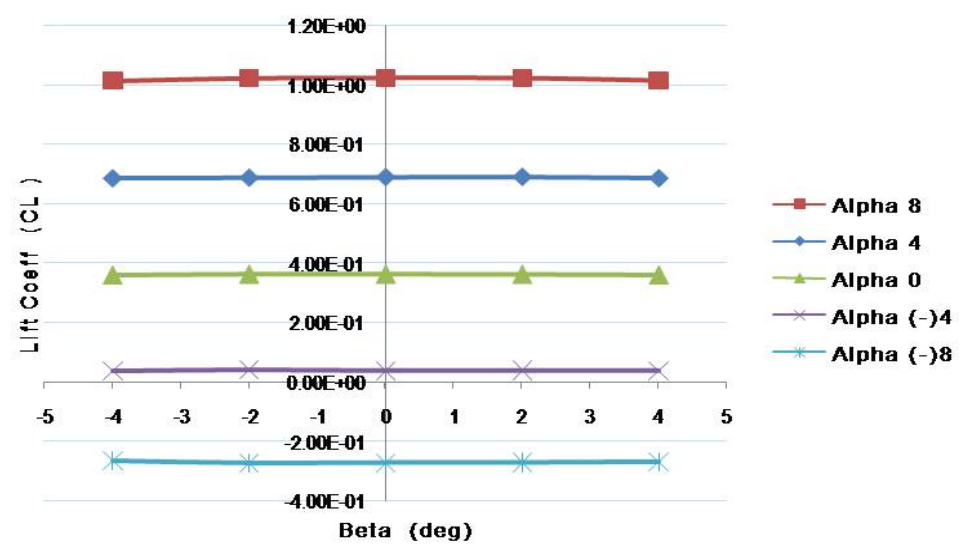

(b)

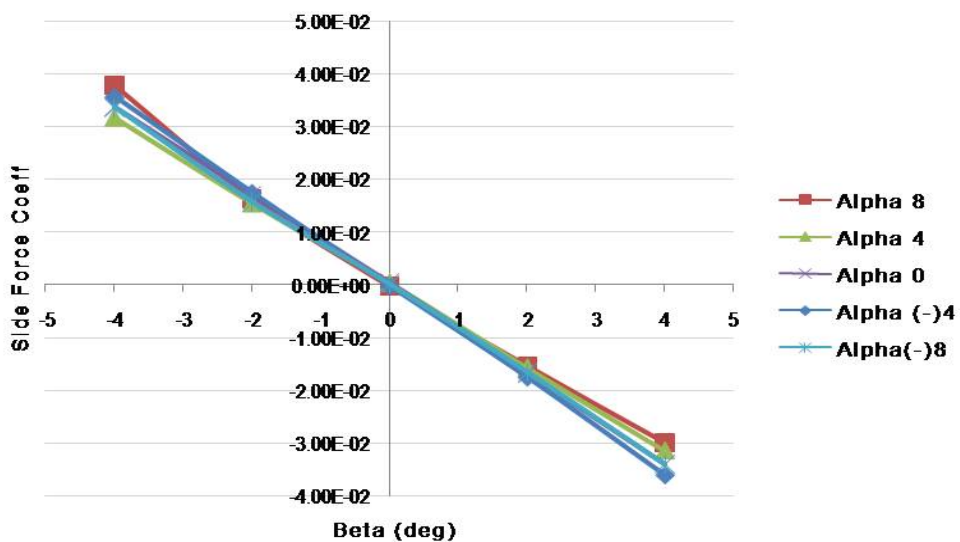

(c)

Figure 5.3. (a) Drag, (b) Lift and (c) Side Force Coefficient vs Side Slip Angle for Sig Kadet Model. 


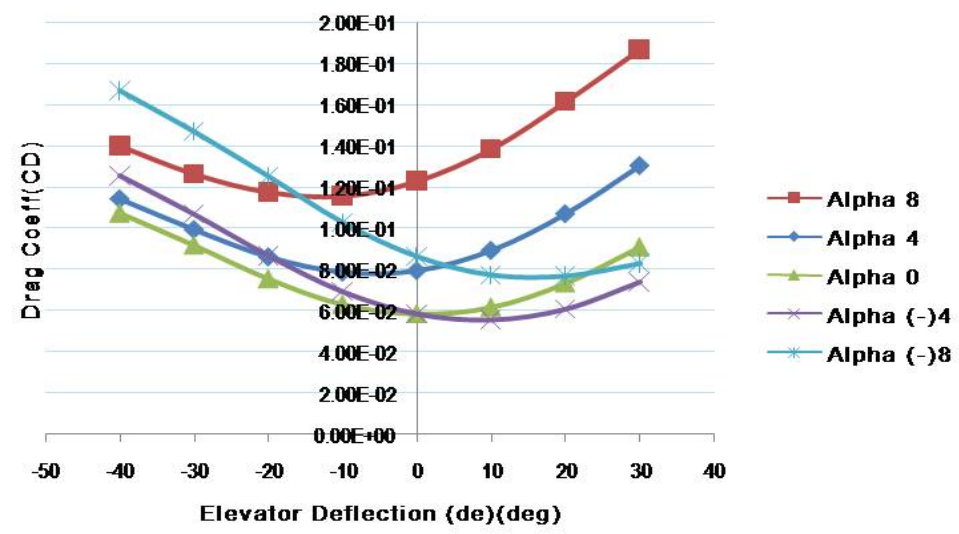

(a)

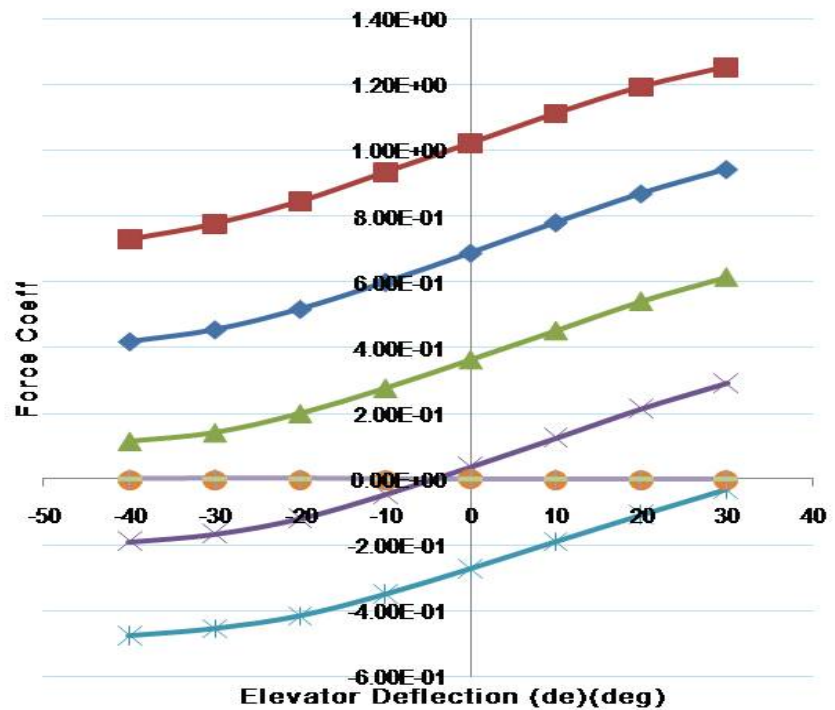

- Side force (Alpha8)

Side Force (Alpha 4)

- Side Force (Alpha 0 )

- Side Force (Alpha (-)4)

$\longrightarrow-$ Side Force (Alpha (-)8)

$\longrightarrow$ Lift (Alpha 8)

— Lift (Alpha 4)

- Lift (Alpha o)

$\longrightarrow$ Lift (Alpha (-)4)

— Lift (Alpha (-)8)

(b)

Figure 5.4. (a) Drag, (b) Lift and Side Force Coefficient vs Elevator Deflection Plot for Sig Kadet Model. 


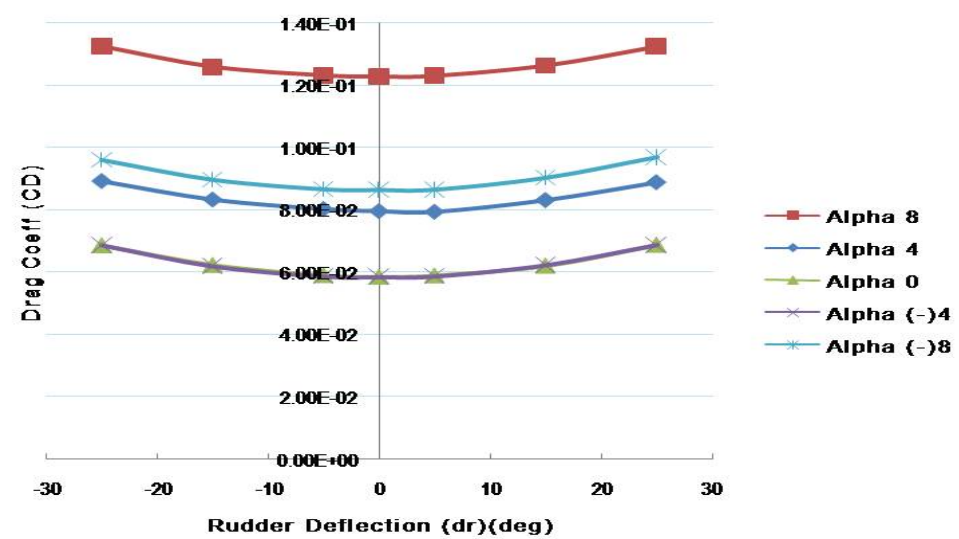

(a)

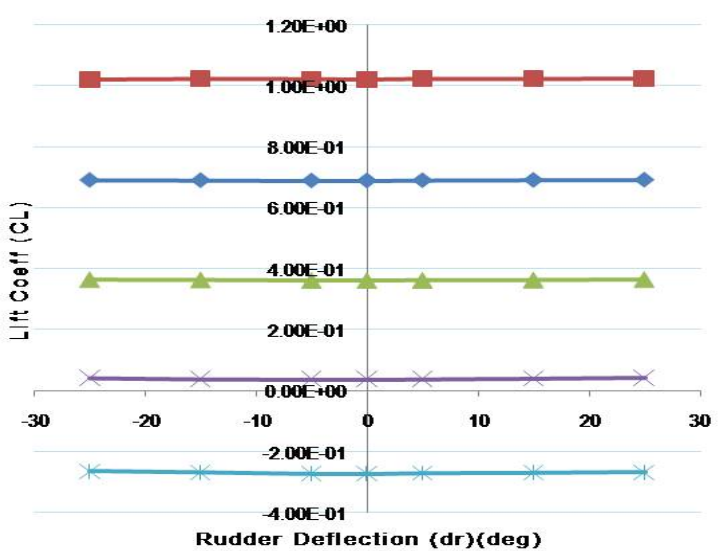

Rudder Deflection (dr)(deg)

(b)

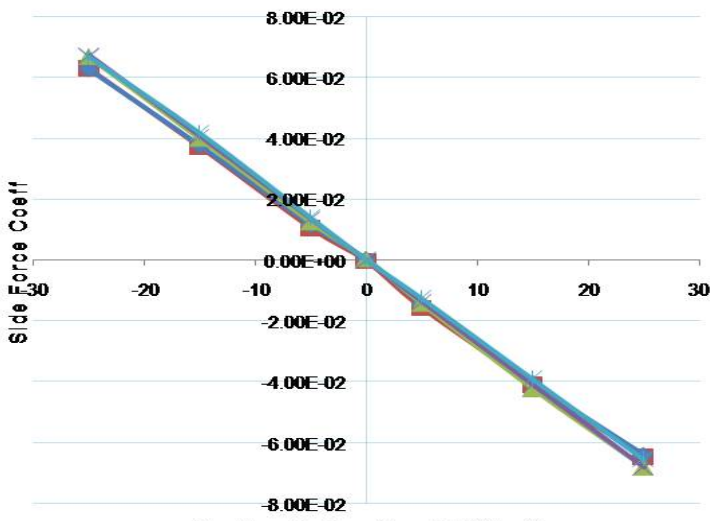

-

$\longrightarrow$ Alpha 4

- Alpha 0

$\longrightarrow$ Alpha (-)4

- Alpha (-)8

Rudder Deflection (dr)(deg)

(c)

Figure 5.5. (a) Drag, (b) Lift and (c) Side Force Coefficient vs Rudder Deflection Plot for Sig Kadet Model. 


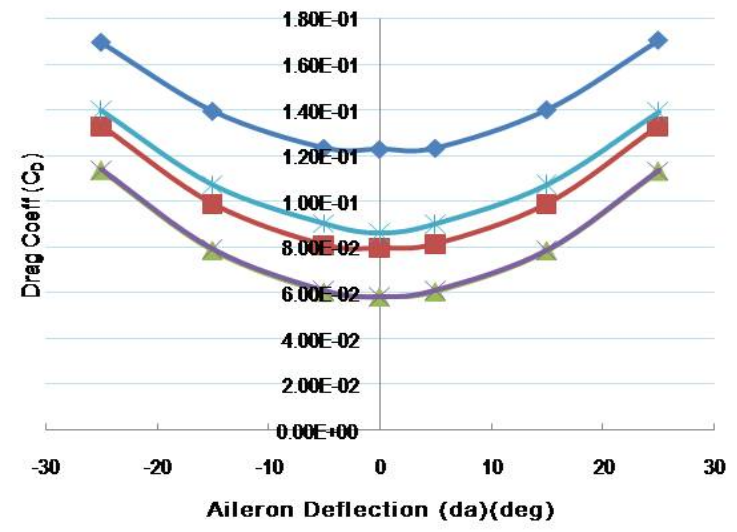

$$
\begin{aligned}
& \longrightarrow \text { Alpha } 8 \\
& - \text { Alpha } 4 \\
& \because \text { Alpha } 0 \\
& \because \text { Alpha (-)4 } \\
& - \text { Alpha (-)8 }
\end{aligned}
$$

(a)

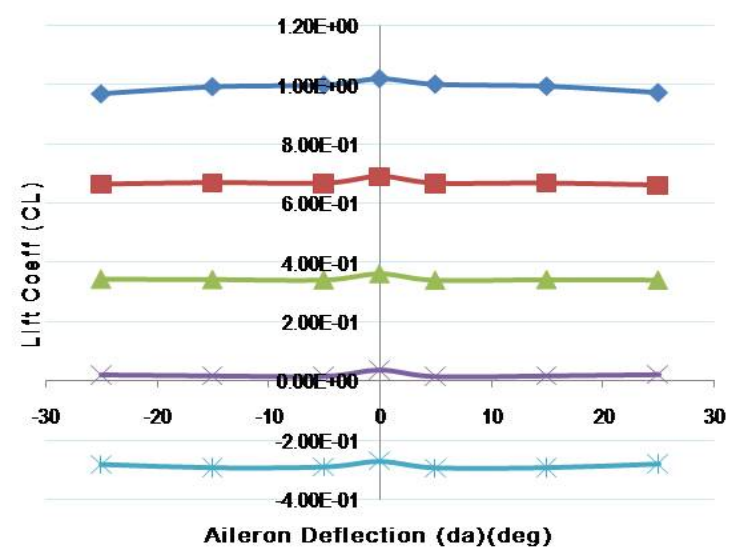

- - Alpha 8

- Alpha 4

$\longrightarrow$ Alpha 0

$\longrightarrow$ Alpha (-)4

- Alpha(-)8

(b)

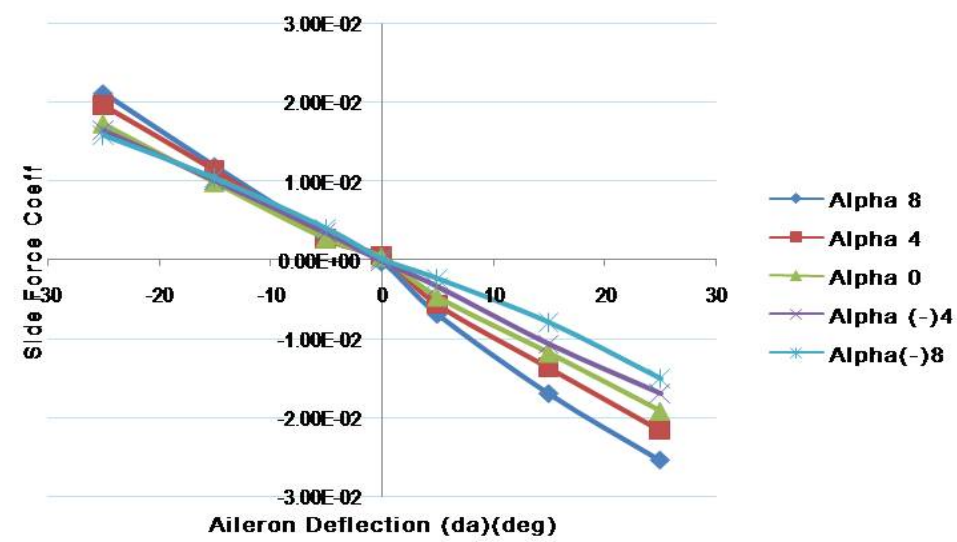

(c)

Figure 5.6. (a) Drag, (b) Lift and (c) Side Force Coefficient vs Aileron Deflection Plot for Sig Kadet Model. 


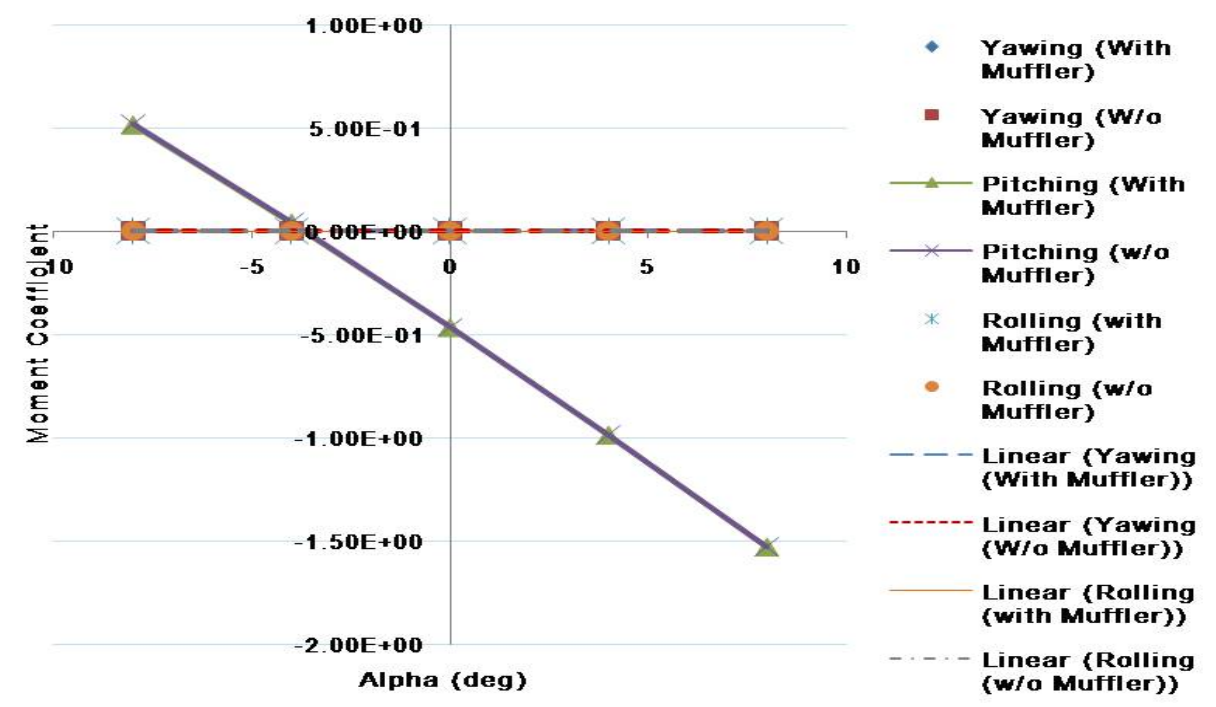

Figure 5.7. Rolling, Pitching and Yawing Moment Coefficient about the Nose vs Angle of Attack for Sig Kadet Model.
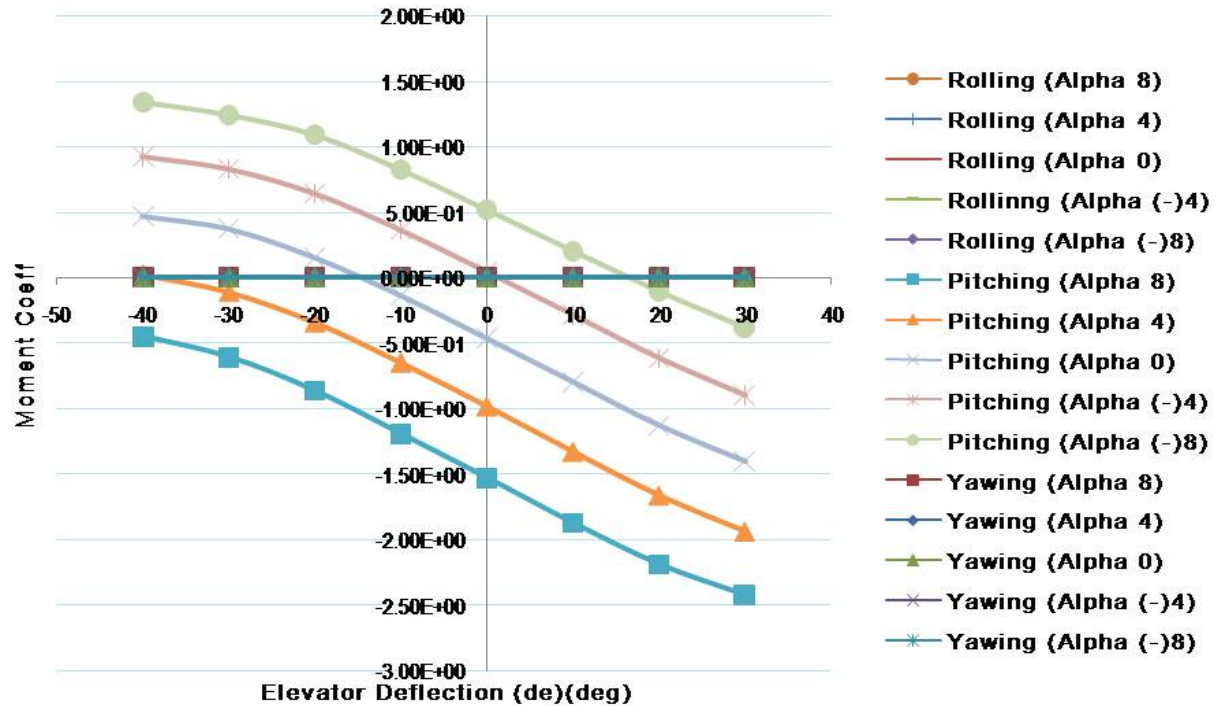

Figure 5.8. Rolling, Pitching and Yawing Moment Coefficient about the Nose vs Elevator Deflection Plot for Sig Kadet Model. 


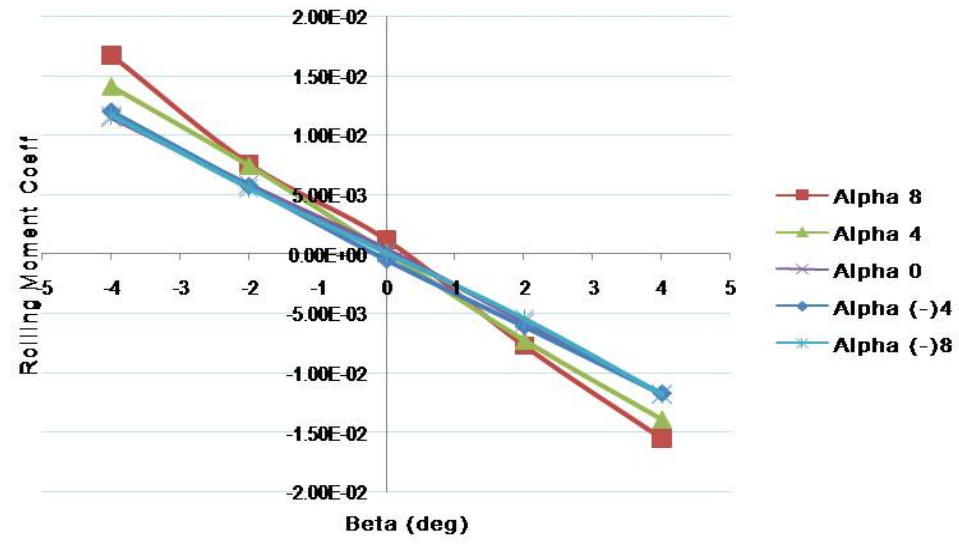

(a)

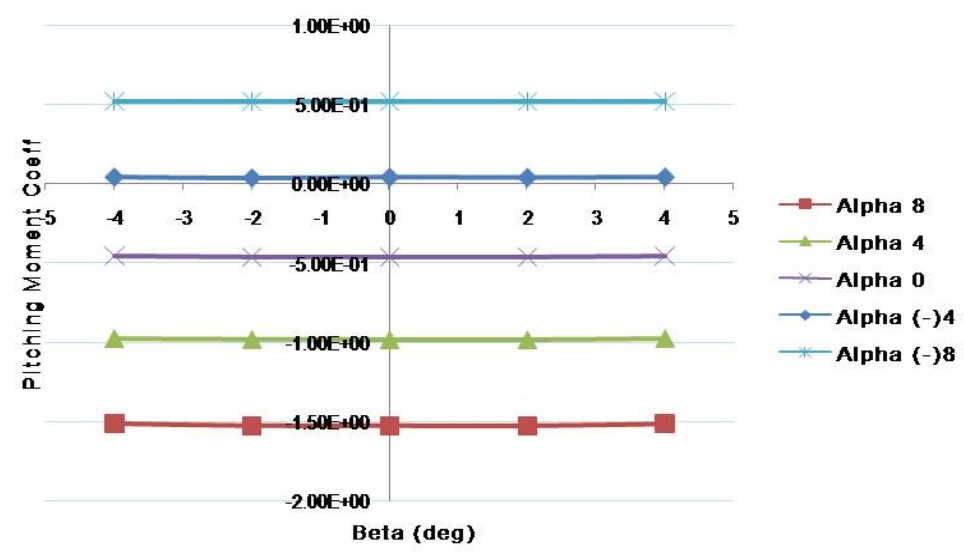

(b)

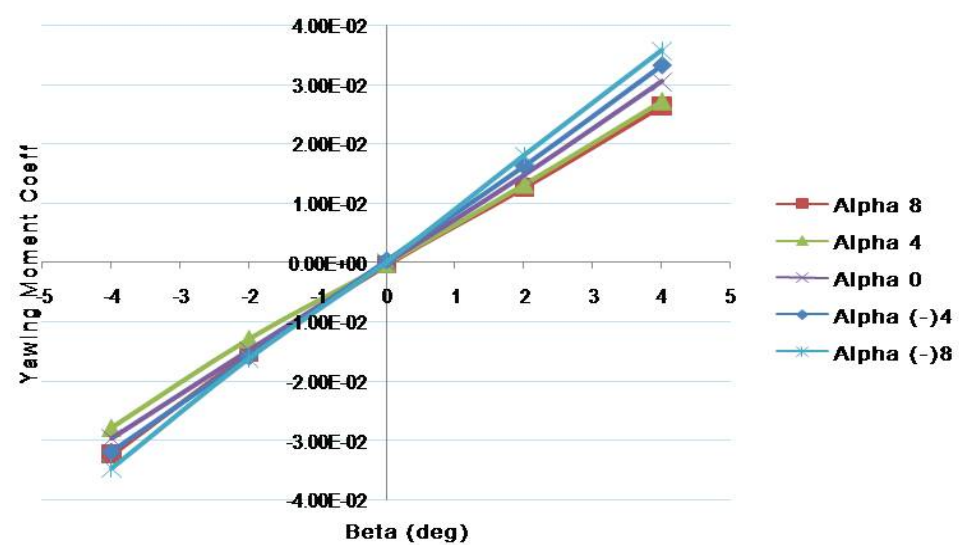

(c)

Figure 5.9. (a) Rolling, (b) Pitching and (c) Yawing Moment Coefficient about the Nose vs Side Slip angle for Sig Kadet Model. 


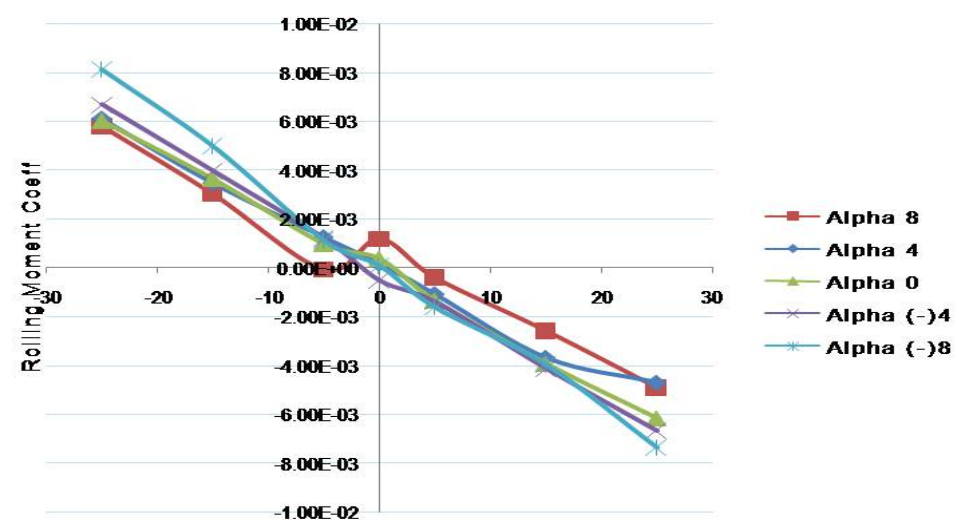

(a)

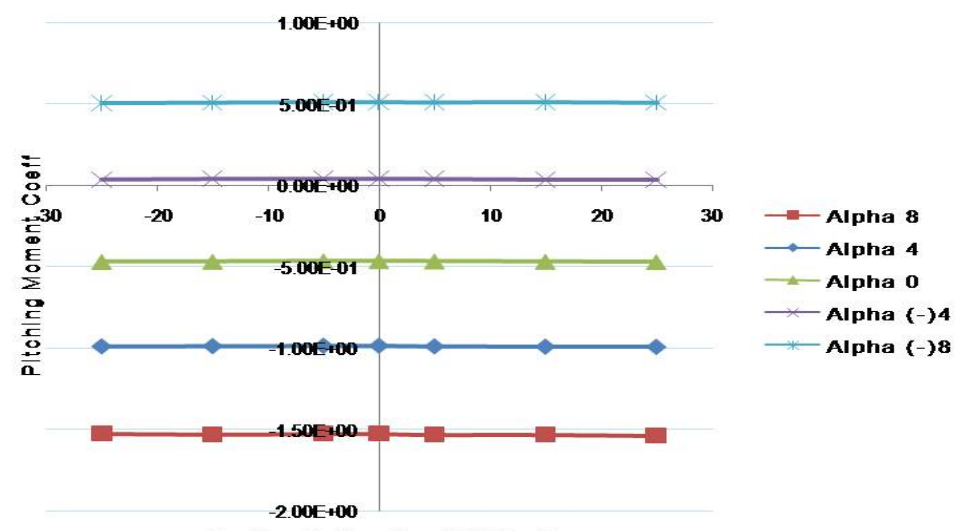

(b)

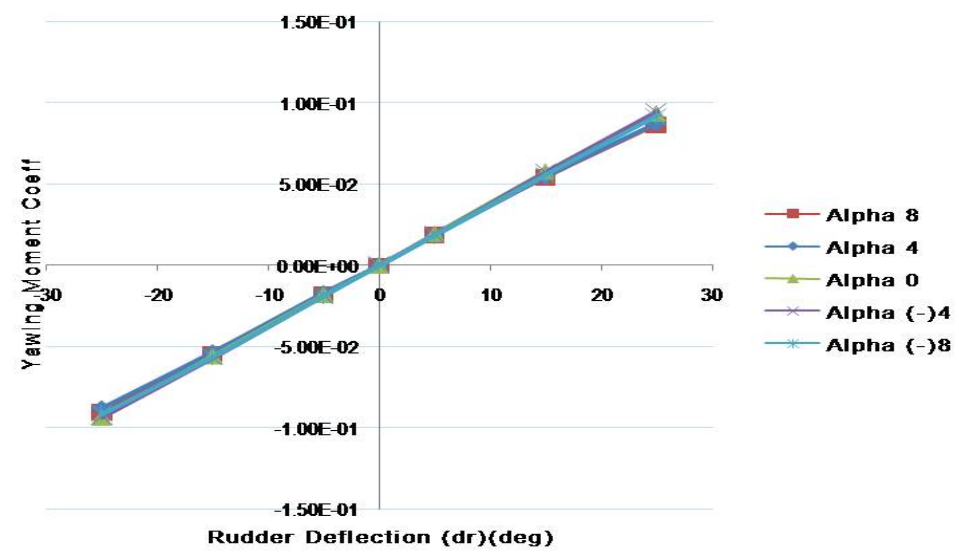

(c)

Figure 5.10. (a) Rolling, (b) Pitching and (c) Yawing Moment Coefficient about the Nose vs Rudder Deflection Plot for Sig Kadet Model. 


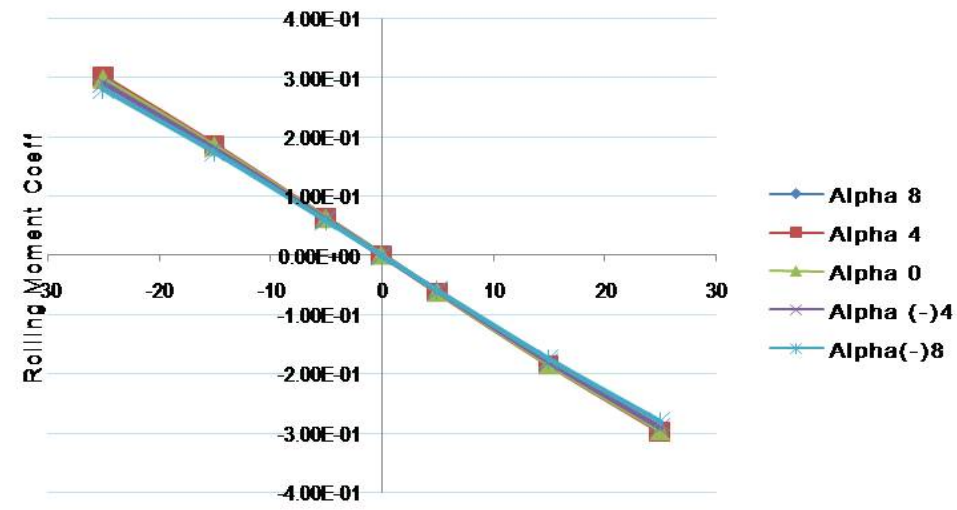

Aileron Deflection (da)(deg)

(a)

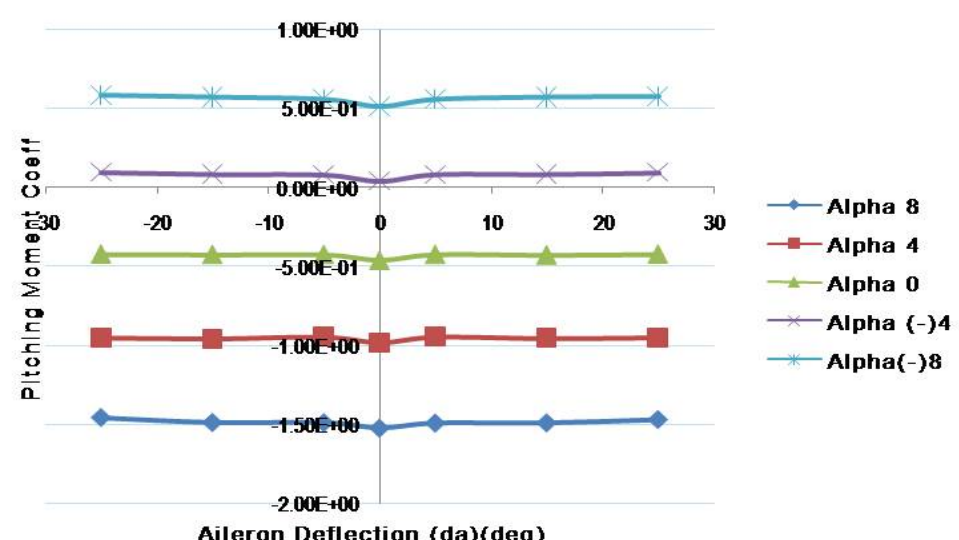

(b)

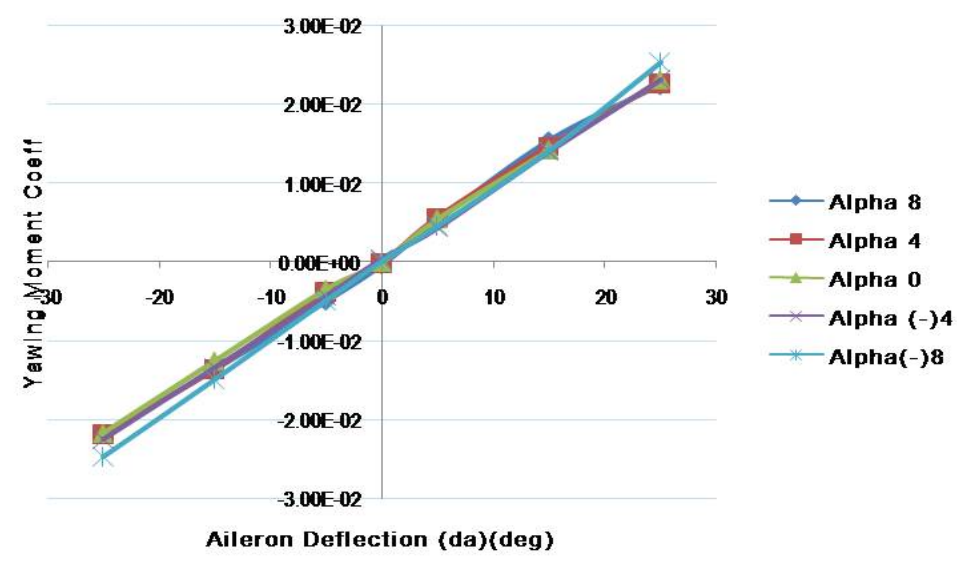

(c)

Figure 5.11. (a) Rolling, (b) Pitching and (c) Yawing Moment Coefficient about the Nose vs Aileron Deflection Plot for Sig Kadet Model. 


\section{CHAPTER 6}

\section{SUMMARY AND FUTURE WORK}

The use of CAE software in calculating the inertia and aerodynamic properties of an R/C airplane is demonstrated using a Sig Kadet Model as an R/C airplane. The sensitivity of aerodynamic force and moment coefficients is analyzed and discussed in Chapter 5. The conclusion from this analysis is that the side force, rolling moment and yawing moment coefficients remain unaffected to the changes in angle of attack and elevator deflection.

Inertia properties are calculated using SolidWorks. The error for $I_{x x}$ when compared with the experimental data is found to be within $7 \%$ of the Experimnetal Results. The error for $I_{y y}$ when compared with the experimental data is found to be within $15 \%$ of the experimnetal results. The deviation in the mass compared to the actual mass is $5 \%$. One of the reason for this variation in mass could be attributed to the servos, servo link and connectors, which are not modeled in SolidWorks.

The work of this thesis can be extended to analyze the structural strength of the airplane. The knowledge of the structural strength of the $\mathrm{R} / \mathrm{C}$ airplane gives information about how much more load can it carry without any structural failure and where is the maximum and minimum stress acting. Developing new techniques will require more hardware components to be installed on the airplane model, thus it is beneficial to do structural analysis of the model.

The knowledge of inertia properties and sensitivity of the aerodynamic coefficients for any change in angle of attack, side slip angle and control surface deflection obtained from this thesis can be incorporated in the controller design. The data ac- 
quired can be even used to simulate the airplane performance and compare it with the flight test data. Simulating the flight of an airplane can give a understanding of how the airplane would behave in given atmospheric conditions. 
APPENDIX A

SIG KADET AIRFOIL POSTPROCESSING 


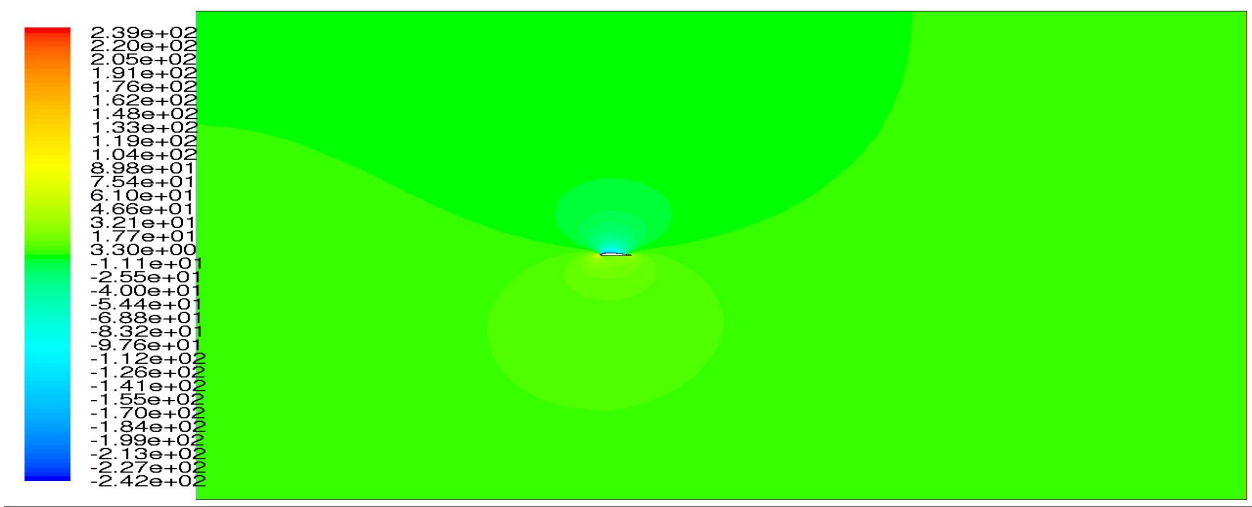

$\begin{array}{ll}\text { Contours of Static Pressure (pascal) } & \text { FLUENT } 6.3 \text { (2d, dp, pbns, rke })\end{array}$

(a)

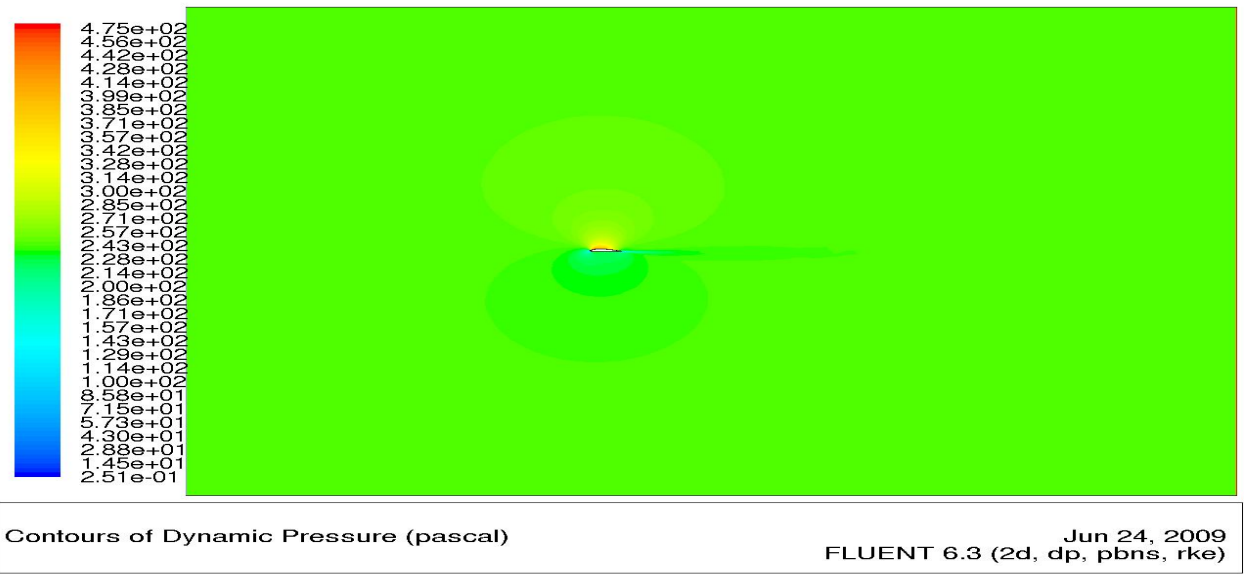

(b)

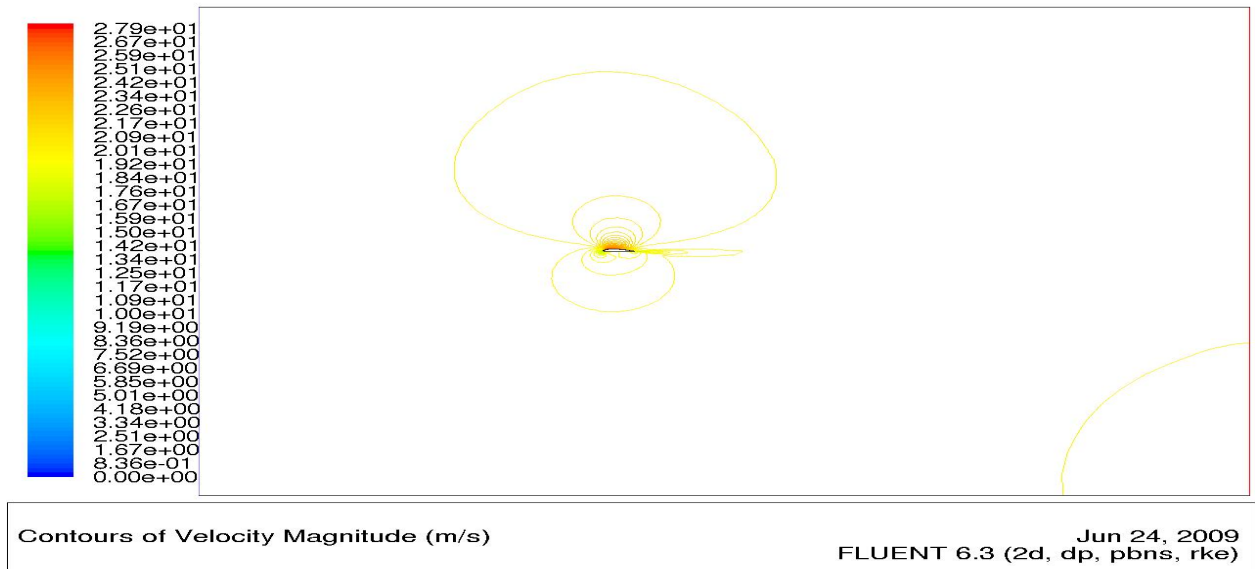

(c)

Figure A.1. (a)Static Pressure (b)Dynamic Pressure (c)Velocity Magnitude Contour Plot for Sig Kadet Airfoil at alpha 0 degrees. 


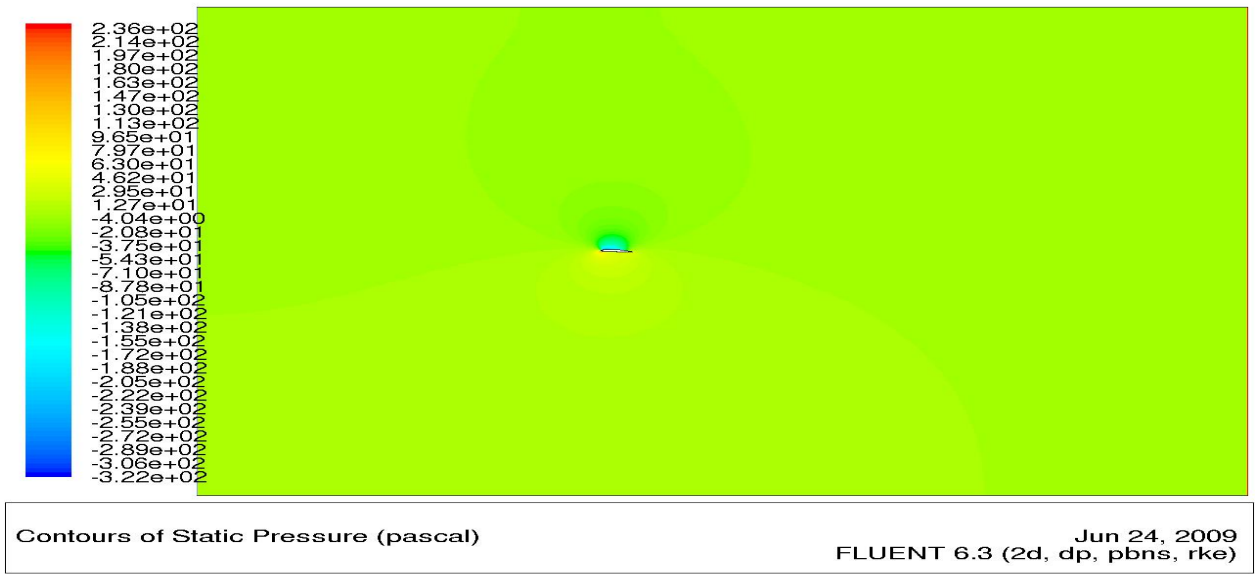

(a)

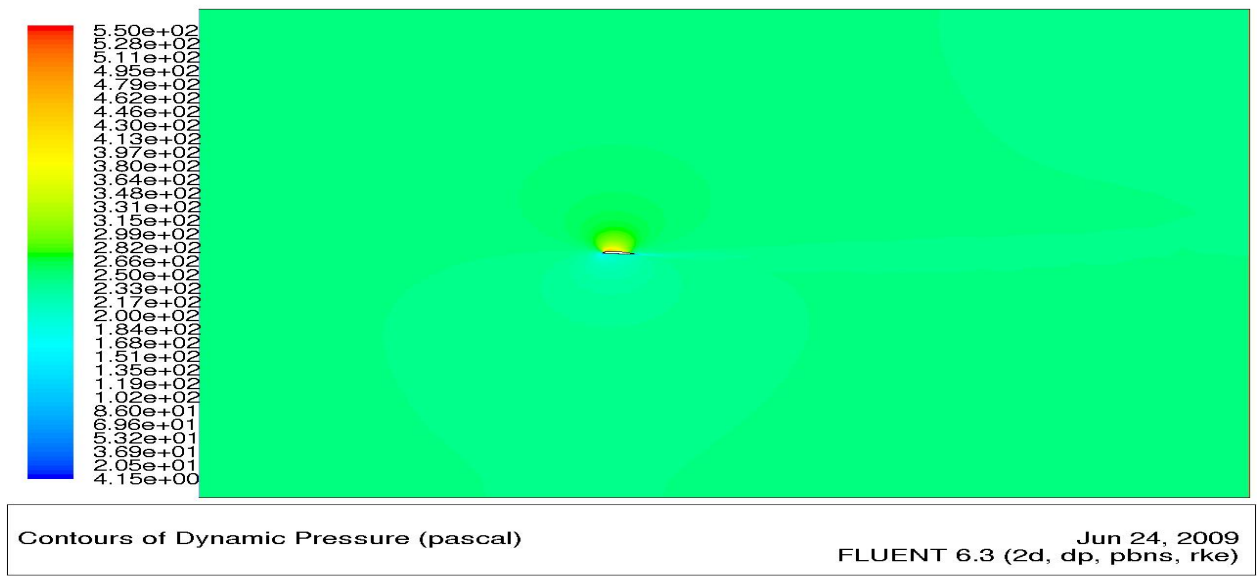

(b)

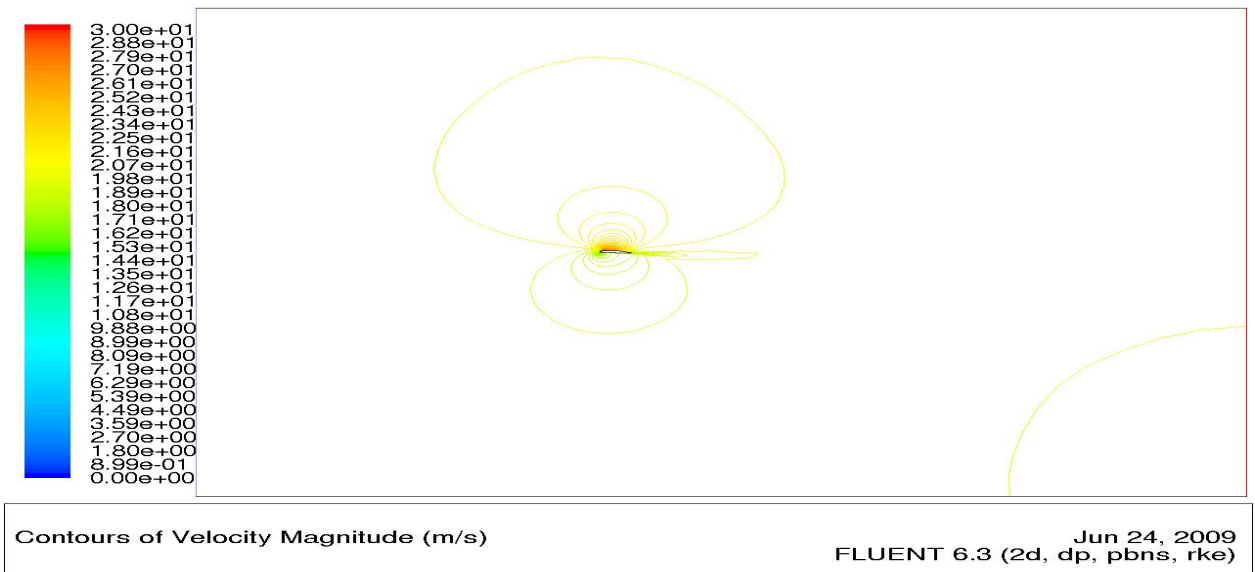

(c)

Figure A.2. (a)Static Pressure (b)Dynamic Pressure (c)Velocity Magnitude Contour Plot for Sig Kadet Airfoil at alpha 2 degrees. 


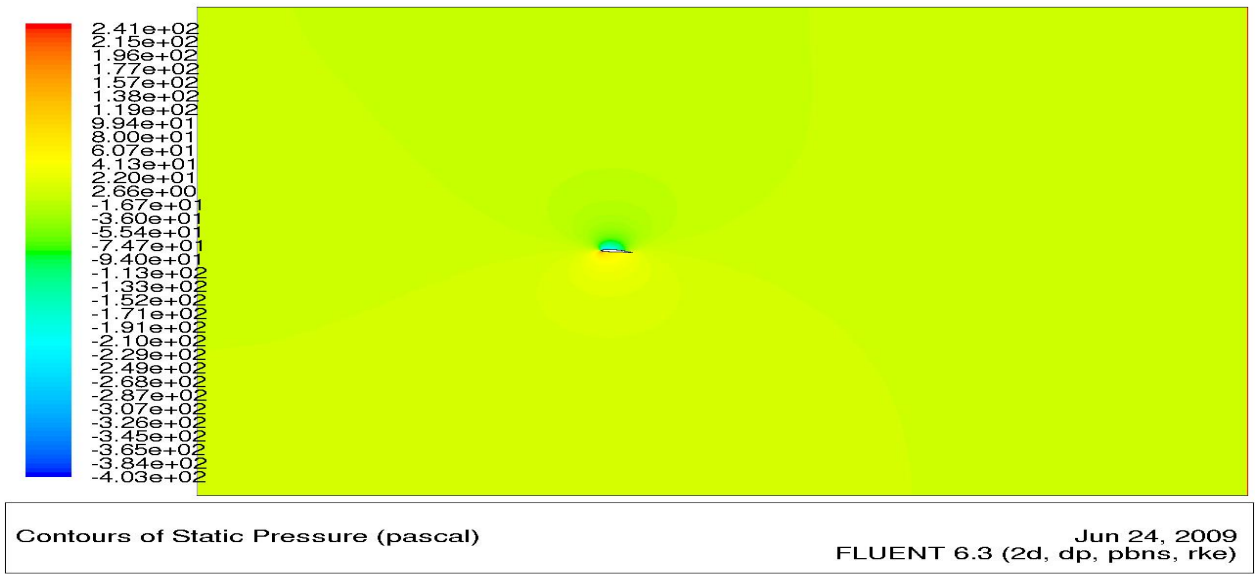

(a)

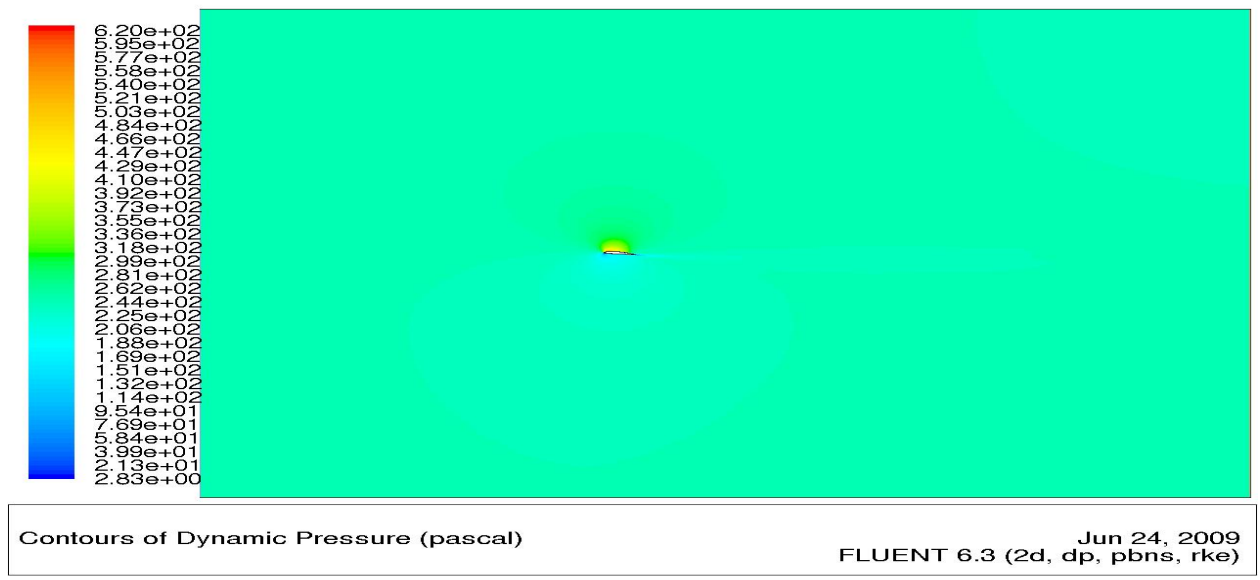

(b)

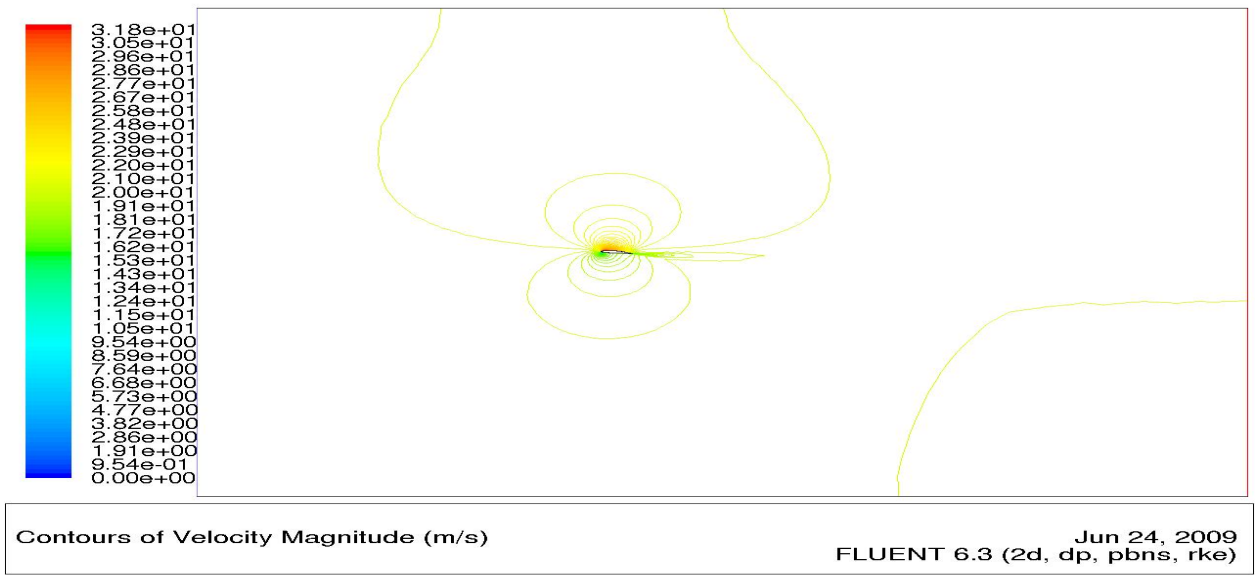

(c)

Figure A.3. (a)Static Pressure (b)Dynamic Pressure (c)Velocity Magnitude Contour Plot for Sig Kadet Airfoil at alpha 4 degrees. 


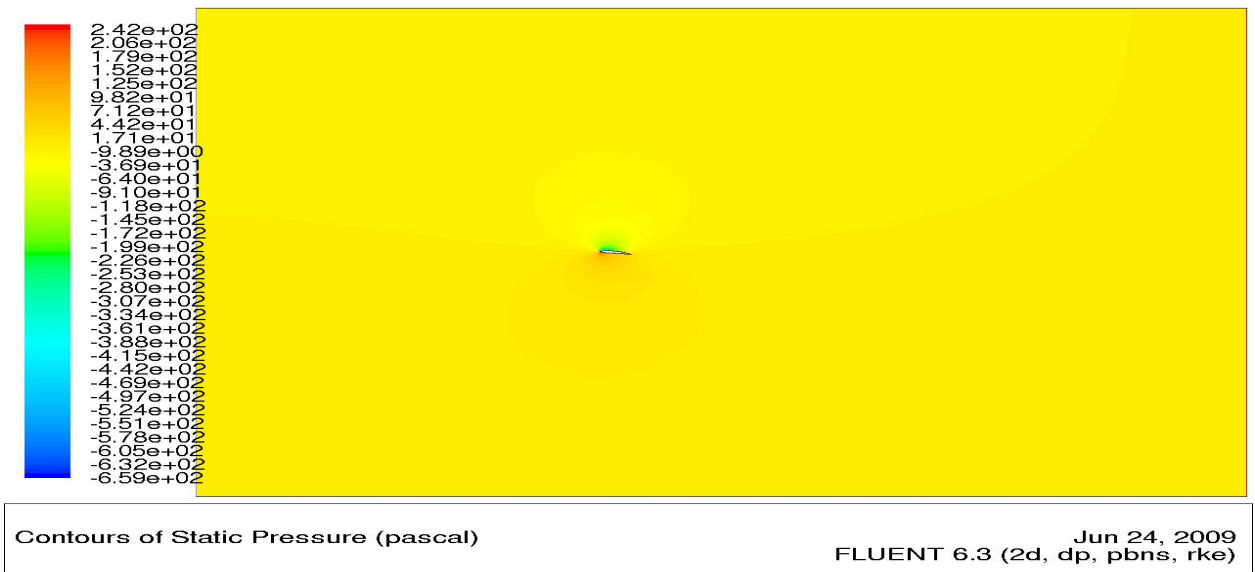

(a)

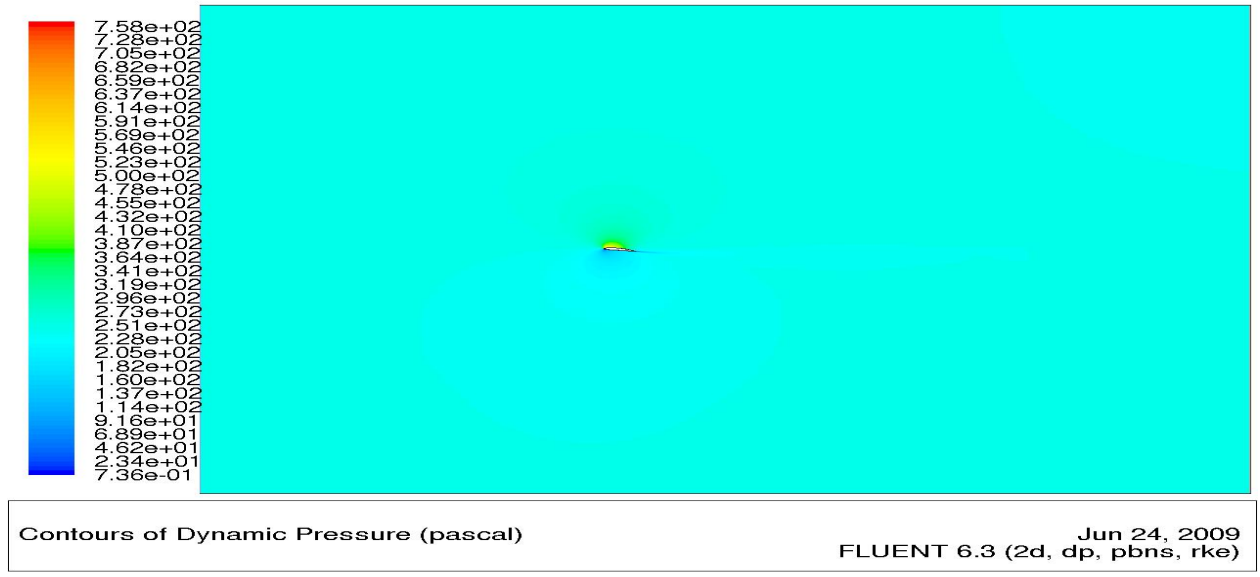

(b)

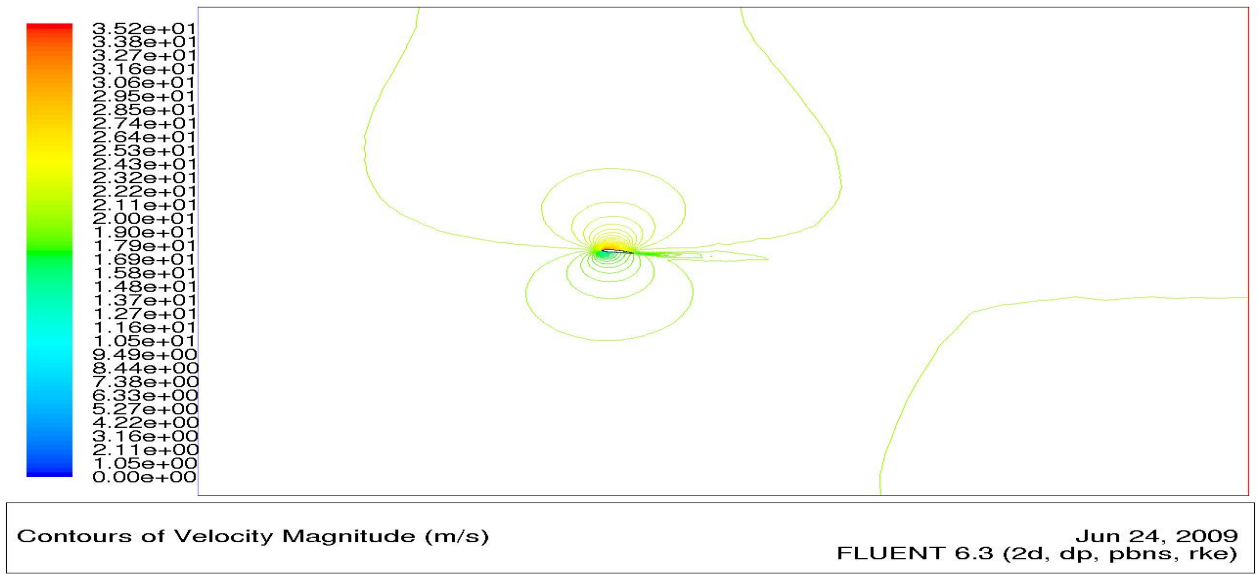

(c)

Figure A.4. (a)Static Pressure (b)Dynamic Pressure (c)Velocity Magnitude Contour Plot for Sig Kadet Airfoil at alpha 6 degrees. 


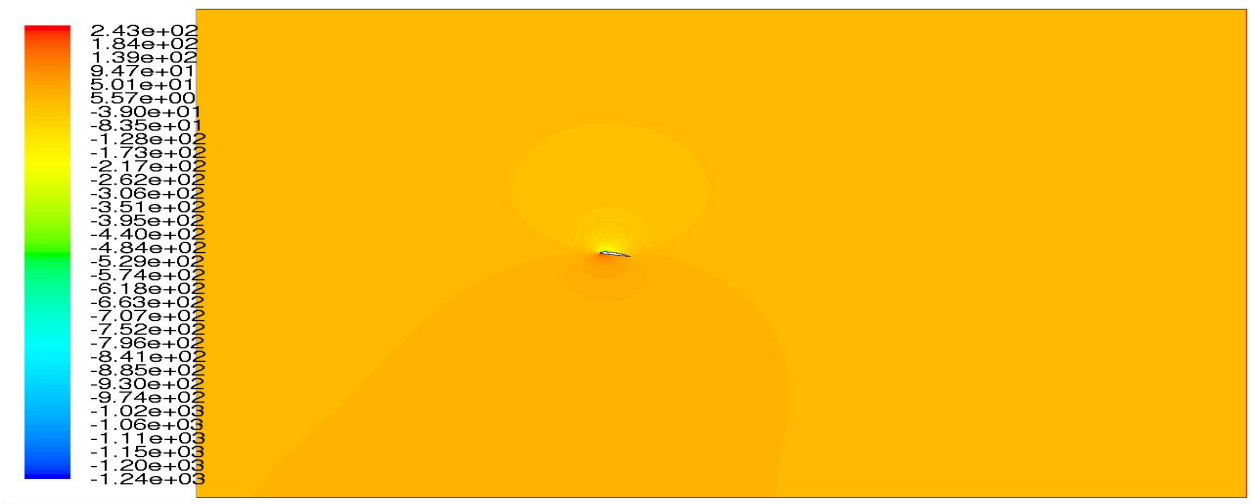

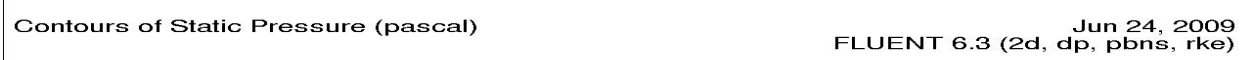

(a)

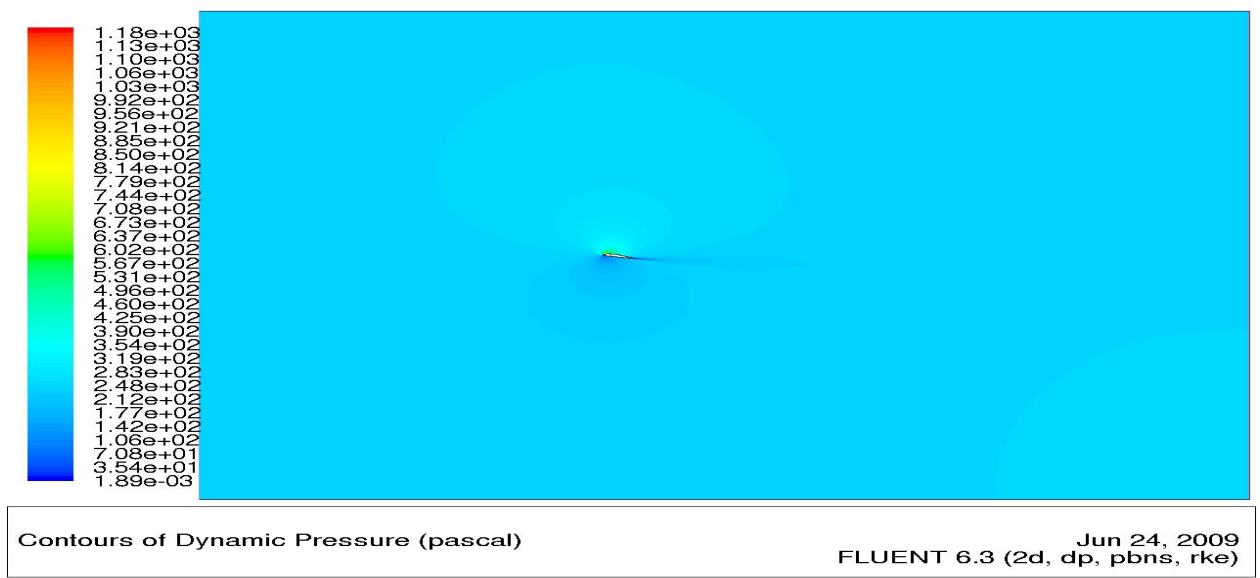

(b)

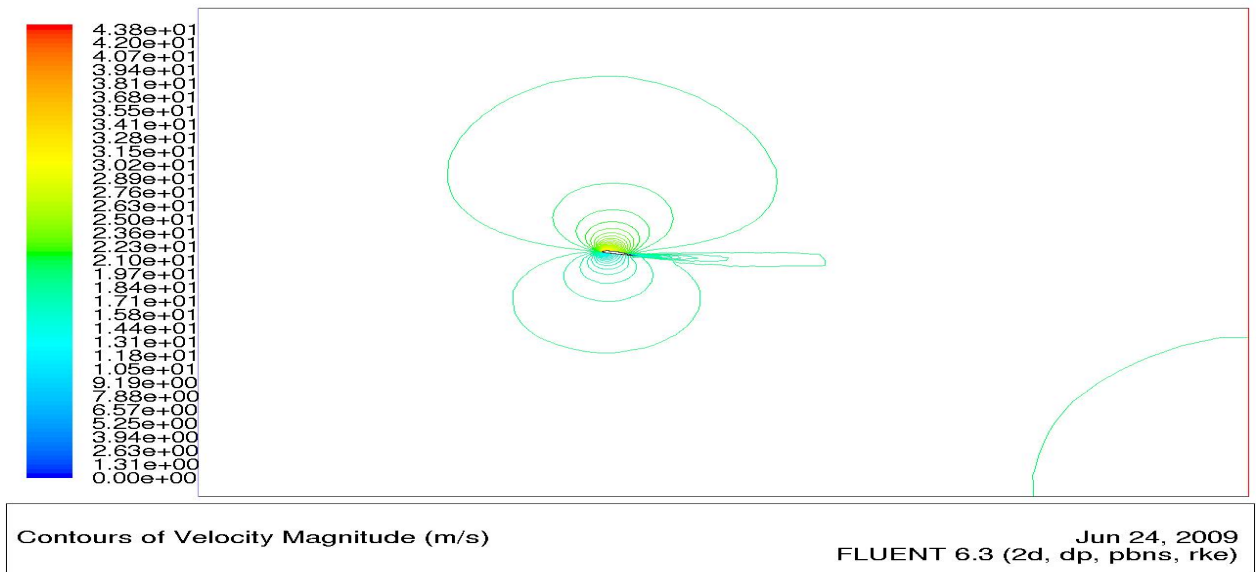

(c)

Figure A.5. (a)Static Pressure (b)Dynamic Pressure (c)Velocity Magnitude Contour Plot for Sig Kadet Airfoil at alpha 10 degrees. 


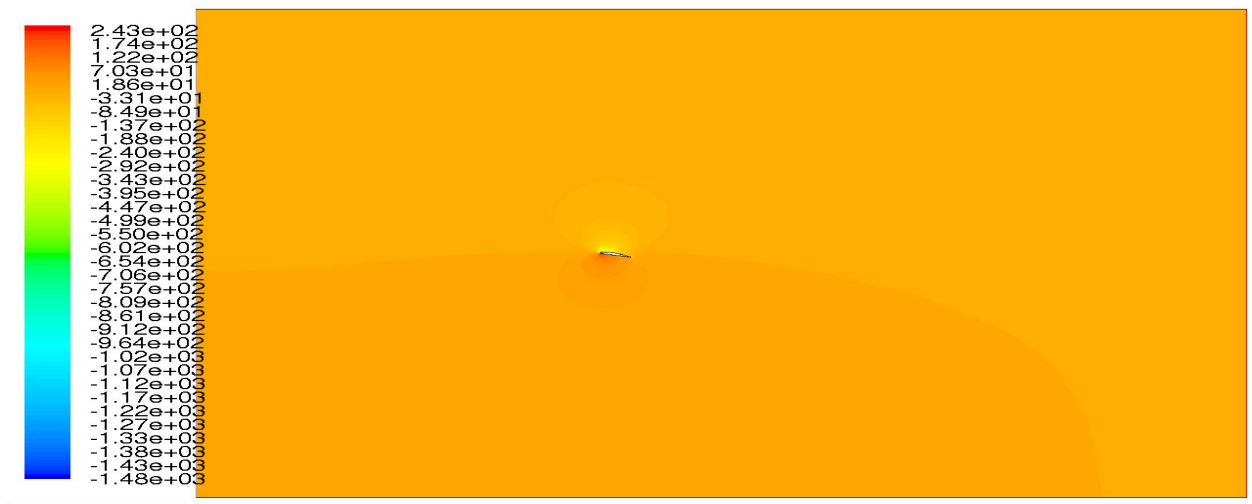

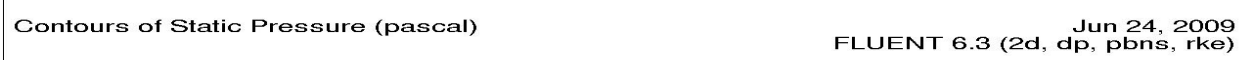

(a)

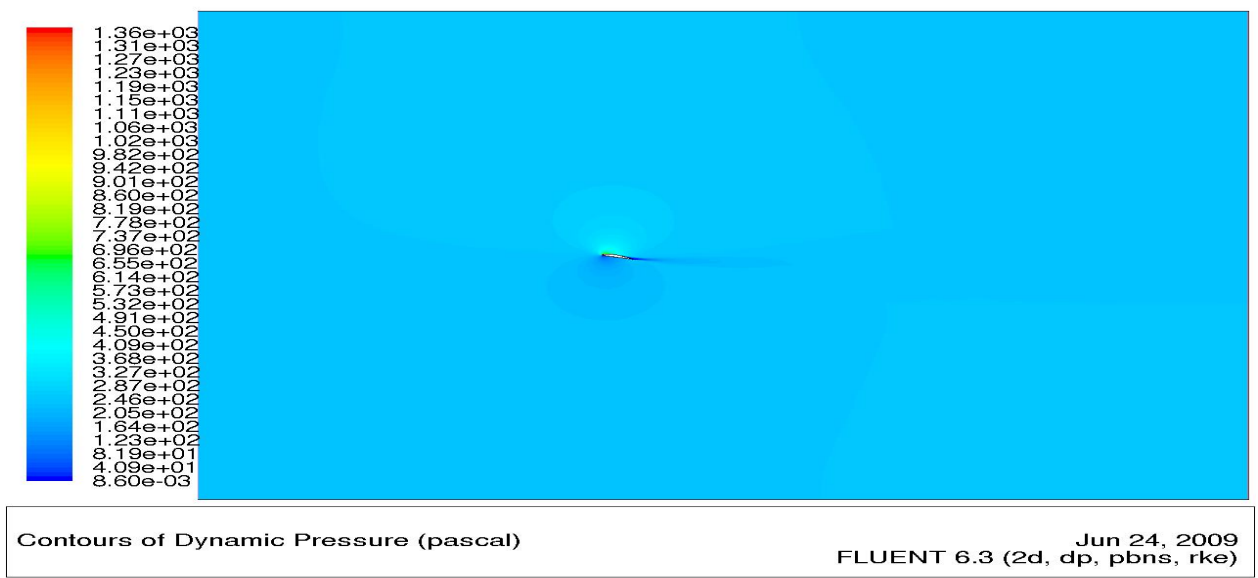

(b)

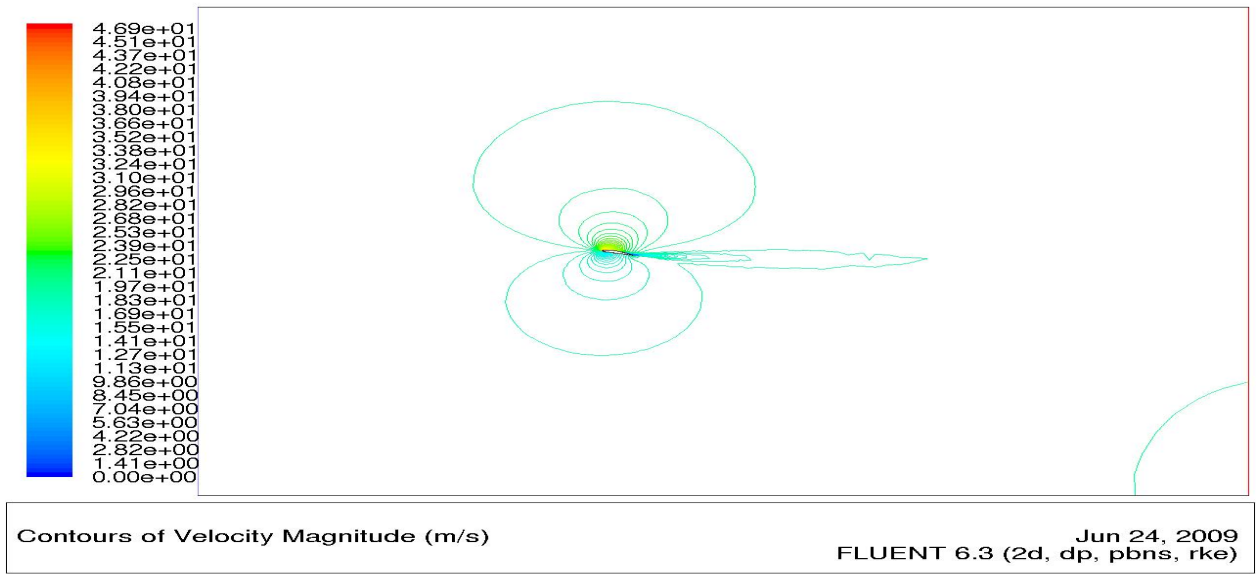

(c)

Figure A.6. (a)Static Pressure (b)Dynamic Pressure (c)Velocity Magnitude Contour Plot for Sig Kadet Airfoil at alpha 12 degrees. 


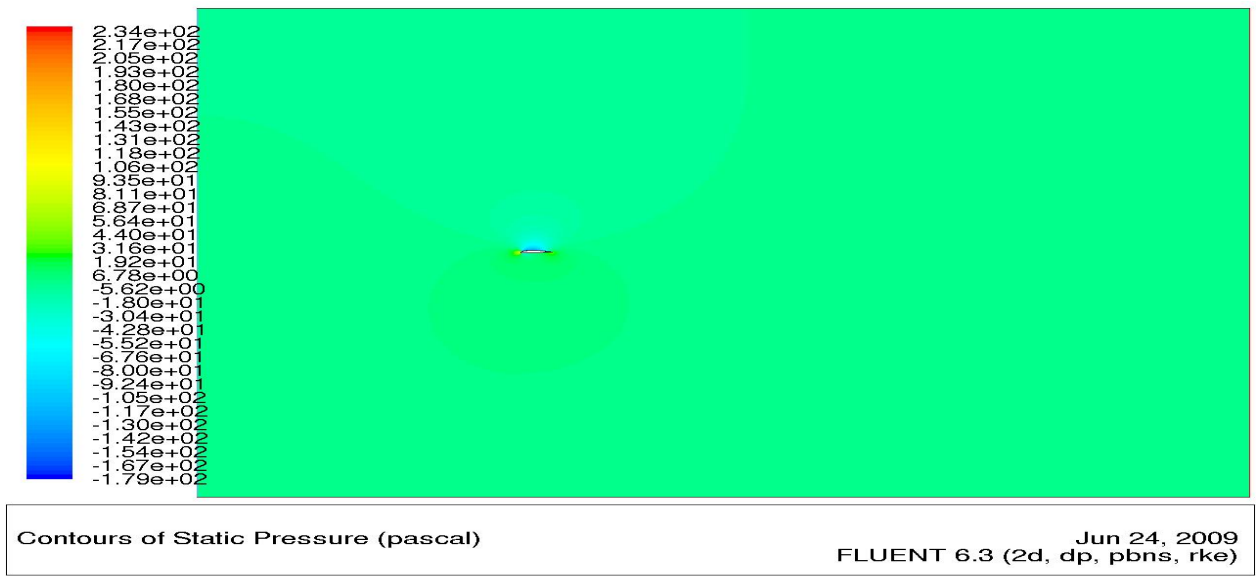

(a)

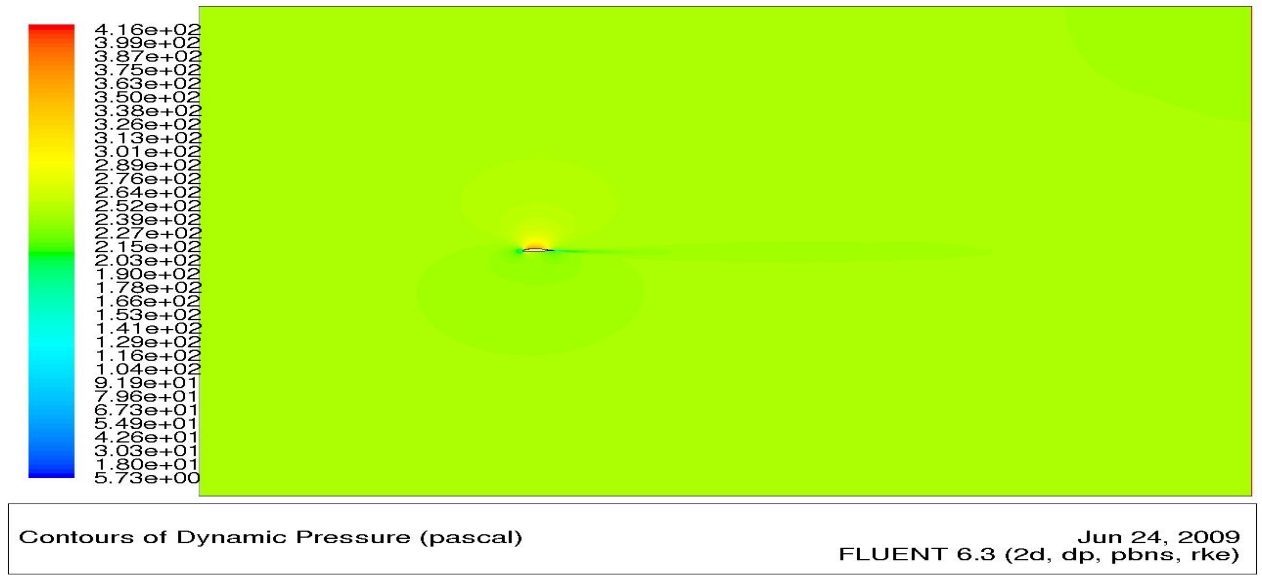

(b)

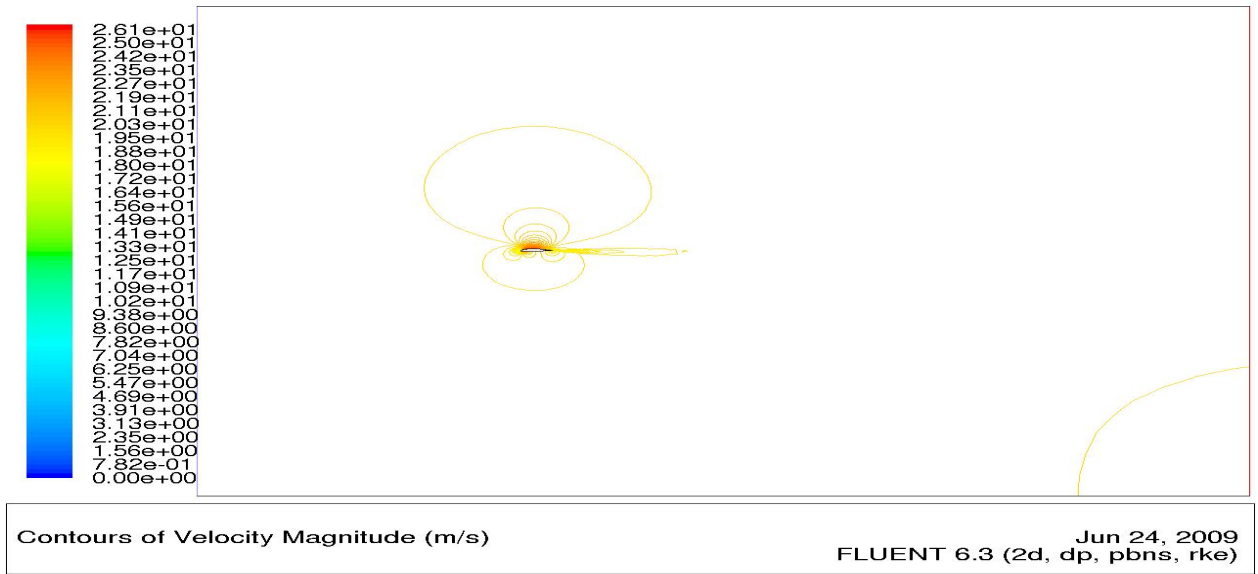

(c)

Figure A.7. (a)Static Pressure (b)Dynamic Pressure (c)Velocity Magnitude Contour Plot for Sig Kadet Airfoil at alpha (-)2 degrees. 


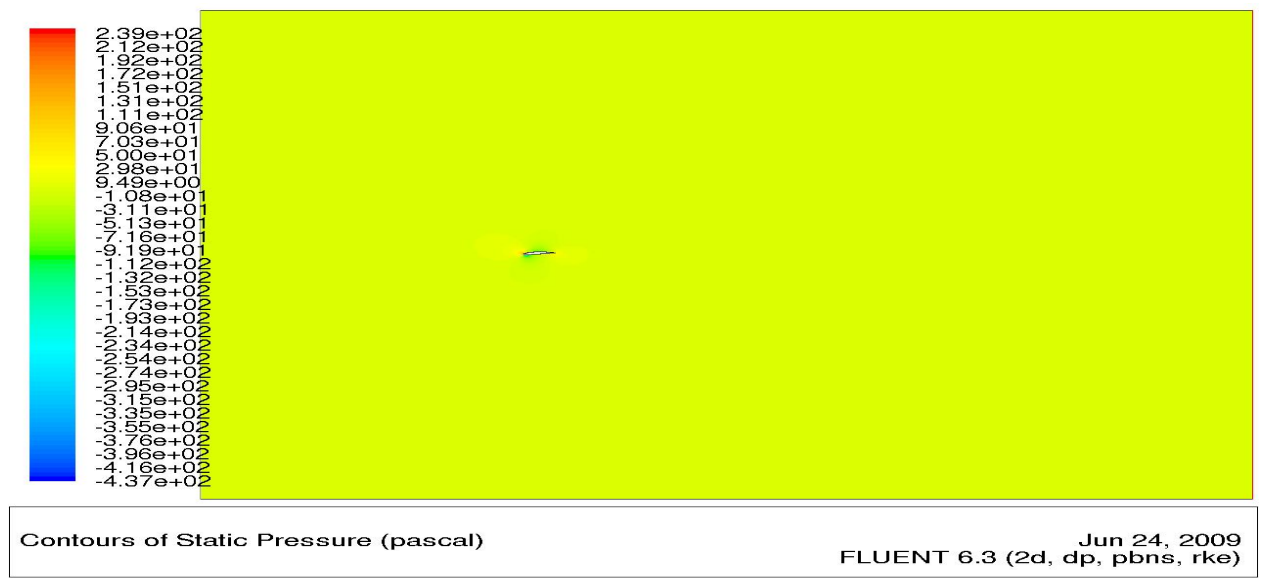

(a)

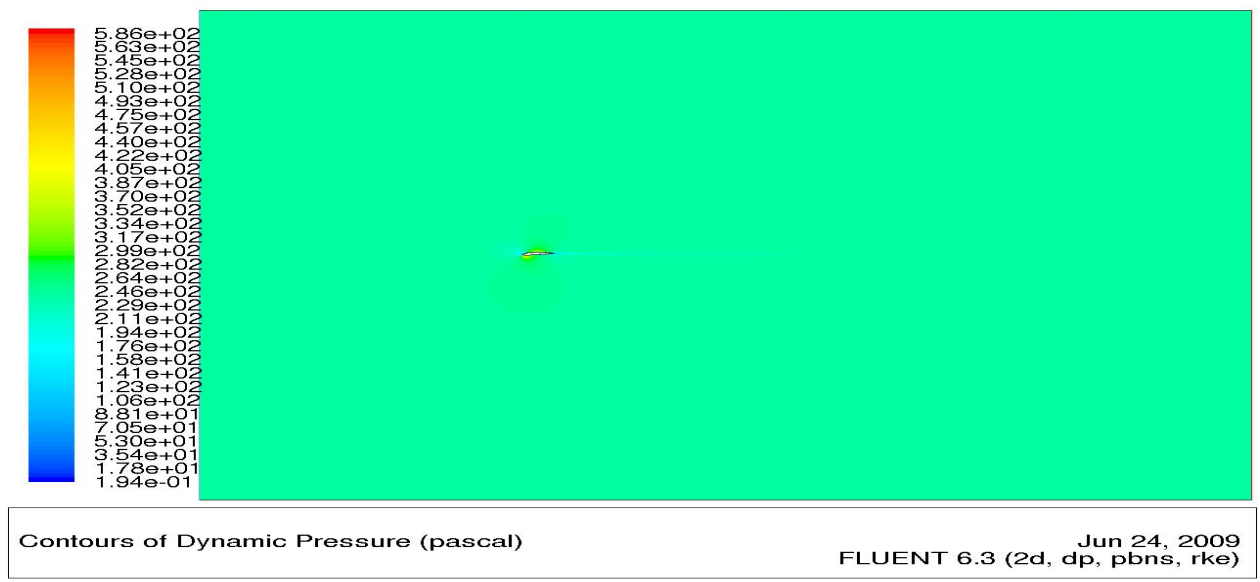

(b)

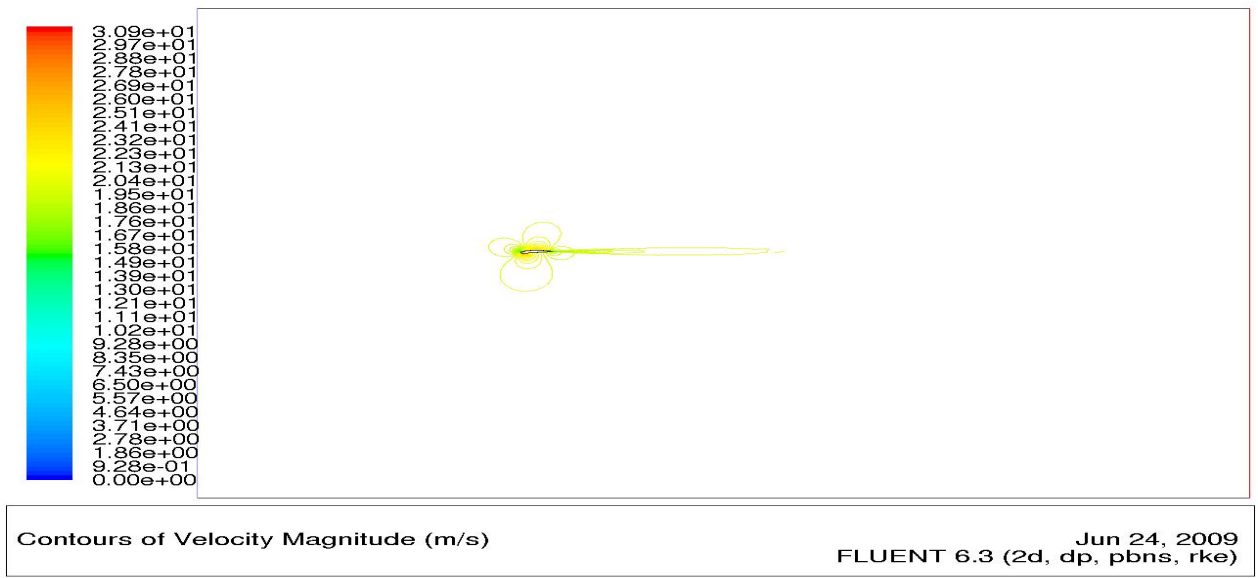

(c)

Figure A.8. (a)Static Pressure (b)Dynamic Pressure (c)Velocity Magnitude Contour Plot for Sig Kadet Airfoil at alpha (-)6 degrees. 

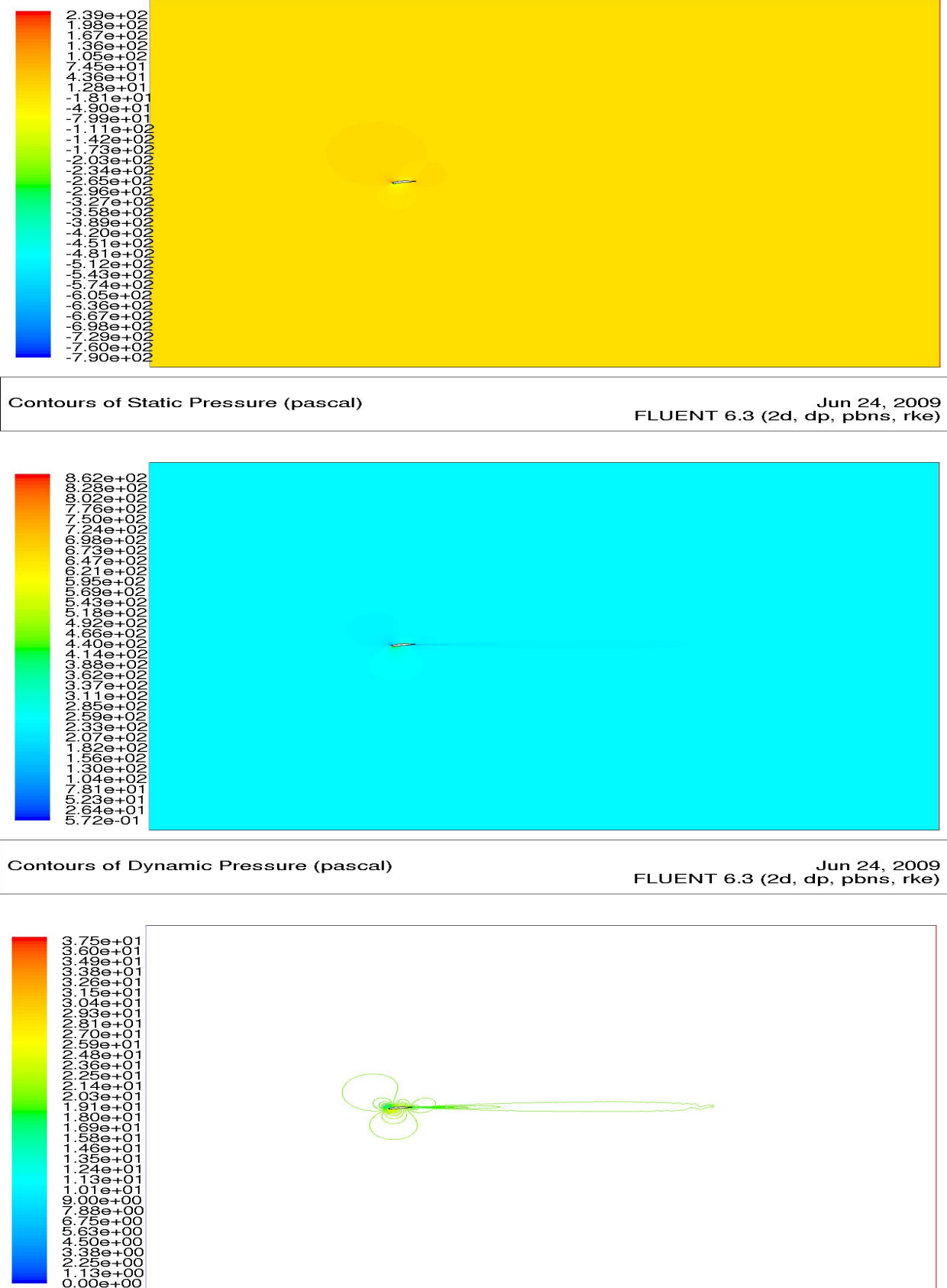

Figure A.9. (a)Static Pressure (b)Dynamic Pressure (c)Velocity Magnitude Contour Plot for Sig Kadet Airfoil at alpha (-)8 degrees. 


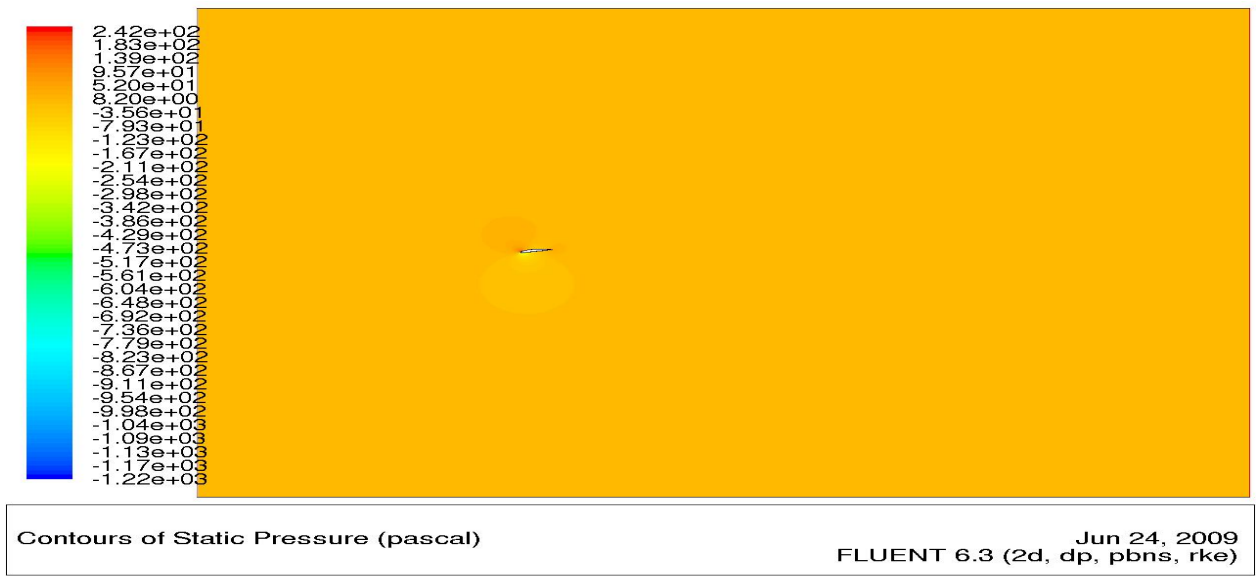

(a)

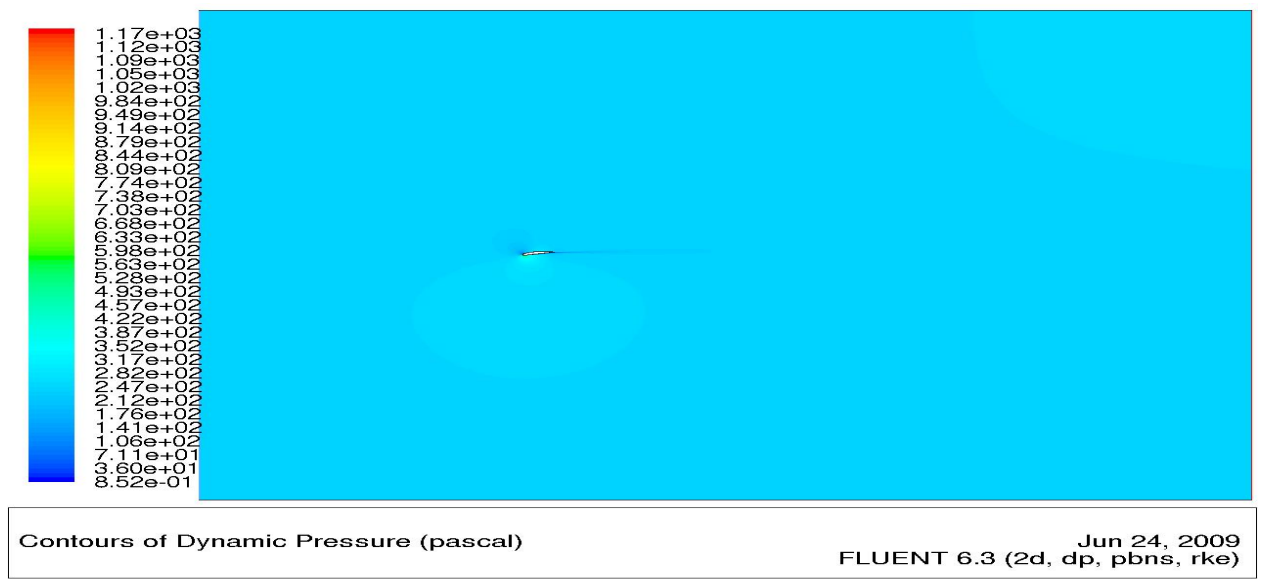

(b)

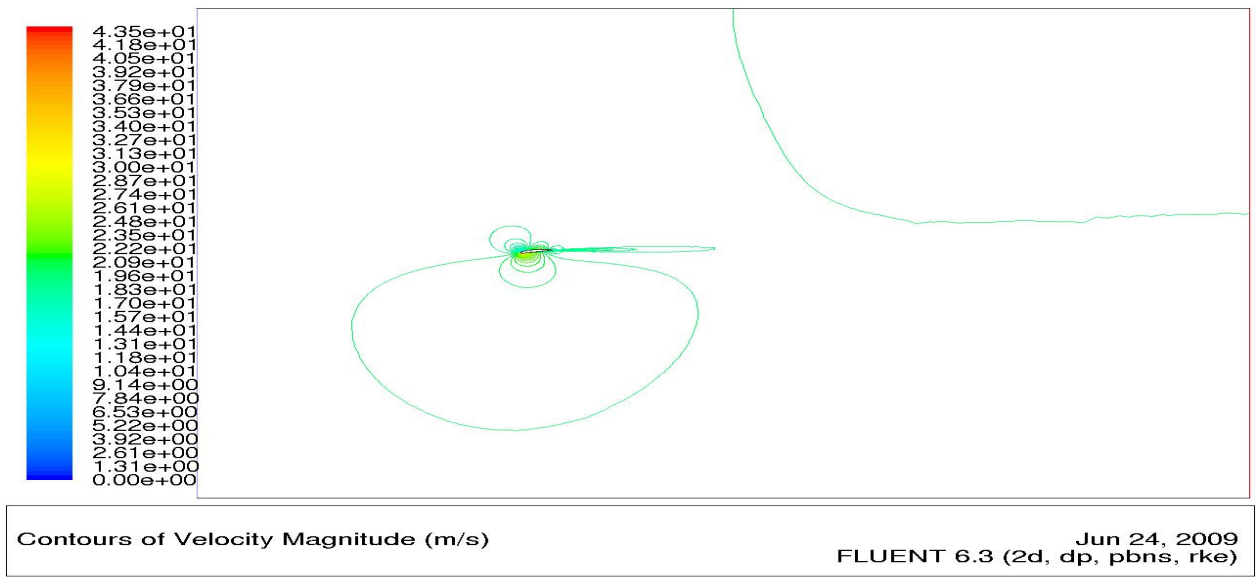

(c)

Figure A.10. (a)Static Pressure (b)Dynamic Pressure (c)Velocity Magnitude Contour Plot for Sig Kadet Airfoil at alpha (-)10 degrees. 


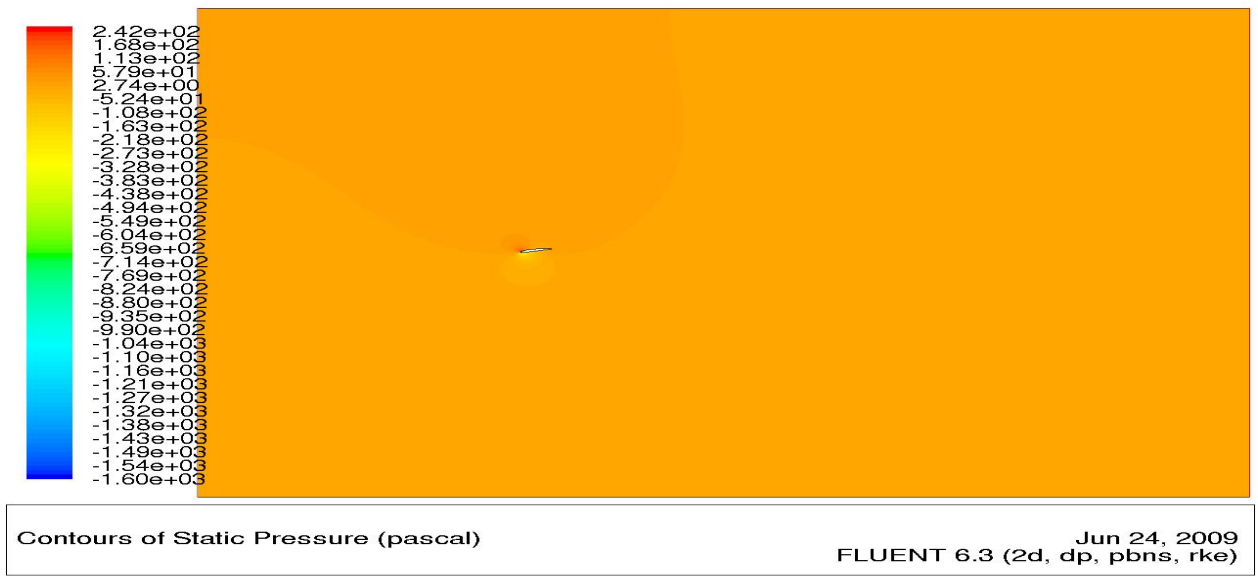

(a)

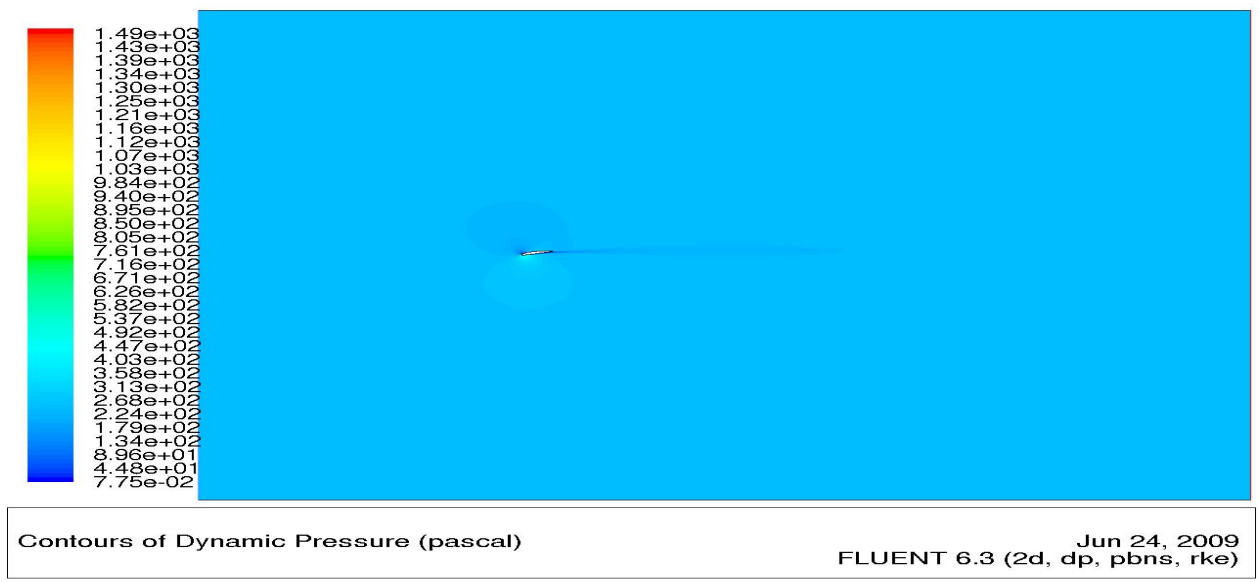

(b)

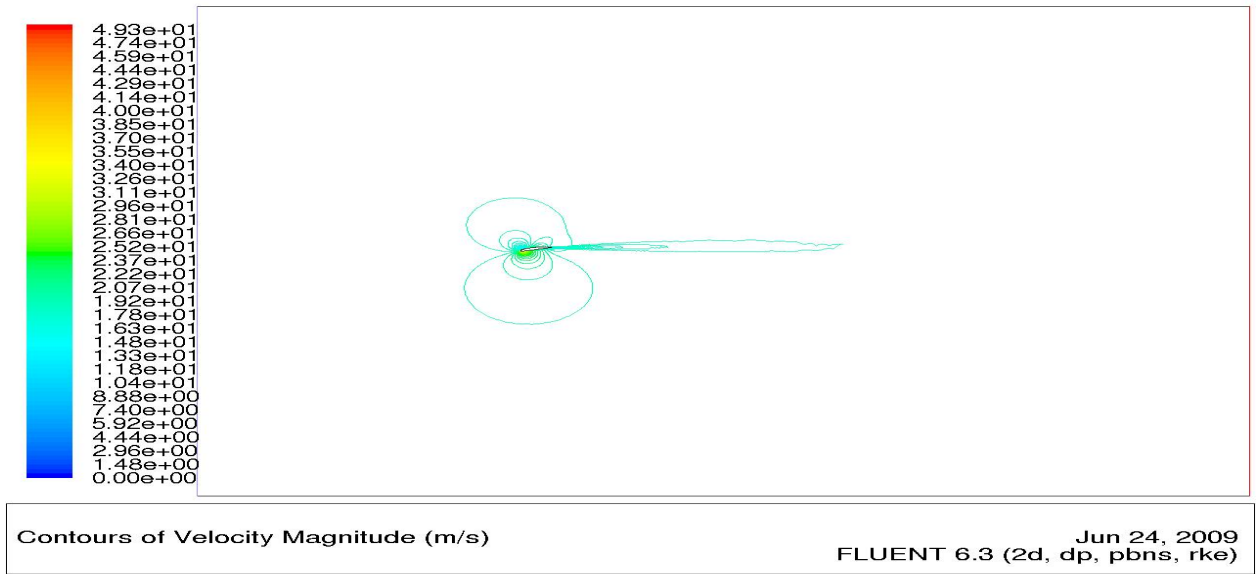

(c)

Figure A.11. (a)Static Pressure (b)Dynamic Pressure (c)Velocity Magnitude Contour Plot for Sig Kadet Airfoil at alpha (-)12 degrees. 
APPENDIX B

\section{AERODYNAMIC COEFFICIENT RESULTS}


Summary of Flow Characteristics Used:

Relative Airspeed: $20 \mathrm{~m} / \mathrm{s}$

Density of Air: $1.225 \mathrm{~kg} / \mathrm{m}^{3}$

Viscosity of Air: $1.7894 e^{-5} \mathrm{~kg} /(\mathrm{m} . \mathrm{s})$

Reynolds Number: 527,132

Chord Length: $385 \mathrm{~mm}$

Wing Span: $2.04 \mathrm{~m}$

Planform Area: $0.7854 \mathrm{~m}^{2}$

Turbulent Intensity: 0.04\%

Turbulent Length Scale: $1 e^{-6} \mathrm{~mm}$

Operating Pressure: $101325 \mathrm{~Pa}$

Gauge Pressure: $0 P a$

Note: Half wing span is used to calculate the rolling and yawing moment coefficient while chord length is used to calculate the pitching moment coefficient. Chord Length is used as the reference length for Reynolds Number calculation.

Table B.1. Aerodynamic Coefficients vs Side Slip Angle for (-)8 degrees Angle of Attack

\begin{tabular}{|c|c|c|c|c|c|c|}
\hline \multirow{3}{*}{ Beta } & \multicolumn{5}{|c|}{ Coefficients } \\
\cline { 2 - 7 } & \multicolumn{3}{|c|}{ Forces $N$} & \multicolumn{3}{c|}{ Moments N.m } \\
\cline { 2 - 7 } & Drag & Side & Lift & Rolling & Pitching & Yawing \\
\hline-4 & $8.84 \mathrm{E}-02$ & $3.36 \mathrm{E}-02$ & $-2.66 \mathrm{E}-01$ & $1.16 \mathrm{E}-02$ & $5.14 \mathrm{E}-01$ & $-3.47 \mathrm{E}-02$ \\
\hline-2 & $8.58 \mathrm{E}-02$ & $1.57 \mathrm{E}-02$ & $-2.73 \mathrm{E}-01$ & $5.52 \mathrm{E}-03$ & $5.17 \mathrm{E}-01$ & $-1.62 \mathrm{E}-02$ \\
\hline 0 & $8.63 \mathrm{E}-02$ & $1.14 \mathrm{E}-04$ & $-2.72 \mathrm{E}-01$ & $7.64 \mathrm{E}-05$ & $5.14 \mathrm{E}-01$ & $6.41 \mathrm{E}-05$ \\
\hline 2 & $8.65 \mathrm{E}-02$ & $-1.65 \mathrm{E}-02$ & $-2.71 \mathrm{E}-01$ & $-5.43 \mathrm{E}-03$ & $5.16 \mathrm{E}-01$ & $1.80 \mathrm{E}-02$ \\
\hline 4 & $8.95 \mathrm{E}-02$ & $-3.40 \mathrm{E}-02$ & $-2.69 \mathrm{E}-01$ & $-1.18 \mathrm{E}-02$ & $5.16 \mathrm{E}-01$ & $3.57 \mathrm{E}-02$ \\
\hline
\end{tabular}


Table B.2. Aerodynamic Coefficients vs Side Slip Angle for (-)4 degrees Angle of Attack

\begin{tabular}{|c|c|c|c|c|c|c|}
\hline \multirow{3}{*}{ Beta } & \multicolumn{5}{|c|}{ Coefficients } \\
\cline { 2 - 7 } & \multicolumn{3}{|c|}{ Forces $N$} & \multicolumn{3}{c|}{ Moments N.m } \\
\hline-4 & Drag & Side & Lift & Rolling & Pitching & Yawing \\
\hline-2 & $6.19 \mathrm{E}-02$ & $3.57 \mathrm{E}-02$ & $3.64 \mathrm{E}-02$ & $1.19 \mathrm{E}-02$ & $4.07 \mathrm{E}-02$ & $-3.18 \mathrm{E}-02$ \\
\hline 0 & $5.84 \mathrm{E}-02$ & $-1.75 \mathrm{E}-02$ & $4.00 \mathrm{E}-02$ & $5.67 \mathrm{E}-03$ & $3.60 \mathrm{E}-02$ & $-1.58 \mathrm{E}-02$ \\
\hline 2 & $5.95 \mathrm{E}-02$ & $-1.74 \mathrm{E}-02$ & $3.73 \mathrm{E}-02$ & $-5.30 \mathrm{E}-04$ & $4.04 \mathrm{E}-02$ & $3.91 \mathrm{E}-04$ \\
\hline 4 & $6.21 \mathrm{E}-02$ & $-3.60 \mathrm{E}-02$ & $3.75 \mathrm{E}-02$ & $-6.09 \mathrm{E}-03$ & $3.87 \mathrm{E}-02$ & $1.63 \mathrm{E}-02$ \\
\hline
\end{tabular}

Table B.3. Aerodynamic Coefficients vs Side Slip Angle for 0 degrees Angle of Attack

\begin{tabular}{|c|c|c|c|c|c|c|}
\hline \multirow{3}{*}{ Beta } & \multicolumn{5}{|c|}{ Coefficients } \\
\cline { 2 - 7 } & \multicolumn{3}{|c|}{ Forces $N$} & \multicolumn{3}{c|}{ Moments N.m } \\
\hline 4 & Drag & Side & Lift & Rolling & Pitching & Yawing \\
\hline 2 & $6.15 \mathrm{E}-02$ & $-3.41 \mathrm{E}-02$ & $3.60 \mathrm{E}-01$ & $-1.18 \mathrm{E}-02$ & $-4.58 \mathrm{E}-01$ & $3.05 \mathrm{E}-02$ \\
\hline 0 & $5.91 \mathrm{E}-02$ & $-1.68 \mathrm{E}-02$ & $3.62 \mathrm{E}-01$ & $-5.75 \mathrm{E}-03$ & $-4.64 \mathrm{E}-01$ & $1.47 \mathrm{E}-02$ \\
\hline-2 & $5.84 \mathrm{E}-02$ & $3.46 \mathrm{E}-04$ & $3.62 \mathrm{E}-01$ & $3.80 \mathrm{E}-04$ & $-4.65 \mathrm{E}-01$ & $-6.95 \mathrm{E}-05$ \\
\hline-4 & $6.94 \mathrm{E}-02$ & $1.70 \mathrm{E}-02$ & $3.62 \mathrm{E}-01$ & $5.82 \mathrm{E}-03$ & $-4.63 \mathrm{E}-01$ & $-1.47 \mathrm{E}-02$ \\
\hline
\end{tabular}

Table B.4. Aerodynamic Coefficients vs Side Slip Angle for 4 degrees Angle of Attack

\begin{tabular}{|c|c|c|c|c|c|c|}
\hline \multirow{3}{*}{ Beta } & \multicolumn{6}{|c|}{ Coefficients } \\
\cline { 2 - 7 } & \multicolumn{3}{|c|}{ Forces $N$} & \multicolumn{3}{c|}{ Moments N.m } \\
\cline { 2 - 7 } & Drag & Side & Lift & Rolling & Pitching & Yawing \\
\hline 4 & $8.26 \mathrm{E}-02$ & $-3.14 \mathrm{E}-02$ & $6.85 \mathrm{E}-01$ & $-1.39 \mathrm{E}-02$ & $-9.76 \mathrm{E}-01$ & $2.72 \mathrm{E}-02$ \\
\hline 2 & $8.08 \mathrm{E}-02$ & $-1.57 \mathrm{E}-02$ & $6.90 \mathrm{E}-01$ & $-7.23 \mathrm{E}-03$ & $-9.86 \mathrm{E}-01$ & $1.32 \mathrm{E}-02$ \\
\hline 0 & $7.97 \mathrm{E}-02$ & $4.64 \mathrm{E}-04$ & $6.89 \mathrm{E}-01$ & $1.64 \mathrm{E}-04$ & $-9.85 \mathrm{E}-01$ & $-1.53 \mathrm{E}-04$ \\
\hline-2 & $8.05 \mathrm{E}-02$ & $1.55 \mathrm{E}-02$ & $6.87 \mathrm{E}-01$ & $7.43 \mathrm{E}-03$ & $-9.83 \mathrm{E}-01$ & $-1.28 \mathrm{E}-02$ \\
\hline-4 & $8.21 \mathrm{E}-02$ & $3.18 \mathrm{E}-02$ & $6.85 \mathrm{E}-01$ & $1.41 \mathrm{E}-02$ & $-9.77 \mathrm{E}-01$ & $-2.78 \mathrm{E}-02$ \\
\hline
\end{tabular}


Table B.5. Aerodynamic Coefficients vs Side Slip Angle for 8 degrees Angle of Attack

\begin{tabular}{|c|c|c|c|c|c|c|}
\hline \multirow{3}{*}{ Beta } & \multicolumn{6}{|c|}{ Coefficients } \\
\cline { 2 - 7 } & \multicolumn{3}{|c|}{ Forces $N$} & \multicolumn{3}{c|}{ Moments N.m } \\
\cline { 2 - 7 } & Drag & Side & Lift & Rolling & Pitching & Yawing \\
\hline 4 & $1.25 \mathrm{E}-01$ & $-2.99 \mathrm{E}-02$ & $1.01 \mathrm{E}+00$ & $-1.55 \mathrm{E}-02$ & $-1.51 \mathrm{E}+00$ & $2.64 \mathrm{E}-02$ \\
\hline 2 & $1.23 \mathrm{E}-01$ & $-1.54 \mathrm{E}-02$ & $1.02 \mathrm{E}+00$ & $-7.74 \mathrm{E}-03$ & $-1.53 \mathrm{E}+00$ & $1.27 \mathrm{E}-02$ \\
\hline 0 & $1.23 \mathrm{E}-01$ & $-3.09 \mathrm{E}-04$ & $1.02 \mathrm{E}+00$ & $1.17 \mathrm{E}-03$ & $-1.53 \mathrm{E}+00$ & $-3.67 \mathrm{E}-04$ \\
\hline-2 & $1.24 \mathrm{E}-01$ & $1.63 \mathrm{E}-02$ & $1.02 \mathrm{E}+00$ & $7.56 \mathrm{E}-03$ & $-1.53 \mathrm{E}+00$ & $-1.53 \mathrm{E}-02$ \\
\hline-4 & $1.25 \mathrm{E}-01$ & $3.78 \mathrm{E}-02$ & $1.01 \mathrm{E}+00$ & $1.67 \mathrm{E}-02$ & $-1.51 \mathrm{E}+00$ & $-3.24 \mathrm{E}-02$ \\
\hline
\end{tabular}

Table B.6. Aerodynamic Coefficients vs Rudder Deflection for (-)8 degrees Angle of Attack

\begin{tabular}{|c|c|c|c|c|c|c|}
\hline \multirow{3}{*}{$\begin{array}{c}\text { Rudder } \\
\text { Deflection }\end{array}$} & \multicolumn{6}{|c|}{ Coefficients } \\
\cline { 2 - 7 } & Drag & Side & Lift & Rolling & Pitching & Yawing \\
\hline-25 & $9.60 \mathrm{E}-02$ & $6.69 \mathrm{E}-02$ & $-2.64 \mathrm{E}-01$ & $8.13 \mathrm{E}-03$ & $5.06 \mathrm{E}-01$ & $-9.15 \mathrm{E}-02$ \\
\hline-15 & $8.96 \mathrm{E}-02$ & $4.18 \mathrm{E}-02$ & $-2.68 \mathrm{E}-01$ & $4.98 \mathrm{E}-03$ & $5.10 \mathrm{E}-01$ & $-5.63 \mathrm{E}-02$ \\
\hline-5 & $8.66 \mathrm{E}-02$ & $1.40 \mathrm{E}-02$ & $-2.71 \mathrm{E}-01$ & $1.12 \mathrm{E}-03$ & $5.15 \mathrm{E}-01$ & $-1.87 \mathrm{E}-02$ \\
\hline 0 & $8.63 \mathrm{E}-02$ & $1.14 \mathrm{E}-04$ & $-2.72 \mathrm{E}-01$ & $7.64 \mathrm{E}-05$ & $5.14 \mathrm{E}-01$ & $6.41 \mathrm{E}-05$ \\
\hline 5 & $8.65 \mathrm{E}-02$ & $-1.25 \mathrm{E}-02$ & $-2.70 \mathrm{E}-01$ & $-1.63 \mathrm{E}-03$ & $5.12 \mathrm{E}-01$ & $1.85 \mathrm{E}-02$ \\
\hline 15 & $9.03 \mathrm{E}-02$ & $-3.90 \mathrm{E}-02$ & $-2.69 \mathrm{E}-01$ & $-3.99 \mathrm{E}-03$ & $5.14 \mathrm{E}-01$ & $5.56 \mathrm{E}-02$ \\
\hline 25 & $9.69 \mathrm{E}-02$ & $-6.54 \mathrm{E}-02$ & $-2.67 \mathrm{E}-01$ & $-7.38 \mathrm{E}-03$ & $5.09 \mathrm{E}-01$ & $9.19 \mathrm{E}-02$ \\
\hline
\end{tabular}

Table B.7. Aerodynamic Coefficients vs Rudder Deflection for (-)4 degrees Angle of Attack

\begin{tabular}{|c|c|c|c|c|c|c|}
\hline \multirow{3}{*}{$\begin{array}{c}\text { Rudder } \\
\text { Deflection }\end{array}$} & \multicolumn{5}{|c|}{ Coefficients } \\
\cline { 2 - 7 } & \multicolumn{3}{|c|}{ Forces $N$} & \multicolumn{3}{c|}{ Moments $N . m$} \\
\hline-25 & $6.85 \mathrm{E}-02$ & $6.74 \mathrm{E}-02$ & $4.09 \mathrm{E}-02$ & $6.69 \mathrm{E}-03$ & $3.53 \mathrm{E}-02$ & $-9.35 \mathrm{E}-02$ \\
\hline-15 & $6.18 \mathrm{E}-02$ & $4.07 \mathrm{E}-02$ & $3.84 \mathrm{E}-02$ & $3.97 \mathrm{E}-03$ & $3.91 \mathrm{E}-02$ & $-5.68 \mathrm{E}-02$ \\
\hline-5 & $5.86 \mathrm{E}-02$ & $1.35 \mathrm{E}-02$ & $3.75 \mathrm{E}-02$ & $1.20 \mathrm{E}-03$ & $3.93 \mathrm{E}-02$ & $-1.86 \mathrm{E}-02$ \\
\hline 0 & $5.84 \mathrm{E}-02$ & $-1.47 \mathrm{E}-04$ & $3.73 \mathrm{E}-02$ & $-5.30 \mathrm{E}-04$ & $4.04 \mathrm{E}-02$ & $3.91 \mathrm{E}-04$ \\
\hline 5 & $5.86 \mathrm{E}-02$ & $-1.37 \mathrm{E}-02$ & $3.82 \mathrm{E}-02$ & $-1.40 \mathrm{E}-03$ & $3.86 \mathrm{E}-02$ & $1.89 \mathrm{E}-02$ \\
\hline 15 & $6.22 \mathrm{E}-02$ & $-4.11 \mathrm{E}-02$ & $4.00 \mathrm{E}-02$ & $-4.14 \mathrm{E}-03$ & $3.43 \mathrm{E}-02$ & $5.75 \mathrm{E}-02$ \\
\hline 25 & $6.86 \mathrm{E}-02$ & $-6.82 \mathrm{E}-02$ & $4.19 \mathrm{E}-02$ & $-6.69 \mathrm{E}-03$ & $3.30 \mathrm{E}-02$ & $9.48 \mathrm{E}-02$ \\
\hline
\end{tabular}


Table B.8. Aerodynamic Coefficients vs Rudder Deflection for 0 degrees Angle of Attack

\begin{tabular}{|c|c|c|c|c|c|c|}
\hline \multirow{3}{*}{$\begin{array}{c}\text { Rudder } \\
\text { Deflection }\end{array}$} & \multicolumn{6}{|c|}{ Coefficients } \\
\cline { 2 - 7 } & Drag & Side & Lift & Rolling & Pitching & Yawing \\
\hline-25 & $6.87 \mathrm{E}-02$ & $6.69 \mathrm{E}-02$ & $3.65 \mathrm{E}-01$ & $6.03 \mathrm{E}-03$ & $-4.69 \mathrm{E}-01$ & $-9.36 \mathrm{E}-02$ \\
\hline-15 & $6.23 \mathrm{E}-02$ & $3.99 \mathrm{E}-02$ & $3.64 \mathrm{E}-01$ & $3.65 \mathrm{E}-03$ & $-4.67 \mathrm{E}-01$ & $-5.58 \mathrm{E}-02$ \\
\hline-5 & $5.89 \mathrm{E}-02$ & $1.25 \mathrm{E}-02$ & $3.62 \mathrm{E}-01$ & $9.86 \mathrm{E}-04$ & $-4.65 \mathrm{E}-01$ & $-1.81 \mathrm{E}-02$ \\
\hline 0 & $5.84 \mathrm{E}-02$ & $3.46 \mathrm{E}-04$ & $3.62 \mathrm{E}-01$ & $3.80 \mathrm{E}-04$ & $-4.65 \mathrm{E}-01$ & $-6.95 \mathrm{E}-05$ \\
\hline 5 & $5.89 \mathrm{E}-02$ & $-1.43 \mathrm{E}-02$ & $3.63 \mathrm{E}-01$ & $-1.34 \mathrm{E}-03$ & $-4.66 \mathrm{E}-01$ & $1.96 \mathrm{E}-02$ \\
\hline 15 & $6.20 \mathrm{E}-02$ & $-4.24 \mathrm{E}-02$ & $3.64 \mathrm{E}-01$ & $-3.92 \mathrm{E}-03$ & $-4.68 \mathrm{E}-01$ & $5.79 \mathrm{E}-02$ \\
\hline 25 & $6.88 \mathrm{E}-02$ & $-6.81 \mathrm{E}-02$ & $3.65 \mathrm{E}-01$ & $-6.16 \mathrm{E}-03$ & $-4.70 \mathrm{E}-01$ & $9.37 \mathrm{E}-02$ \\
\hline
\end{tabular}

Table B.9. Aerodynamic Coefficients vs Rudder Deflection for 4 degrees Angle of Attack

\begin{tabular}{|c|c|c|c|c|c|c|}
\hline \multirow{3}{*}{$\begin{array}{c}\text { Rudder } \\
\text { Deflection }\end{array}$} & \multicolumn{6}{|c|}{ Coefficients } \\
\cline { 2 - 7 } & Drag & Side & Lift & Rolling & Pitching & Yawing \\
\hline-25 & $8.93 \mathrm{E}-02$ & $6.28 \mathrm{E}-02$ & $6.91 \mathrm{E}-01$ & $6.12 \mathrm{E}-03$ & $-9.90 \mathrm{E}-01$ & $-8.79 \mathrm{E}-02$ \\
\hline-15 & $8.34 \mathrm{E}-02$ & $3.78 \mathrm{E}-02$ & $6.90 \mathrm{E}-01$ & $3.48 \mathrm{E}-03$ & $-9.88 \mathrm{E}-01$ & $-5.34 \mathrm{E}-02$ \\
\hline-5 & $8.04 \mathrm{E}-02$ & $1.16 \mathrm{E}-02$ & $6.89 \mathrm{E}-01$ & $1.25 \mathrm{E}-03$ & $-9.86 \mathrm{E}-01$ & $-1.69 \mathrm{E}-02$ \\
\hline 0 & $7.97 \mathrm{E}-02$ & $4.64 \mathrm{E}-04$ & $6.89 \mathrm{E}-01$ & $1.64 \mathrm{E}-04$ & $-9.85 \mathrm{E}-01$ & $-1.53 \mathrm{E}-04$ \\
\hline 5 & $7.95 \mathrm{E}-02$ & $-1.43 \mathrm{E}-02$ & $6.90 \mathrm{E}-01$ & $-1.09 \mathrm{E}-03$ & $-9.89 \mathrm{E}-01$ & $1.83 \mathrm{E}-02$ \\
\hline 15 & $8.32 \mathrm{E}-02$ & $-4.01 \mathrm{E}-02$ & $6.91 \mathrm{E}-01$ & $-3.70 \mathrm{E}-03$ & $-9.91 \mathrm{E}-01$ & $5.47 \mathrm{E}-02$ \\
\hline 25 & $8.89 \mathrm{E}-02$ & $-6.38 \mathrm{E}-02$ & $6.91 \mathrm{E}-01$ & $-4.72 \mathrm{E}-03$ & $-9.92 \mathrm{E}-01$ & $8.74 \mathrm{E}-02$ \\
\hline
\end{tabular}


Table B.10. Aerodynamic Coefficients vs Rudder Deflection for 8 degrees Angle of Attack

\begin{tabular}{|c|c|c|c|c|c|c|}
\hline \multirow{3}{*}{$\begin{array}{l}\text { Rudder } \\
\text { Deflection }\end{array}$} & \multicolumn{6}{|c|}{ Coefficients } \\
\hline & \multicolumn{3}{|c|}{ Forces $N$} & \multicolumn{3}{|c|}{ Moments N.m } \\
\hline & Drag & Side & Lift & Rolling & Pitching & Yawing \\
\hline-25 & $1.32 \mathrm{E}-01$ & $6.32 \mathrm{E}-02$ & $1.02 \mathrm{E}+00$ & $5.80 \mathrm{E}-03$ & $-1.53 \mathrm{E}+00$ & -9.08 \\
\hline-15 & 01 & $3.73 \mathrm{E}$ & $1.02 \mathrm{E}+00$ & & -1.5 & \\
\hline-5 & $23 \mathrm{E}$ & 1.06 & $1.02 \mathrm{E}+00$ & $-8.67 \mathrm{E}-05$ & $-1.53 \mathrm{E}+00$ & -1.8 \\
\hline 0 & 1 & $-3.09 \mathrm{E}$ & $1.02 \mathrm{E}+00$ & $1.17 \mathrm{E}$ & $-1.53 \mathrm{E}+00$ & $-3.67 \mathrm{E}-04$ \\
\hline 5 & $1.23 \mathrm{E}$ & $-1.56 \mathrm{E}-02$ & $1.02 \mathrm{E}+00$ & $-4.16 \mathrm{E}-04$ & $-1.53 \mathrm{E}+00$ & $1.88 \mathrm{E}-02$ \\
\hline 15 & $1.26 \mathrm{E}-01$ & $-4.10 \mathrm{E}-02$ & $1.02 \mathrm{E}+00$ & $-2.59 \mathrm{E}-03$ & $-1.53 \mathrm{E}+00$ & $5.43 \mathrm{E}-02$ \\
\hline 25 & $1.32 \mathrm{E}-01$ & $-6.48 \mathrm{E}-02$ & $1.02 \mathrm{E}+00$ & $-4.93 \mathrm{E}-03$ & $-1.54 \mathrm{E}+00$ & $8.68 \mathrm{E}-02$ \\
\hline
\end{tabular}

Table B.11. Aerodynamic Coefficients vs Ailerons Deflection for (-)8 degrees Angle of Attack

\begin{tabular}{|c|c|c|c|c|c|c|}
\hline \multirow{2}{*}{$\begin{array}{c}\text { Ailerons } \\
\text { Deflection }\end{array}$} & \multicolumn{6}{|c|}{ Coefficients } \\
\cline { 2 - 7 } & Drag & Side & Lift & Rolling & Pitching & Yawing \\
\hline-25 & $1.40 \mathrm{E}-01$ & $1.58 \mathrm{E}-02$ & $-2.83 \mathrm{E}-01$ & $2.82 \mathrm{E}-01$ & $5.83 \mathrm{E}-01$ & $-2.48 \mathrm{E}-02$ \\
\hline-15 & $1.07 \mathrm{E}-01$ & $1.04 \mathrm{E}-02$ & $-2.95 \mathrm{E}-01$ & $1.75 \mathrm{E}-01$ & $5.72 \mathrm{E}-01$ & $-1.50 \mathrm{E}-02$ \\
\hline-5 & $9.05 \mathrm{E}-02$ & $3.99 \mathrm{E}-03$ & $-2.92 \mathrm{E}-01$ & $5.89 \mathrm{E}-02$ & $5.58 \mathrm{E}-01$ & $-4.93 \mathrm{E}-03$ \\
\hline 0 & $8.63 \mathrm{E}-02$ & $1.14 \mathrm{E}-04$ & $-2.72 \mathrm{E}-01$ & $7.64 \mathrm{E}-05$ & $5.14 \mathrm{E}-01$ & $6.41 \mathrm{E}-05$ \\
\hline 5 & $9.04 \mathrm{E}-02$ & $-2.40 \mathrm{E}-03$ & $-2.96 \mathrm{E}-01$ & $-5.92 \mathrm{E}-02$ & $5.58 \mathrm{E}-01$ & $4.52 \mathrm{E}-03$ \\
\hline 15 & $1.07 \mathrm{E}-01$ & $-7.98 \mathrm{E}-03$ & $-2.95 \mathrm{E}-01$ & $-1.75 \mathrm{E}-01$ & $5.72 \mathrm{E}-01$ & $1.41 \mathrm{E}-02$ \\
\hline 25 & $1.39 \mathrm{E}-01$ & $-1.51 \mathrm{E}-02$ & $-2.81 \mathrm{E}-01$ & $-2.81 \mathrm{E}-01$ & $5.76 \mathrm{E}-01$ & $2.53 \mathrm{E}-02$ \\
\hline
\end{tabular}


Table B.12. Aerodynamic Coefficients vs Ailerons Deflection for (-)4 degrees Angle of Attack

\begin{tabular}{|c|c|c|c|c|c|c|}
\hline \multirow{3}{*}{$\begin{array}{c}\text { Ailerons } \\
\text { Deflection }\end{array}$} & \multicolumn{6}{|c|}{ Coefficients } \\
\hline & \multicolumn{3}{|c|}{ Forces $N$} & \multicolumn{3}{|c|}{ Moments N.m } \\
\hline & Drag & Side & Lift & Rolling & Pitching & Yawing \\
\hline-25 & $1.14 \mathrm{E}-01$ & $1.65 \mathrm{E}-02$ & $2.04 \mathrm{E}-02$ & $2.92 \mathrm{E}-01$ & $9.56 \mathrm{E}-02$ & $-2.26 \mathrm{E}-02$ \\
\hline-15 & $7.92 \mathrm{E}-02$ & $1.01 \mathrm{E}-02$ & $1.70 \mathrm{E}-02$ & $1.80 \mathrm{E}-01$ & $8.41 \mathrm{E}-02$ & $-1.34 \mathrm{E}-02$ \\
\hline-5 & $6.12 \mathrm{E}-02$ & $3.48 \mathrm{E}-03$ & $1.56 \mathrm{E}-02$ & $6.09 \mathrm{E}-02$ & $8.01 \mathrm{E}-02$ & $-4.34 \mathrm{E}-03$ \\
\hline 0 & $5.84 \mathrm{E}-02$ & $-1.47 \mathrm{E}-04$ & $3.73 \mathrm{E}-02$ & $-5.30 \mathrm{E}-04$ & $4.04 \mathrm{E}-02$ & $3.91 \mathrm{E}-04$ \\
\hline 5 & $6.13 \mathrm{E}-02$ & $-3.36 \mathrm{E}-03$ & $1.44 \mathrm{E}-02$ & $-6.05 \mathrm{E}-02$ & $8.28 \mathrm{E}-02$ & $4.31 \mathrm{E}-03$ \\
\hline 15 & $7.88 \mathrm{E}-02$ & $-1.07 \mathrm{E}-02$ & $1.68 \mathrm{E}-02$ & $-1.80 \mathrm{E}-01$ & $8.37 \mathrm{E}-02$ & $1.40 \mathrm{E}-02$ \\
\hline 25 & $1.13 \mathrm{E}-01$ & $-1.69 \mathrm{E}-02$ & $2.13 \mathrm{E}-02$ & $-2.92 \mathrm{E}-01$ & $9.35 \mathrm{E}-02$ & $2.31 \mathrm{E}-02$ \\
\hline
\end{tabular}

Table B.13. Aerodynamic Coefficients vs Ailerons Deflection for 0 degrees Angle of Attack

\begin{tabular}{|c|c|c|c|c|c|c|}
\hline \multirow{3}{*}{$\begin{array}{c}\text { Ailerons } \\
\text { Deflection }\end{array}$} & \multicolumn{6}{|c|}{ Coefficients } \\
\cline { 2 - 7 } & Drag & Side & Lift & Rolling & Pitching & Yawing \\
\hline-25 & $1.14 \mathrm{E}-01$ & $1.72 \mathrm{E}-02$ & $3.44 \mathrm{E}-01$ & $2.97 \mathrm{E}-01$ & $-4.24 \mathrm{E}-01$ & $-2.18 \mathrm{E}-02$ \\
\hline-15 & $7.87 \mathrm{E}-02$ & $9.80 \mathrm{E}-03$ & $3.43 \mathrm{E}-01$ & $1.84 \mathrm{E}-01$ & $-4.27 \mathrm{E}-01$ & $-1.26 \mathrm{E}-02$ \\
\hline-5 & $6.05 \mathrm{E}-02$ & $2.67 \mathrm{E}-03$ & $3.41 \mathrm{E}-01$ & $6.22 \mathrm{E}-02$ & $-4.27 \mathrm{E}-01$ & $-3.48 \mathrm{E}-03$ \\
\hline 0 & $5.84 \mathrm{E}-02$ & $3.46 \mathrm{E}-04$ & $3.62 \mathrm{E}-01$ & $3.80 \mathrm{E}-04$ & $-4.65 \mathrm{E}-01$ & $-6.95 \mathrm{E}-05$ \\
\hline 5 & $6.07 \mathrm{E}-02$ & $-4.71 \mathrm{E}-03$ & $3.40 \mathrm{E}-01$ & $-6.22 \mathrm{E}-02$ & $-4.26 \mathrm{E}-01$ & $5.44 \mathrm{E}-03$ \\
\hline 15 & $7.86 \mathrm{E}-02$ & $-1.18 \mathrm{E}-02$ & $3.42 \mathrm{E}-01$ & $-1.84 \mathrm{E}-01$ & $-4.30 \mathrm{E}-01$ & $1.42 \mathrm{E}-02$ \\
\hline 25 & $1.13 \mathrm{E}-01$ & $-1.92 \mathrm{E}-02$ & $3.41 \mathrm{E}-01$ & $-2.96 \mathrm{E}-01$ & $-4.24 \mathrm{E}-01$ & $2.31 \mathrm{E}-02$ \\
\hline
\end{tabular}


Table B.14. Aerodynamic Coefficients vs Ailerons Deflection for 4 degrees Angle of Attack

\begin{tabular}{|c|c|c|c|c|c|c|}
\hline \multirow{2}{*}{$\begin{array}{c}\text { Ailerons } \\
\text { Deflection }\end{array}$} & \multicolumn{5}{|c|}{ Coefficients } \\
\cline { 2 - 7 } & Drag & Side & Lift & Rolling & Pitching & Yawing \\
\hline-25 & $1.33 \mathrm{E}-01$ & $1.96 \mathrm{E}-02$ & $6.63 \mathrm{E}-01$ & $3.02 \mathrm{E}-01$ & $-9.51 \mathrm{E}-01$ & $-2.20 \mathrm{E}-02$ \\
\hline-15 & $9.89 \mathrm{E}-02$ & $1.14 \mathrm{E}-02$ & $6.68 \mathrm{E}-01$ & $1.86 \mathrm{E}-01$ & $-9.58 \mathrm{E}-01$ & $-1.37 \mathrm{E}-02$ \\
\hline-5 & $8.10 \mathrm{E}-02$ & $2.66 \mathrm{E}-03$ & $6.66 \mathrm{E}-01$ & $6.25 \mathrm{E}-02$ & $-9.46 \mathrm{E}-01$ & $-3.87 \mathrm{E}-03$ \\
\hline 0 & $7.97 \mathrm{E}-02$ & $4.64 \mathrm{E}-04$ & $6.89 \mathrm{E}-01$ & $1.64 \mathrm{E}-04$ & $-9.85 \mathrm{E}-01$ & $-1.53 \mathrm{E}-04$ \\
\hline 5 & $8.15 \mathrm{E}-02$ & $-5.70 \mathrm{E}-03$ & $6.67 \mathrm{E}-01$ & $-6.31 \mathrm{E}-02$ & $-9.46 \mathrm{E}-01$ & $5.63 \mathrm{E}-03$ \\
\hline 15 & $9.90 \mathrm{E}-02$ & $-1.37 \mathrm{E}-02$ & $6.67 \mathrm{E}-01$ & $-1.86 \mathrm{E}-01$ & $-9.56 \mathrm{E}-01$ & $1.47 \mathrm{E}-02$ \\
\hline 25 & $1.33 \mathrm{E}-01$ & $-2.17 \mathrm{E}-02$ & $6.60 \mathrm{E}-01$ & $-2.99 \mathrm{E}-01$ & $-9.50 \mathrm{E}-01$ & $2.27 \mathrm{E}-02$ \\
\hline
\end{tabular}

Table B.15. Aerodynamic Coefficients vs Ailerons Deflection for 8 degrees Angle of Attack

\begin{tabular}{|c|c|c|c|c|c|c|}
\hline \multirow{2}{*}{$\begin{array}{c}\text { Ailerons } \\
\text { Deflection }\end{array}$} & \multicolumn{5}{|c|}{ Coefficients } \\
\cline { 2 - 7 } & Drag & Side & Lift & Rolling & Pitching & Yawing \\
\hline & $1.69 \mathrm{E}-01$ & $2.11 \mathrm{E}-02$ & $9.70 \mathrm{E}-01$ & $2.92 \mathrm{E}-01$ & $-1.46 \mathrm{E}+00$ & $-2.18 \mathrm{E}-02$ \\
\hline-25 & $1.39 \mathrm{E}-01$ & $1.18 \mathrm{E}-02$ & $9.94 \mathrm{E}-01$ & $1.83 \mathrm{E}-01$ & $-1.49 \mathrm{E}+00$ & $-1.36 \mathrm{E}-02$ \\
\hline-15 & $1.23 \mathrm{E}-01$ & $3.04 \mathrm{E}-03$ & $1.00 \mathrm{E}+00$ & $6.28 \mathrm{E}-02$ & $-1.49 \mathrm{E}+00$ & $-4.98 \mathrm{E}-03$ \\
\hline-5 & $1.23 \mathrm{E}-01$ & $-3.09 \mathrm{E}-04$ & $1.02 \mathrm{E}+00$ & $1.17 \mathrm{E}-03$ & $-1.53 \mathrm{E}+00$ & $-3.67 \mathrm{E}-04$ \\
\hline 0 & $1.23 \mathrm{E}-01$ & $-6.95 \mathrm{E}-03$ & $1.00 \mathrm{E}+00$ & $-6.20 \mathrm{E}-02$ & $-1.49 \mathrm{E}+00$ & $5.23 \mathrm{E}-03$ \\
\hline 5 & $1.40 \mathrm{E}-01$ & $-1.70 \mathrm{E}-02$ & $9.96 \mathrm{E}-01$ & $-1.84 \mathrm{E}-01$ & $-1.49 \mathrm{E}+00$ & $1.54 \mathrm{E}-02$ \\
\hline 15 & $1.70 \mathrm{E}-01$ & $-2.55 \mathrm{E}-02$ & $9.74 \mathrm{E}-01$ & $-2.93 \mathrm{E}-01$ & $-1.47 \mathrm{E}+00$ & $2.24 \mathrm{E}-02$ \\
\hline 25 & & & & & &
\end{tabular}


Table B.16. Aerodynamic Coefficients vs Elevator Deflection for (-)8 degrees Angle of Attack

\begin{tabular}{|c|c|c|c|c|c|c|}
\hline \multirow{2}{*}{$\begin{array}{c}\text { Elevator } \\
\text { Deflection }\end{array}$} & \multicolumn{6}{|c|}{ Coefficients } \\
\cline { 2 - 7 } & Drag & Side & Lift & Rolling & Pitching & Yawing \\
\hline-40 & $1.67 \mathrm{E}-01$ & $1.07 \mathrm{E}-03$ & $-4.77 \mathrm{E}-01$ & $3.04 \mathrm{E}-04$ & $1.34 \mathrm{E}+00$ & $-3.98 \mathrm{E}-04$ \\
\hline-30 & $1.47 \mathrm{E}-01$ & $1.83 \mathrm{E}-03$ & $-4.55 \mathrm{E}-01$ & $5.13 \mathrm{E}-04$ & $1.24 \mathrm{E}+00$ & $-1.39 \mathrm{E}-03$ \\
\hline-20 & $1.25 \mathrm{E}-01$ & $1.79 \mathrm{E}-03$ & $-4.16 \mathrm{E}-01$ & $3.96 \mathrm{E}-04$ & $1.09 \mathrm{E}+00$ & $-4.91 \mathrm{E}-04$ \\
\hline-10 & $1.03 \mathrm{E}-01$ & $6.29 \mathrm{E}-04$ & $-3.50 \mathrm{E}-01$ & $4.79 \mathrm{E}-04$ & $8.21 \mathrm{E}-01$ & $-3.56 \mathrm{E}-04$ \\
\hline 0 & $8.63 \mathrm{E}-02$ & $1.14 \mathrm{E}-04$ & $-2.72 \mathrm{E}-01$ & $7.64 \mathrm{E}-05$ & $5.14 \mathrm{E}-01$ & $6.41 \mathrm{E}-05$ \\
\hline 10 & $7.74 \mathrm{E}-02$ & $3.07 \mathrm{E}-04$ & $-1.90 \mathrm{E}-01$ & $-2.03 \mathrm{E}-04$ & $2.02 \mathrm{E}-01$ & $4.00 \mathrm{E}-04$ \\
\hline 20 & $7.69 \mathrm{E}-02$ & $6.27 \mathrm{E}-04$ & $-1.09 \mathrm{E}-01$ & $4.01 \mathrm{E}-04$ & $-1.07 \mathrm{E}-01$ & $2.93 \mathrm{E}-04$ \\
\hline 30 & $8.30 \mathrm{E}-02$ & $2.53 \mathrm{E}-04$ & $-3.06 \mathrm{E}-02$ & $1.04 \mathrm{E}-04$ & $-3.84 \mathrm{E}-01$ & $-5.72 \mathrm{E}-04$ \\
\hline
\end{tabular}

Table B.17. Aerodynamic Coefficients vs Elevator Deflection for (-)4 degrees Angle of Attack

\begin{tabular}{|c|c|c|c|c|c|c|}
\hline \multirow{2}{*}{$\begin{array}{c}\text { Elevator } \\
\text { Deflection }\end{array}$} & \multicolumn{6}{|c|}{ Coefficients } \\
\cline { 2 - 7 } & \multicolumn{3}{|c|}{ Forces $N$} & \multicolumn{3}{c|}{ Moments $N . m$} \\
\hline-40 & $1.26 \mathrm{E}-01$ & $1.77 \mathrm{E}-04$ & $-1.90 \mathrm{E}-01$ & $-2.68 \mathrm{E}-04$ & $9.22 \mathrm{E}-01$ & $-4.36 \mathrm{E}-04$ \\
\hline-30 & $1.07 \mathrm{E}-01$ & $3.42 \mathrm{E}-04$ & $-1.67 \mathrm{E}-01$ & $-3.34 \mathrm{E}-04$ & $8.27 \mathrm{E}-01$ & $-4.56 \mathrm{E}-04$ \\
\hline-20 & $8.67 \mathrm{E}-02$ & $-1.76 \mathrm{E}-04$ & $-1.20 \mathrm{E}-01$ & $-7.10 \mathrm{E}-04$ & $6.40 \mathrm{E}-01$ & $5.24 \mathrm{E}-04$ \\
\hline-10 & $6.92 \mathrm{E}-02$ & $-1.50 \mathrm{E}-04$ & $-4.62 \mathrm{E}-02$ & $-5.56 \mathrm{E}-04$ & $3.60 \mathrm{E}-01$ & $7.98 \mathrm{E}-05$ \\
\hline 0 & $5.84 \mathrm{E}-02$ & $-1.47 \mathrm{E}-04$ & $3.73 \mathrm{E}-02$ & $-5.30 \mathrm{E}-04$ & $4.04 \mathrm{E}-02$ & $3.91 \mathrm{E}-04$ \\
\hline 10 & $5.55 \mathrm{E}-02$ & $-1.51 \mathrm{E}-04$ & $1.25 \mathrm{E}-01$ & $-7.70 \mathrm{E}-06$ & $-2.87 \mathrm{E}-01$ & $2.22 \mathrm{E}-04$ \\
\hline 20 & $6.08 \mathrm{E}-02$ & $-5.77 \mathrm{E}-04$ & $2.14 \mathrm{E}-01$ & $-8.08 \mathrm{E}-05$ & $-6.18 \mathrm{E}-01$ & $-1.07 \mathrm{E}-03$ \\
\hline 30 & $7.40 \mathrm{E}-02$ & $-8.97 \mathrm{E}-04$ & $2.91 \mathrm{E}-01$ & $1.05 \mathrm{E}-05$ & $-9.02 \mathrm{E}-01$ & $1.29 \mathrm{E}-03$ \\
\hline
\end{tabular}


Table B.18. Aerodynamic Coefficients vs Elevator Deflection for 0 degrees Angle of Attack

\begin{tabular}{|c|c|c|c|c|c|c|}
\hline \multirow{2}{*}{$\begin{array}{c}\text { Elevator } \\
\text { Deflection }\end{array}$} & \multicolumn{5}{|c|}{ Forces $N$} & \multicolumn{3}{c|}{ Moments N.m } \\
\cline { 2 - 7 } & Drag & Side & Lift & Rolling & Pitching & Yawing \\
\hline-40 & $1.08 \mathrm{E}-01$ & $-7.55 \mathrm{E}-06$ & $1.14 \mathrm{E}-01$ & $-2.52 \mathrm{E}-04$ & $4.68 \mathrm{E}-01$ & $-6.00 \mathrm{E}-04$ \\
\hline-30 & $9.20 \mathrm{E}-02$ & $-9.90 \mathrm{E}-05$ & $1.41 \mathrm{E}-01$ & $2.68 \mathrm{E}-04$ & $3.71 \mathrm{E}-01$ & $-4.30 \mathrm{E}-04$ \\
\hline-20 & $7.56 \mathrm{E}-02$ & $-1.41 \mathrm{E}-04$ & $1.99 \mathrm{E}-01$ & $-5.73 \mathrm{E}-05$ & $1.53 \mathrm{E}-01$ & $-1.91 \mathrm{E}-04$ \\
\hline-10 & $6.32 \mathrm{E}-02$ & $-6.30 \mathrm{E}-04$ & $2.76 \mathrm{E}-01$ & $-4.58 \mathrm{E}-04$ & $-1.38 \mathrm{E}-01$ & $2.51 \mathrm{E}-04$ \\
\hline 0 & $5.86 \mathrm{E}-02$ & $-8.95 \mathrm{E}-04$ & $3.62 \mathrm{E}-01$ & $-2.85 \mathrm{E}-04$ & $-4.65 \mathrm{E}-01$ & $5.81 \mathrm{E}-04$ \\
\hline 10 & $6.18 \mathrm{E}-02$ & $-1.19 \mathrm{E}-03$ & $4.51 \mathrm{E}-01$ & $-1.15 \mathrm{E}-04$ & $-7.96 \mathrm{E}-01$ & $9.65 \mathrm{E}-04$ \\
\hline 20 & $7.35 \mathrm{E}-02$ & $-1.39 \mathrm{E}-03$ & $5.40 \mathrm{E}-01$ & $2.52 \mathrm{E}-04$ & $-1.13 \mathrm{E}+00$ & $1.52 \mathrm{E}-03$ \\
\hline 30 & $9.11 \mathrm{E}-02$ & $-1.27 \mathrm{E}-03$ & $6.13 \mathrm{E}-01$ & $-8.67 \mathrm{E}-05$ & $-1.40 \mathrm{E}+00$ & $1.26 \mathrm{E}-03$ \\
\hline
\end{tabular}

Table B.19. Aerodynamic Coefficients vs Elevator Deflection for 4 degrees Angle of Attack

\begin{tabular}{|c|c|c|c|c|c|c|}
\hline \multirow{2}{*}{$\begin{array}{c}\text { Elevator } \\
\text { Deflection }\end{array}$} & \multicolumn{5}{|c|}{ Coefficients } \\
\cline { 2 - 7 } & Drag & Side & Lift & Rolling & Pitching & Yawing \\
\hline-40 & $1.14 \mathrm{E}-01$ & $-1.06 \mathrm{E}-03$ & $4.19 \mathrm{E}-01$ & $3.46 \mathrm{E}-04$ & $2.09 \mathrm{E}-02$ & $4.51 \mathrm{E}-04$ \\
\hline-30 & $9.95 \mathrm{E}-02$ & $-1.39 \mathrm{E}-03$ & $4.56 \mathrm{E}-01$ & $4.26 \mathrm{E}-04$ & $-1.14 \mathrm{E}-01$ & $6.32 \mathrm{E}-04$ \\
\hline-20 & $8.63 \mathrm{E}-02$ & $-1.59 \mathrm{E}-03$ & $5.18 \mathrm{E}-01$ & $4.22 \mathrm{E}-04$ & $-3.45 \mathrm{E}-01$ & $1.19 \mathrm{E}-03$ \\
\hline-10 & $7.89 \mathrm{E}-02$ & $-1.69 \mathrm{E}-03$ & $6.00 \mathrm{E}-01$ & $1.50 \mathrm{E}-04$ & $-6.52 \mathrm{E}-01$ & $1.33 \mathrm{E}-03$ \\
\hline 0 & $7.97 \mathrm{E}-02$ & $4.64 \mathrm{E}-04$ & $6.89 \mathrm{E}-01$ & $1.64 \mathrm{E}-04$ & $-9.85 \mathrm{E}-01$ & $-1.53 \mathrm{E}-04$ \\
\hline 10 & $8.94 \mathrm{E}-02$ & $-1.34 \mathrm{E}-03$ & $7.81 \mathrm{E}-01$ & $6.23 \mathrm{E}-04$ & $-1.33 \mathrm{E}+00$ & $8.67 \mathrm{E}-04$ \\
\hline 20 & $1.07 \mathrm{E}-01$ & $-1.72 \mathrm{E}-03$ & $8.69 \mathrm{E}-01$ & $-2.58 \mathrm{E}-04$ & $-1.67 \mathrm{E}+00$ & $1.09 \mathrm{E}-04$ \\
\hline 30 & $1.30 \mathrm{E}-01$ & $-1.39 \mathrm{E}-03$ & $9.43 \mathrm{E}-01$ & $8.12 \mathrm{E}-04$ & $-1.94 \mathrm{E}+00$ & $1.12 \mathrm{E}-03$ \\
\hline
\end{tabular}


Table B.20. Aerodynamic Coefficients vs Elevator Deflection for 8 degrees Angle of Attack

\begin{tabular}{|c|c|c|c|c|c|c|}
\hline \multirow{2}{*}{$\begin{array}{c}\text { Elevator } \\
\text { Deflection }\end{array}$} & \multicolumn{5}{|c|}{ Coefficients } \\
\cline { 2 - 7 } & Drag & Side & Lift & Rolling & Pitching & Yawing \\
\hline-40 & $1.40 \mathrm{E}-01$ & $-3.44 \mathrm{E}-03$ & $7.28 \mathrm{E}-01$ & $-3.82 \mathrm{E}-04$ & $-4.47 \mathrm{E}-01$ & $2.05 \mathrm{E}-03$ \\
\hline-30 & $1.26 \mathrm{E}-01$ & $-3.07 \mathrm{E}-03$ & $7.75 \mathrm{E}-01$ & $4.64 \mathrm{E}-04$ & $-6.05 \mathrm{E}-01$ & $1.43 \mathrm{E}-03$ \\
\hline-20 & $1.17 \mathrm{E}-01$ & $-2.88 \mathrm{E}-03$ & $8.44 \mathrm{E}-01$ & $3.52 \mathrm{E}-04$ & $-8.62 \mathrm{E}-01$ & $8.99 \mathrm{E}-04$ \\
\hline-10 & $1.15 \mathrm{E}-01$ & $-2.32 \mathrm{E}-03$ & $9.33 \mathrm{E}-01$ & $3.87 \mathrm{E}-04$ & $-1.19 \mathrm{E}+00$ & $4.06 \mathrm{E}-04$ \\
\hline 0 & $1.23 \mathrm{E}-01$ & $-3.09 \mathrm{E}-04$ & $1.02 \mathrm{E}+00$ & $1.17 \mathrm{E}-03$ & $-1.53 \mathrm{E}+00$ & $-3.67 \mathrm{E}-04$ \\
\hline 10 & $1.38 \mathrm{E}-01$ & $-2.47 \mathrm{E}-03$ & $1.11 \mathrm{E}+00$ & $1.00 \mathrm{E}-03$ & $-1.87 \mathrm{E}+00$ & $6.65 \mathrm{E}-04$ \\
\hline 20 & $1.62 \mathrm{E}-01$ & $-2.92 \mathrm{E}-03$ & $1.19 \mathrm{E}+00$ & $-3.05 \mathrm{E}-04$ & $-2.19 \mathrm{E}+00$ & $1.33 \mathrm{E}-03$ \\
\hline 30 & $1.87 \mathrm{E}-01$ & $-2.94 \mathrm{E}-03$ & $1.25 \mathrm{E}+00$ & $3.14 \mathrm{E}-04$ & $-2.42 \mathrm{E}+00$ & $1.52 \mathrm{E}-03$ \\
\hline
\end{tabular}




\section{REFERENCES}

[1] I. I. Kaminer, O. A. Yakimenko, V. N. Dobrokhodov, and K. D. Jones, "Rapid flight test prototyping system and the fleet of uavs and mavs at the naval postgraduate school."

[2] R. Lee. System identification of cessna 182 model uav. [Online]. Available: http://www.stanford.edu/class/cs229/proj2007/

[3] S. H. Lee and Y. M. Park. System identification of dragonfly uav via bayesian estimation.

[4] S. Hashimoto, T. Ogawa, S. Adachi, A. Tan, and G. Miyamori, "System identification experiments on a large-scale unmanned helicopter for autonomous flight," in Proc. IEEE International Conference on Control Applications, Alaska, USA, 2000, pp. 850-855.

[5] S. S. Patankar, D. E. Schinstock, and R. M. Caplinger, "Application of pendulum method to uav momental ellipsoid estimation."

[6] M. Jardin and E. Mueller, "Optimized measurements of uav mass moment of inertia with a bifilar pendulum."

[7] R. Bhaskaran and L. Collins. Introduction to cfd basics. [Online]. Available: http://courses.cit.cornell.edu/fluent/cfd/

[8] GAMBIT Menu Commands, GAMBIT 2.4 Documentation, User's Guide, FLUENT.

[9] Airplane Geometry, GAMBIT 2.4 Documentation, Tutorial Guide, FLUENT.

[10] Using the Solver, FLUENT 6.3 Documentation, User's Guide, FLUENT.

[11] Modeling Turbulence, FLUENT 6.3 Documentation, User's Guide, FLUENT. 
[12] Boundary Conditions, FLUENT 6.3 Documentation, User's Guide, FLUENT.

[13] S. S. Sathaye, "Lift distribution on low aspect ratio wings at low reynolds numbers," M.S. Thesis, Worcester Polytechnic Institute, Worcester, Massachusetts, May 2004.

[14] GAMBIT Defaults, GAMBIT 2.4 Documentation, Defaults Guide, FLUENT.

[15] GAMBIT Modeling Guide, GAMBIT 2.4 Documentation, Modeling Guide, FLUENT. 


\section{BIOGRAPHICAL STATEMENT}

Kartik K. Parikh was born in Mumbai, India, in 1983. He received his B.Tech. degree from Jawaharlal Nehru Technological University, Hyderabad, India, in 2005, in Mechanical Engineering. He is presently pursuing his Master's degree in Mechanical Engineering at The University of Texas at Arlington (UTA), Arlington, Texas, U.S.A. He is a member of Autonomous Vehicle Laboratory (AVL) at UTA and AIAA. His research interests include Aerodynamics and Design. 